\title{
Large scale investigation in yeast to identify novel gene(s) involved in mRNA nonstop decay pathway
}

$$
\text { by }
$$

Narges Zare

\begin{abstract}
A thesis submitted to the Faculty of Graduate and Postdoctoral Affairs in partial fulfillment of the requirements for the degree of

Master of Science

in

Biology

Carleton University

Ottawa, Ontario

(C) 2020

Narges Zare
\end{abstract}




\section{Abstract}

Nonstop decay is an mRNA degradation pathway involved in identifying and eliminating transcripts that lack an in frame stop codon. Nonstop mRNAs are identified at the first round of translation when the ribosome reaches 3' mRNA and stalls and subsequently recruits other factors involved in NSD machinery for mRNA degradation. This process keeps the cell safe from possible harmful of the truncated proteins. Compared to other RNA degradation pathways, very little is known about the NSD mechanism. In order to identify novel genes involved in NSD, we first performed a large-scale analysis in Saccharomyces cerevisiae, and identified 68 gene candidates. From these results we picked three helicases, NAM7, ECM32, and SKI2 to further investigate their role in the NSD process. Spot test and colony count assay confirmed the role of selected candidates in NSD. The abundance of the nonstop mRNA was then evaluated using qRT-PCR method, and it was confirmed that the deletions of the selected candidates had no significant effect on nonstop mRNA at the transcriptional level when compared to the wildtype strain. Negative genetic interaction revealed the association between candidate genes and translational regulation genes. The results of this study confirm the role of candidates in NSD but further research to characterize these novel candidates is needed. 


\section{Acknowledgements}

First and foremost, I would like to express my sincere gratitude to my advisor Dr. Ashkan Golshani for giving me the opportunity to join his team at Carleton. You supported, inspired and guided me all the way. Thank you for being the amazing, patient, understanding and encouraging human being you are. I will be forever grateful.

I would also like to thank my thesis committee members Dr. Mark Ekker, Dr. Bahram Samanfar and Dr. Tim Xing for their valuable time and reading my thesis in such short notice. I would also extend my gratitude to Dr. Alex Wong.

I wish to extend my gratitude to the Department of Biology at Carleton University for their friendship and support.

I would like to specially thank Bahram and Katie for being amazing and supportive friends. Sticking by my side and giving unconditional support and love. This would not have been possible without you two.

I would like to thank all members of the Golshani lab members during the last few years, namely Maryam, Sara, Houman, Sasi, Natalia, Taylor, Houman, Dan, Duale and Kristina, Grace and Kathryn for all the help and kindness. And all the third floor Nesbitt crew for all the amazing times we shared.

I would also like to thank and express my appreciation to all my closest friends especially, Shaya, Fakhte, Elnaz, Shadi, Katayoun, Maryam, Bahram, Reza, Shaghayegh, Mehdi, Mohsen, Sara, Anna and Imad for their friendship love, support and encouragement.

I am especially thankful to my previous academic supervisors at Tehran University, Dr. Ardeshir Nejaty and Dr. Hassan Mehrabani-Yeganeh for guiding and initiating this journey in my career.

Finally, my deep and sincere gratitude to my family in Iran for their continuous and unparalleled love, help and support. I love you, Mom and Dad. I am grateful to my brothers, Abolfazl and Ali, for always being there for me as a friend. I extend my thankfulness to my lovely Aunts for always loving and caring for me. I am forever indebted to my parents for giving me the opportunities and experiences that have made me who I am. 
I would like to dedicate this thesis to Fareed 


\section{Table of Contents}

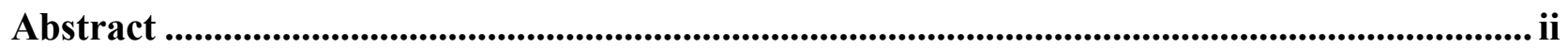

Acknowledgements ............................................................................................................................... iii

Table of Contents ..................................................................................................................... v

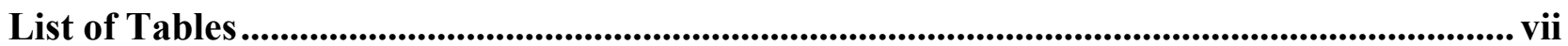

List of Figures .............................................................................................................................................. viii

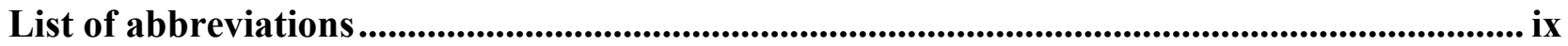

Chapter 1: Introduction ...................................................................................................................... 11

$1.1 \quad$ Translation in Eukaryotes …………………………………………………………...... 11

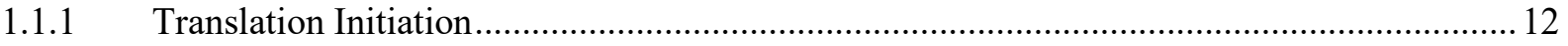

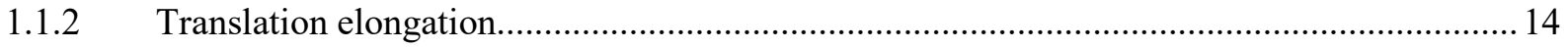

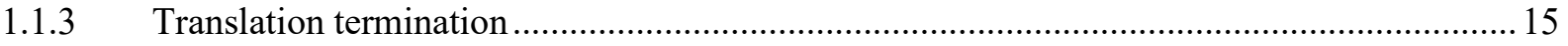

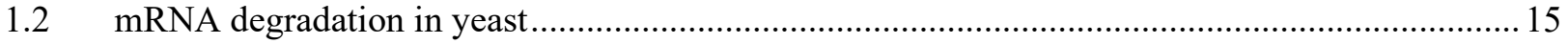

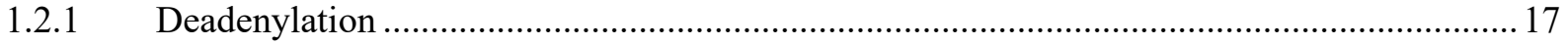

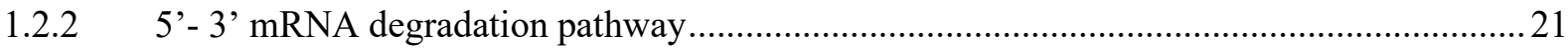

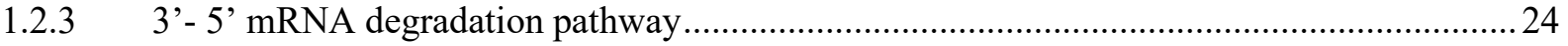

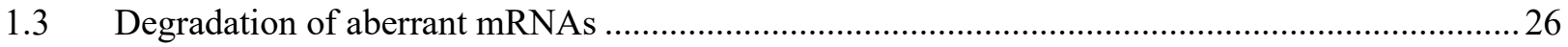

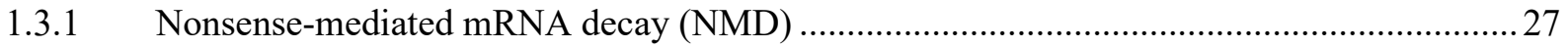

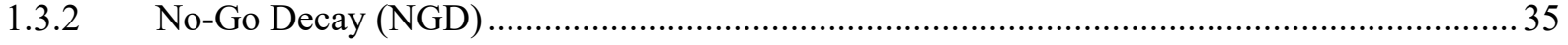

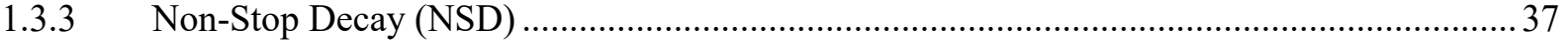

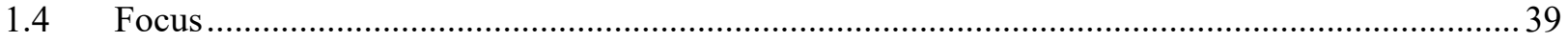

Chapter 2: Materials and Methods.....................................................................................4 40

2.1 Plasmid Constructs and S. cerevisiae strains, media, reagents, and drugs.....................................40

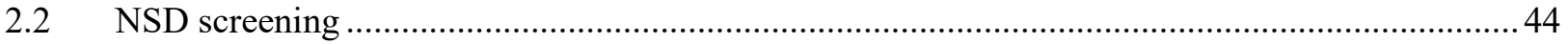

2.2.1 Standard transformation protocol................................................................................. 44

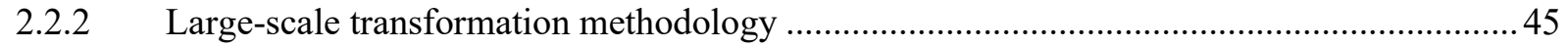

2.2.3 Selection of genes involved in NSD ......................................................................... 46

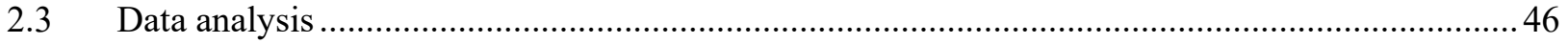

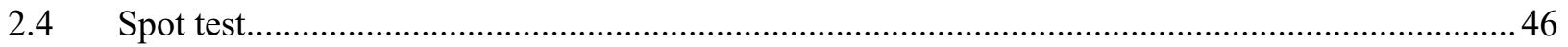

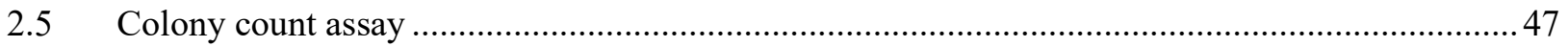

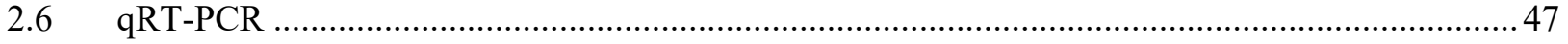

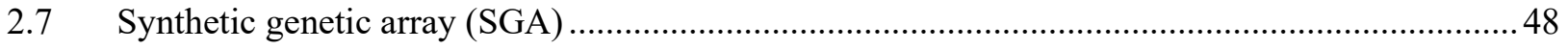

Chapter 3: Results ................................................................................................................................... 50 


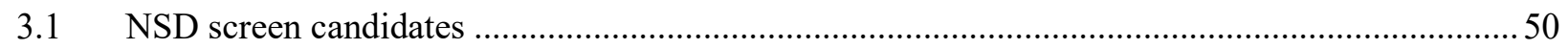

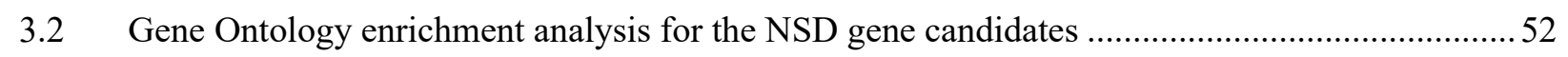

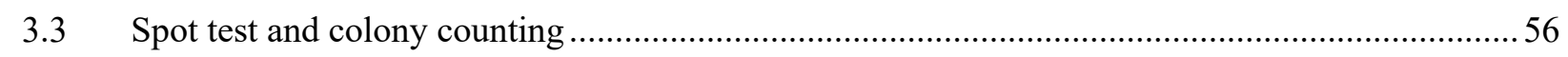

3.4 Analysis of the non-stop mRNA content of mutants for HIS3 gene.........................................59

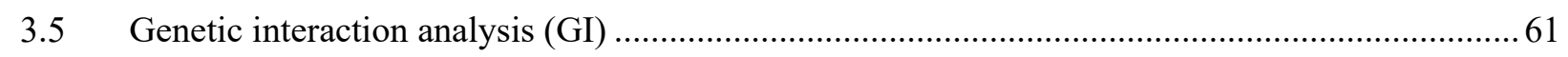

Chapter 4: Discussion..................................................................................................................66

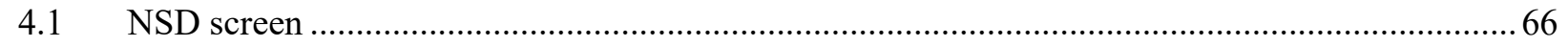

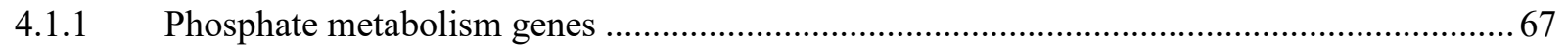

4.1.2 Possible link between Sporulation (SPO) and Recombination (REC) genes with mRNA

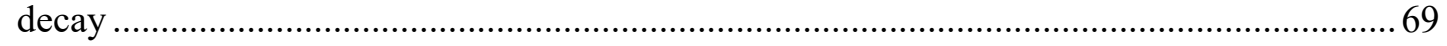

4.2 Identification of candidate genes involved in mRNA NSD pathway ......................................... 72

4.3 SGA reveals genetic interactions with known genes involved in translation regulation ............... 74

Chapter 5: Conclusion and future directions........................................................................ 76

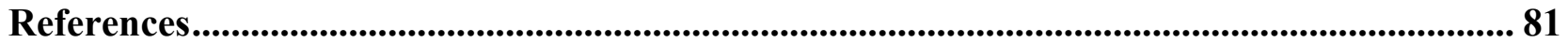




\section{List of Tables}

Table 1: Gene clusters and description of the screened genes.............................53 


\section{List of Figures}

Figure 1: Schematic presentation of eukaryotic translation initiation......................................... 13

Figure 2: Schematic model of Pan2-Pan3 complex. ………...................................................... 20

Figure 3: Deadenylated dependant mRNA degradation pathways................................................. 23

Figure 4: Schematic presentation of the exosome and its core subunits in yeast.......................... 25

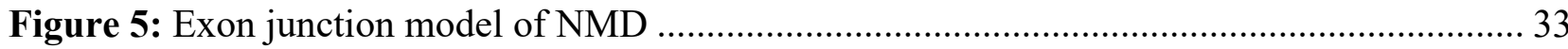

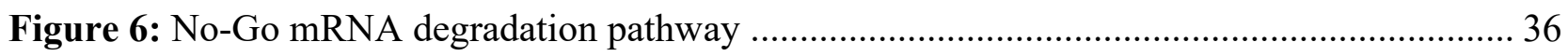

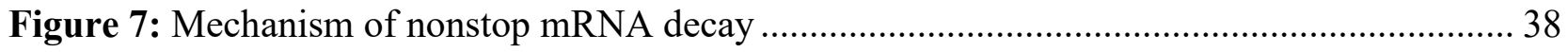

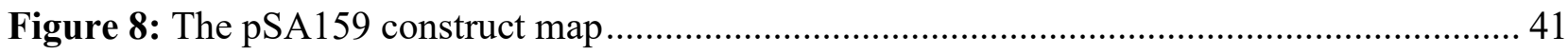

Figure 9: Nonstop HIS3 reporter gene ............................................................................. 42

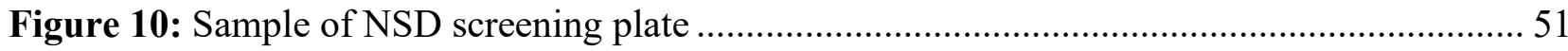

Figure 11: Gene ontology enrichment analysis for NSD screened genes .................................... 54

Figure 12: Candidate gene enrichment based on classified protein class...................................... 55

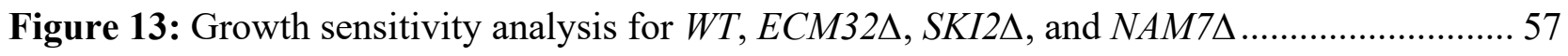

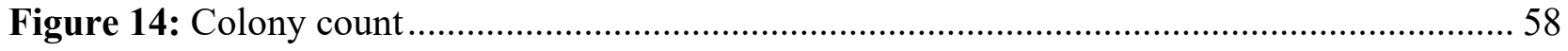

Figure 15: Relative His 3 mRNA levels for $W T, N A M 7 \Delta, E C M 32 \Delta$ and SKI2A ......................... 60

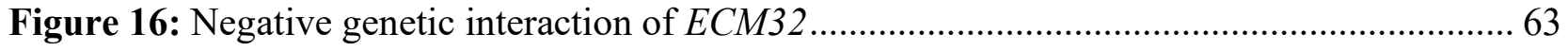

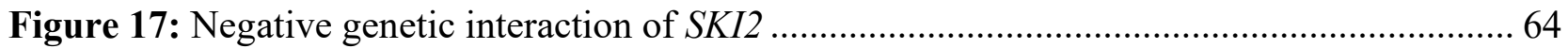

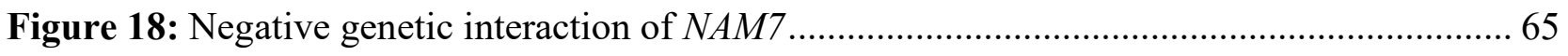

Figure 19: Interaction network of $\mathrm{SPOI} 1$ in yeast …….............................................................. 70 


\section{List of abbreviations}

\begin{tabular}{|c|c|}
\hline $\boldsymbol{\mu} \mathbf{L}$ & Micro liters \\
\hline $\mathbf{o C}$ & Degrees Celsius \\
\hline 3'-UTR & 3' untranslated region \\
\hline 3-AT & 3-Amino-1,2,4 triazole \\
\hline ATP & Adenosine triphosphate \\
\hline cdna & Complementary DNA \\
\hline clonNAT & Nourseothricin \\
\hline DECID & Decay-inducing complex \\
\hline DNA & Deoxyribonucleic acid \\
\hline DSBs & Double strand breaks \\
\hline eEF & Eukaryotic elongation factor \\
\hline eIF & Eukaryotic initiation factor \\
\hline EJC & Exon Junction Complex \\
\hline ESM & Enriched Sporulation Media \\
\hline g & Gram \\
\hline G418 & Geneticin \\
\hline GI & Genetic interaction \\
\hline GTP: & Guanine Triphosphate \\
\hline IGDP & Imidazoleglycerol-phosphate dehydratase \\
\hline $\mathbf{L B}$ & Lysogeny broth \\
\hline MAT & Mating type locus \\
\hline mg & Milligram \\
\hline
\end{tabular}




\begin{tabular}{|c|c|}
\hline $\min$ & Minute \\
\hline $\mathbf{m L}$ & Milli liter \\
\hline mRNA & messenger RNA \\
\hline NGD & No-go Decay \\
\hline NMD & Nonsense-mediated Decay \\
\hline NSD & Nonstop Decay \\
\hline OD & Optical density \\
\hline ORF & Open reading frame \\
\hline ORF & Open reading frame \\
\hline PABP & Poly A binding protein \\
\hline PABP & Poly(A) Binding Protein \\
\hline PCR & Polymerase chain reaction \\
\hline PIC & Preinitiation complex \\
\hline PSA & Phenotypic Suppression Array \\
\hline PTC & Premature termination codon \\
\hline qRT-PCR & Quantitative RT-PCR \\
\hline RNA & Ribonucleic acid \\
\hline RT-PCR & Reverse transcriptase RCR \\
\hline SDL & Synthetic dosage lethality \\
\hline SGA & Synthetic genetic array \\
\hline tRNA & Transfer RNA \\
\hline WT & Wild type \\
\hline YPD & Yeast extracts peptone dextro \\
\hline
\end{tabular}




\section{Chapter 1: Introduction}

\subsection{Translation in Eukaryotes}

In molecular biology, the flow of information from specific segments in the DNA to polypeptides is done in two major steps: transcription and translation. The initial step, transcription, involves passing information on the DNA to messenger RNA (mRNA) molecules. In the second step, mRNA is decoded to synthesize a polypeptide. Translation can be divided into three major steps: initiation, elongation and termination. The most regulated step is translation initiation, followed by translation elongation in which the amino acids are connected to form an amino acid chain. Finally, when the ribosome reaches the stop codon the protein synthesis is completed. This step is known as translation termination. After this, the ribosome is recycled. This important step will allow more rounds of translation in the cell.

Translation is the most expensive energy expenditure in the cell (Pontes et al., 2015). This accounts for over $30 \%$ and $50 \%$ of total energy costs in mammalian and growing bacteria cells, respectively (Buttgereit \& Brand, 1995; Russell \& Cook, 1995). It has also been reported that in growing yeast cells an estimated amount of 60,000 mRNAs exist in a cell producing roughly 13,000 polypeptides every second (von der Haar, 2008; Zenklusen et al., 2008). 


\subsubsection{Translation Initiation}

Eukaryotic translation initiation consists of two main steps. Firstly, a ternary complex is formed called eIF2-TC. This complex is a combination of the eukaryotic initiation factor 2 (eIF2), guanosine triphosphate (GTP) and methionyl tRNA. The eIF2-TC in association with eIF1, eIF1A, eIF3, eIF5, and 40S small ribosomal subunit form the 43S preinitiation complex (PIC) (Jackson et al., 2010). The 43S PIC then binds to the 5' capped region of the mRNA and forms the $48 \mathrm{~S}$ complex which then scans 5' to 3' direction to find the AUG start codon. This step requires unwinding of the mRNA's secondary structure at the 5' end using eIF4B, eIF4F and eIF4A which is an RNA helicase (Butland et al., 2007; Jackson et al., 2010). Once the start codon has been recognized by the complex, eIF5 and eIF5B hydrolyzes eIF2-GTP and the initiation factors are released. Finally, the large $60 \mathrm{~S}$ ribosomal subunit joins and the 80S ribosome is formed (Dever et al., 2016; Unbehaun et al., 2004). Different steps of translation initiation in eukaryotes is presented in Figure 1. 


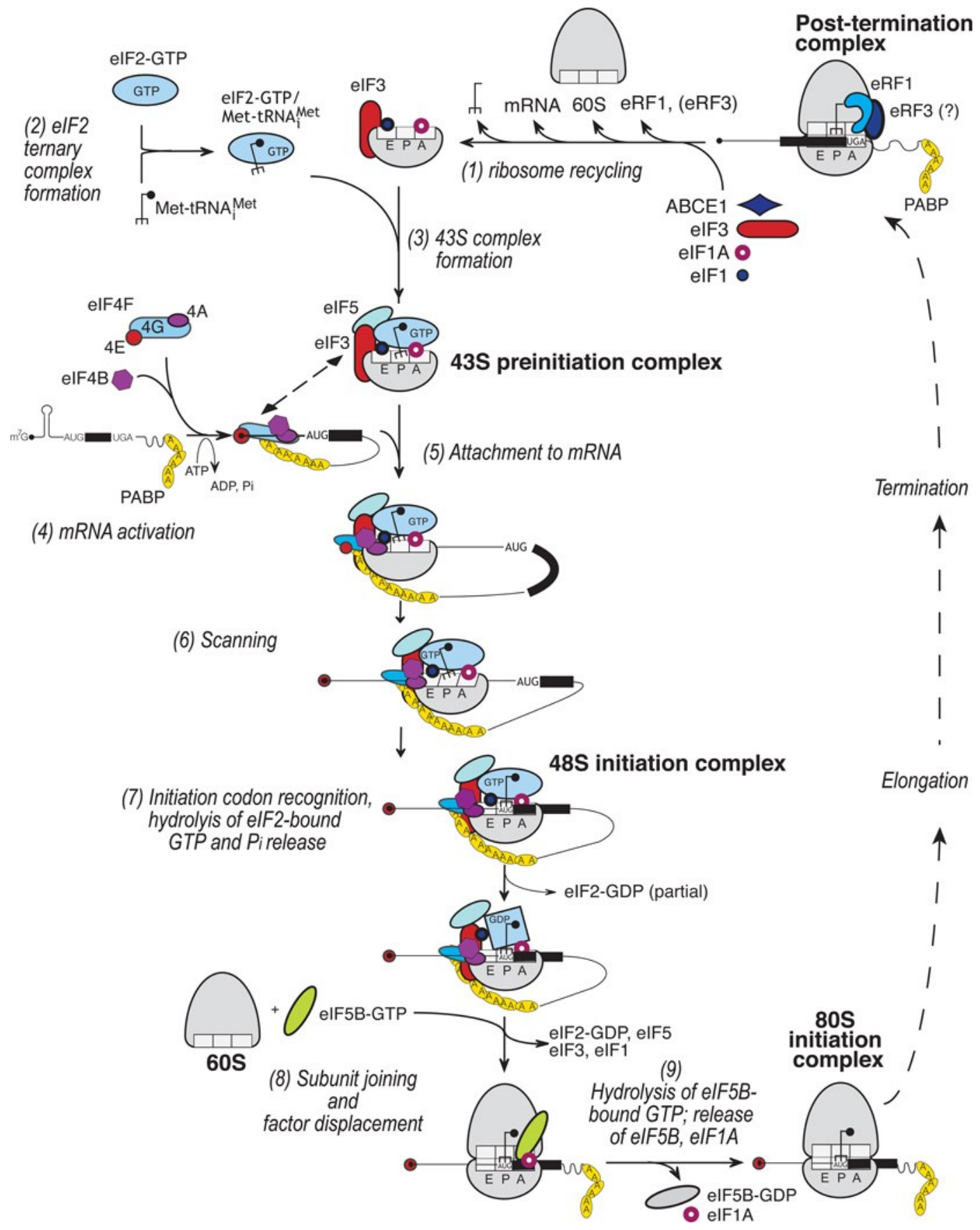

Figure 1: Schematic presentation of eukaryotic translation initiation. The pathway is illustrated in distinct stages. Starting with forming the eIF2-TC and subsequently the $43 \mathrm{~S}$ preinitiation complex. The PIC then attaches to the mRNA near the cap and starts scanning. After recognition of the initiation codon 60S ribosomal subunits joins to form $80 \mathrm{~S}$ translational initiation complex which can start the translation elongation phase. (Adapted with permission from Jackson et al., 2010) 


\subsubsection{Translation elongation}

In this step of mRNA translation, the polypeptide chain is produced. It starts when the Met-tRNA binds to the $\mathrm{P}$ site of the 80S ribosome in which the start codon exists and the next codon of the open reading frame (ORF) is in the A (acceptor) site of the ribosome. The second aminoacyl tRNA-GTP is transferred to the A site of the ribosome by the eukaryotic elongation factor1 A (eEF1A). After the mRNA codon and anti codon on the tRNA have interacted the eEF1A is released and the aminoacyl tRNA is now placed in ribosomal A site (Dever \& Green, 2012).

Next, a chain of amino acids needs to be made by forming a peptide bond with the aminoacyl tRNA. The tRNA bound to the peptide moves to the P-site of the ribosome. At this point the A-site is vacant and the ribosome moves along the mRNA, placing the new code in the Asite of the ribosome (Kapp \& Lorsch, 2004). The shift of peptidyl-tRNA from A-site to Psite of the ribosome is done by eukaryotic elongation factor 2 (eEF2). This elongation factor also catalyzes the movement of tRNA to E-site where the deacylated tRNA can exit the ribosome. Moreover, in yeast elongation factor $3(\mathrm{EF} 3)$ is required. Unlike the other elongation factors mentioned above EF3 is ATP dependant (Andersen et al., 2006; Sandbake\& et al., 1990). 


\subsubsection{Translation termination}

Termination of translation occurs when the translation machinery reached a stop codon (UAA, UAG, UGA) in the open reading frame reaches the A-site of the ribosome. A complex composed of eukaryotic release factors 1 and 3 (eRF1 and eRF3) are responsible for identifying the stop codon on the mRNA. eRF1 recognizes the stop codon and hydrolyzes the bond between the tRNA and the peptide (Parker, 2012). eRF3 is GTP dependant and releases the eRF1 by binding to the ribosome (Grentzmann et al., 1998).

After identifying the stop codon and termination of protein synthesis has occurred, ribosome is disassembled and recycled for additional rounds of translation. An ATP-binding cassette protein $(\mathrm{ABC})$ named Rli1 facilitates the release of the $60 \mathrm{~S}$ subunit of the ribosome. This subunit can then be re-initiate translation in the cell (Shoemaker \& Green, 2011). Additionally, Rlil contributes to breaking the $80 \mathrm{~S}$ ribosome and is associated with forming the PIC (Dong et al., 2004).

\section{2 mRNA degradation in yeast}

RNA degradation is an essential part of controlling gene expression (Samanfar et al., 2014). Maintaining a balance between RNA production and degradation in the cell is essential to cell's capability to adapt to different environmental conditions and regulate cells growth (Gagarinova et al., 2016). RNA decay can also act as a defense mechanism to eliminate viral infections. In this review we will focus on RNA degradation in eukaryotes and specifically yeast. 
Two main pathways have been identified for mRNA decay in yeast. Both mechanisms start by deadenylating which is shortening of the poly A tail on the mRNA. This step is facilitated by two complexes: Pan2-Pan3 and Ccr4-not complex (Wahle \& Winkler, 2013a). The deadenylated RNA is then degraded 3' to 5' by the exosome complex or subjected to decapping by the Dcp1-Dcp2 complex followed by 5' to 3' decay by Xrn1 (Liu et al., 2014; Long \& McNally, 2003; Valencia-Sanchez et al., 2006).

Previous studies have reported significantly different rates of decay among mRNAs (Herrick et al., 1990; Presnyak et al., 2015; Sun et al., 2013). These variations can be due to several reasons such as varying targeting of decapping, deadenylation, or exonucleolytic degradation. Therefore, having a thorough knowledge of these mechanisms and their regulation is essential for elucidation of degradation pathways of the mRNA in the cell.

Besides normal mRNAs decay pathways, there are other mechanisms that identify and dispose transcripts that are aberrant in order to maintain translation fidelity as well as mRNA quality in the cell. Three main pathways are Nonsense Mediated mRNA decay (NMD) (Leeds et al., 1991; Peltz et al., 1993; Pulak \& Anderson, 1993); Non-Stop Decay (NSD) (Frischmeyer et al., 2002; van Hoof et al., 2002); and No-Go Decay (NGD) (Doma \& Parker, 2006). These pathways employ similar degradation machinery as normal mRNA decay pathway. 
In this introduction a summary of different degradation pathways and different factors involved in the process to eliminate aberrant transcripts is provided. The relatedness between different degradation pathways and the complexes involved in each process explains how precisely RNA degradation and gene expression is regulated.

\subsubsection{Deadenylation}

mRNA maturation in eukaryotes involves adding poly A tail and 7-methylguanosine cap to the 3' and 5' end of the mRNA, respectively. These changes to the mRNA significantly effect their half life. And most importantly have a profound role in mRNA translation efficiency and exposure to mRNA degradation machinery (Coller et al., 1998; Gray et al., 2000). Therefore, pathways involved in mRNA decay can also target the 5' cap and the poly A tail, and regulation of removal of these two is a significant process in regulating gene expression in the cells.

mRNA deadenylation is required for both 5' $-3^{\prime}$ and $3^{\prime}-5^{\prime}$ degradation pathways (Schmitt et al., 1990). Two main complexes are responsible for mRNA deadenylation in yeast: Ccr4-Not complex and Pan2-Pan3 complex which is a poly A specific RNase. The two work together to regulate removal of the poly A tail in yeast.

\subsubsection{Ccr4-Not complex}

The prime deadenylase in eukaryotes is the Ccr4-Not complex (Wahle \& Winkler, 2013b). It consists of several canonical subunits: Not1, Not2, Not3/5, Caf1/Pop2 and Ccr4 (Albert et 
al., 2000; Chen et al., 2001; Winkler et al., 2006). Caf1 and Ccr4 are catalytic subunits of this complex. Ccr4 is from a protein class family of exonuclease-endonuclease-phosphatase (EEP) and Caf1 has nuclease activity in the cell (Dlaklc, 2000). The complex is involved in processive poly A tail decay, however poly A binding proteins such as Pab1 can inhibit its activity (Tucker et al., 2001; Yi et al., 2018). Therefore, another pathway is required to eliminate and reduce affinity of poly A binding proteins and accommodate poly A tail shortening. This is done by the Pan2-Pan3 complex.

\subsubsection{Pan2-Pan3 complex}

The first deadenylase identified was the poly A specific nuclease (PAN) complex (Sachs \& Deardorff, 1992). The deadenylating enzyme consists of two subunits: Pan2 and Pan3 (Boeck et al., 1996; C. E. Brown et al., 1996; Wolf et al., 2014). Pan2 is a catalytic subunit and similar to Caf1 is a member of the exonuclease DEDD family (C. E. Brown et al., 1996; Wolf et al., 2014). Unlike the Ccr4-Not complex, Pan3 and PABPs increase Pan2 activity in the cell (Sachs \& Deardorff, 1992; Schäfer et al., 2014; Uchida et al., 2004). In vitro studies have shown that Pan2 is able to deadenylate without PABPs but Pan3 needs to be present (Jonas et al., 2014; Schäfer et al., 2014). The interaction between Pan3 and Pab1 increases the activity of Pan2 and deadenylation (Schäfer et al., 2019; Wolf et al., 2014; L. Zhang et al., 2013). In summary, Pan2-Pan3 complex shortens the poly A tail (Lowell et al., 1992; Yamashita et al., 2005) and then a complete poly A tail decay occurs by the Ccr4-Not complex (Petit et al., 2012; Temme et al., 2004; Tucker et al., 2001). Several invitro studies have shown in cells lacking pab1 (pab1 $\Delta$ ), mRNAs have elongated poly A tails and 
deadenylation process is delayed (Caponigro \& Parker, 1995; Sachs \& Davis, 1989). Schematic model for Pan2-Pan3 complex is shown in Figure 2. 


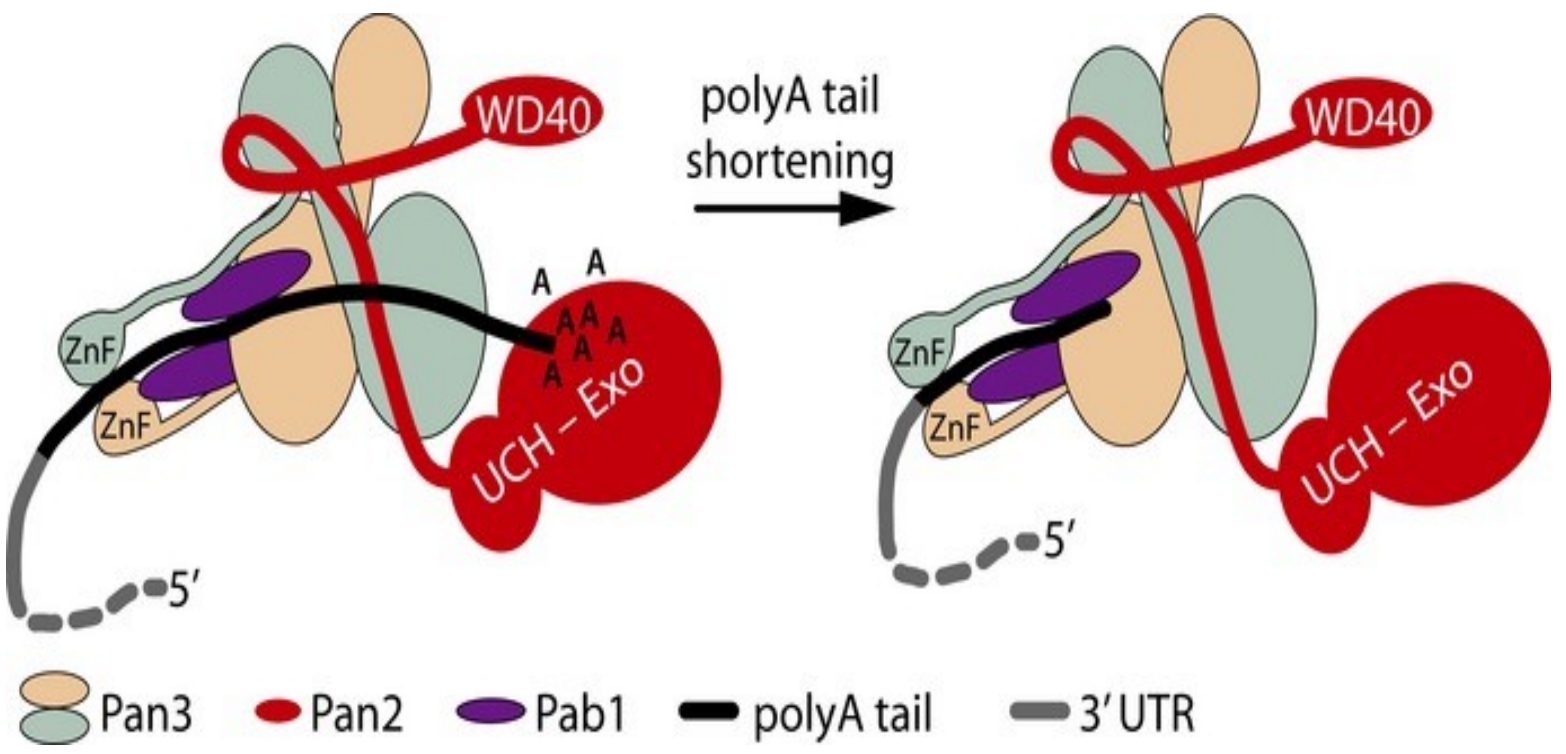

Figure 2: Schematic model of Pan2-Pan3 complex. Pan2-Pan3 complex is involved in degrading the mRNA poly A tail, by which Pan3 channels the mRNA to the exonuclease domain of Pan 2 for degradation. (Adapted with permission from Wolf et al., 2014) 


\subsubsection{5'-3' mRNA degradation pathway}

After deadenylation of the mRNA, as depicted in Figure 3, degradation proceeds in two irreversible paths. 5' to 3' direction mRNA decay removes the 7-methylguanosine cap at 5' of the mRNA followed by decay in towards the 3' end. The second possible pathway is 3 ' to 5 ' direction degradation which is carried out by the exosome and removal of the outstanding cap by an enzyme named, DeCapping Scavenger 1 (Dcs1) (Garneau et al., 2007; Parker, 2012).

5'-3 degradation is the main mRNA decay pathway in yeast. It starts with an irreversible step of eliminating the $5^{\prime} \mathrm{m}^{7} \mathrm{G}$ cap This is done by the decapping complex which consists of Dcpl and Dcp2. Both proteins in the complex are highly conserved. Dcp2 which is the catalytic subunit (Steiger et al., 2003; van Dijk et al., 2002). The catalytic domain of Dcp2 is in the C-terminal of the protein and it interacts with Dcpl at a conserved motif on the N-terminal (Hu et al., 2015). Dcp1 takes part in ensuring Dcp2 maintains its conformation (Feng He et al., 2003). Although Dcp1-Dcp2 complex has the main role in decapping the mRNA, another decapping protein named Ddp1 has been reported in yeast (Song et al., 2013).

The decapped mRNA is now prone to degradation from the $5^{\prime}$ end by Xrn1. Xrn1 is a $5^{\text {' }}$ exoribonuclease that can identify the 5' monophosphate and detangle the secondary structure of the decapped mRNA (Jinek et al., 2011). This protein also interacts with other complexes involved in mRNA degradation such as Dcp1, Dcp2 and the Lsm1-7 complex (Eulalio et al., 2007; Parker \& Sheth, 2007). 
Moreover, degrading the mRNA 5' to 3' direction is the principle decay pathway in yeast and research shows deletion of any component of this pathway increases gene expression in the cell. For example, when the decapping complex and Xrn1 were compromised genes were upregulated by $16.2 \%$ and $18.6 \%$, respectively (Feng He et al., 2003). This data shows that 3'-5' mRNA degradation process is most likely compensating for this disruption. 


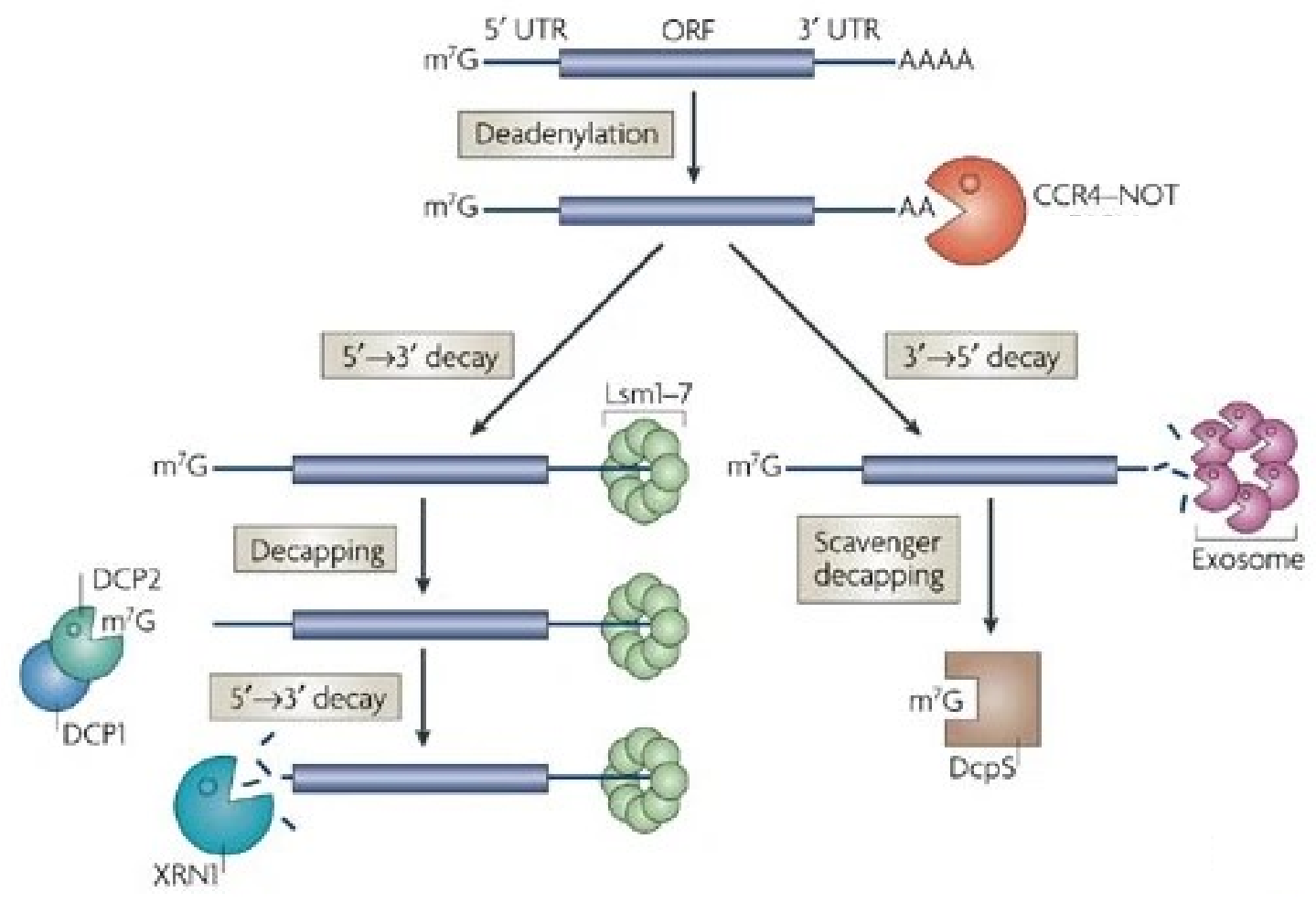

Figure 3: Deadenylated dependant mRNA degradation pathways. Ccr4-Not complex first removes the poly A tail of the mRNA. The deadenylated mRNA is then prone to two different degradation mechanisms. Either 3'-5' degradation y the exosome or 5' -3' decay which involves Lsm1-7 and decapping by Dcp1. (Adapted with permission from Garneau et al., 2007) 


\subsubsection{3'- 5' mRNA degradation pathway}

Degrading the mRNA from 3' to 5' direction also occurs after deadenylation and is known to be alternative to 5-3' decay. It is carried out by exosome. The intracellular complex is made of 10 subunits. First, Dis3 protein which has a catalytic activity and has both 5' -3' and 3'-5' exonuclease activity (Dziembowski et al., 2007; Lebreton et al., 2008). Nine other subunits of the exosome makeup Exo-9 ring. The ring is formed by proteins of Ribosomal RNA Processing family: Rrp41, Rrp42, Rrp43, Rrp46, Rrp45 as well as Mtr3 and Rrp4, Rrp40 and Cs14 are on top of the ring (Synowsky et al., 2009). Yeast exosome and the position of its subunits are shown in Figure 4.

In spite of the fact that core complex of the exosome lacks catalytic activity, it plays an important role in the exosome (Allmang et al., 1999; Dziembowski et al., 2007; Mitchell et al., 1997). The degradation rate of mRNAs is significantly reduced by attachment of molecules to the core complex of the exosome. This event disrupts the RNA binding capability of exonucleases (Wasmuth \& Lima, 2012). The reduced activity of exosome through molecule binding is specifically important to prevent random and nonselective degradation of mRNAs. 


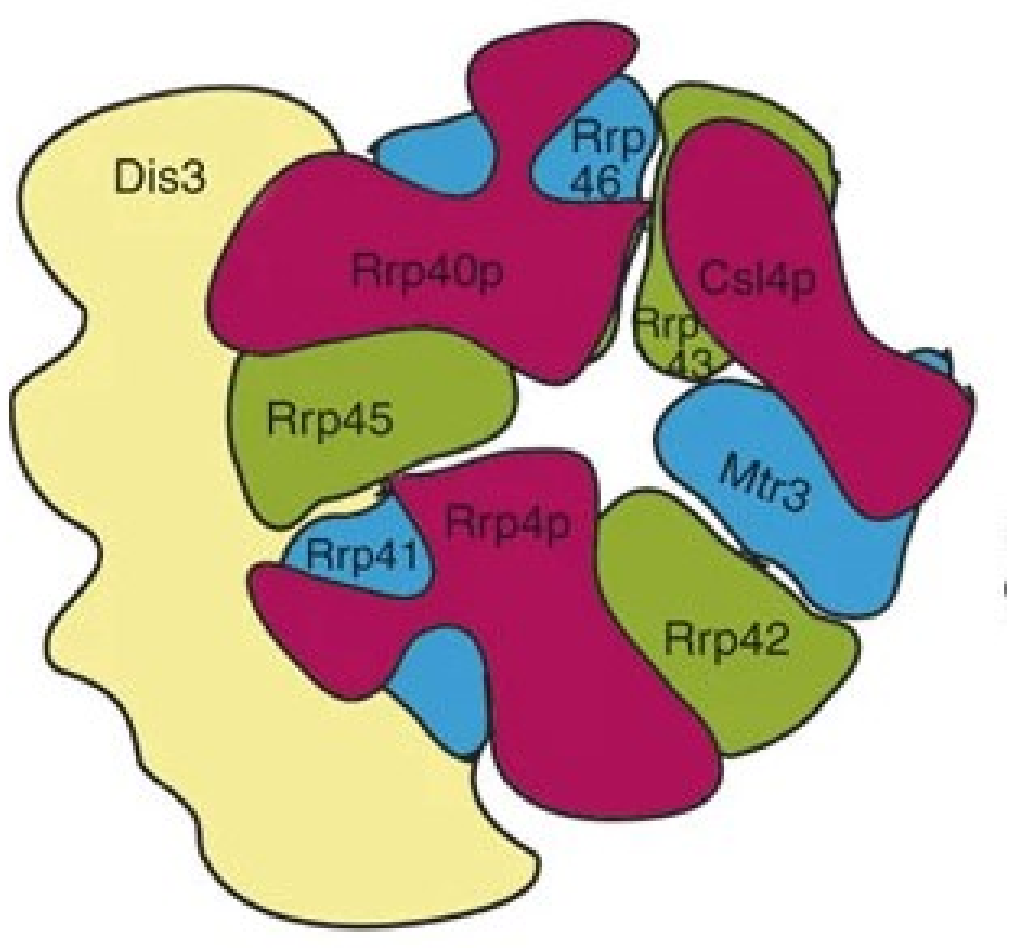

Figure 4: Schematic presentation of the exosome and its core subunits in yeast. Relative positioning of Dis3 and the Exo-9 ring proteins can be seen. (Adapted with permission from Dziembowski et al., 2007) 
Exosome can be found in both Nucleus and cytoplasm in yeasts. The core of the exosomes present in the nucleus are linked to two other proteins: Rrp6, which is an RNase with hydrolytic activity (Kadaba et al., 2004; LaCava et al., 2005; Vaňáčová et al., 2005; Wyers et al., 2005), and Rrp47, which works alongside Rrp6 (Mitchell et al., 2003). On the other hand, exosomes in the cytoplasm are associated with Ski7 which is also part of the Ski complex and has a significant role in RNA surveillance pathways (Takahashi et al., 2003; van Hoof et al., 2000).

In the cytoplasm, a group of proteins named superkillers (Ski) control the activity of mRNA degradation in the exosome (SJacobs Anderson \& Parker, 1998). The Ski complex in yeast consists of Ski2, Ski3, Ski8 and Ski7. It has also been proven that the Ski complex takes part in 3'-5' degradation in yeast (Araki et al., 2001; S. A. Synowsky \& Heck, 2007; van Hoof et al., 2000; Wang et al., 2005). Ski7 connects the ski complex to the exosome in order to regulate RNA degradation and Ski2, Ski3 and Ski8 have a role in modulating protein to protein interaction (D'Andrea \& Regan, 2003; Stirnimann et al., 2010). While this pathway acts secondary and most mRNA degradation is done through Xrn1 in the cytoplasm, aberrant transcripts mainly get discarded by the exosome through processes such as Nonsense mediated decay (NMD) pathway or nonstop decay (NSD) pathway.

\subsection{Degradation of aberrant mRNAs}

Errors are likely to occur during translation and transcription and result in unwanted products. It can arise at different levels, from gene, mRNA transcript to protein production. 
Therefore, to avoid such mistakes and to sustain fidelity, the cell has developed processes to quickly identify and remove aberrant transcripts. mRNA surveillance processes in the cell are responsible for identifying and differentiating between aberrant and normal mRNAs. Transcripts missing a stop codon or poly A tail or contain a premature stop codon are examples of transcripts containing mistakes (Doma \& Parker, 2006; Isken \& Maquat, 2007; Meaux \& van Hoof, 2006), and they each prompt a specific mRNA degradation pathway. Nonsense-mediated decay (NMD) pathway is triggered by the ribosome reaching a premature stop codon on the mRNA (Nicholson \& Mühlemann, 2010). Long pauses during translation caused by secondary structures and rare codons on the mRNA activate the no-go decay (NGD) channel (Harigaya \& Parker, 2010). Finally, transcripts that lack an in frame stop codon trigger the non-stop decay (NSD) pathway (van Hoof et al., 2002). Moreover, there is a connection between these aberrant mRNA degradation pathways and the factors involved in these processes are similar (Shoemaker \& Green, 2012; van Hoof \& Wagner, 2011).

\subsubsection{Nonsense-mediated mRNA decay (NMD)}

NMD is an mRNA surveillance pathway that identifies and degrades transcripts with a premature stop codon within the ORF (Celik et al., 2017; J. Lykke-Andersen \& Bennett, 2014; Shoemaker \& Green, 2011). It was first identified in yeast and nematodes (Leeds et al., 1991; Peltz et al., 1993; Pulak \& Anderson, 1993) and it is a preserved degradation pathway in eukaryotes (Schweingruber et al., 2013). At first, it was believed that the NMD pathway is triggered in cell to eliminate transcripts with PTCs and by this protecting the cell 
from unwanted and undesirable effects of truncated proteins (Feng He et al., 2003; Pulak \& Anderson, 1993). Further studies have identified that NMD besides having a role in nonsense mRNA decay, it is also involved in post transcription regulation of the mRNA (Feng He et al., 2003).

\subsubsection{NMD machinery}

NMD pathway is triggered when the A site of the ribosome reaches a nonsense codon during mRNA translation elongation (Amrani et al., 2004). NMD pathway utilizes a series of factors to identify, target and degrade the nonsense transcript. The principle regulators of the NMD process are described below.

\subsection{Upf proteins}

This group of proteins are the main regulators of the NMD pathway. Upf1, Upf2, and Upf3 are three well conserved protein from this family that have an essential role in eukaryotes (Leeds et al., 1991; J. Lykke-Andersen et al., 2000; Nicholson et al., 2010; Perlick et al., 1996; Salas-Marco \& Bedwell, 2004). All three proteins exist in the cytoplasm of the cell except for Upf3 that is also found in the nucleus (J. Lykke-Andersen et al., 2000; Serin et al., 2001)

Upf1 is an ATP-dependent RNA helicase and the only protein from this family that has an enzymatic activity (Bhattacharya et al., 2000; Czaplinski et al., 1995). The helicase activity of Upf1 is boosted with the inclusion of Upf2 and Upf3 (Chamieh et al., 2008; Fiorini et al., 
2013). Yeast two-hybrid studies have revealed that Upf1 has a $\mathrm{CH}$ domain and through that it can bind to other decay factors such as Rrps26 (Min et al., 2013), C-terminal of Upf2 (Arias-Palomo et al., 2011; Ferná Ndez et al., n.d.; Yamashita et al., 2009), and Dcp2 (Feng He \& Jacobson, 1995, 2001). The shared binding domain on Upf1 suggest that physical interaction between these NMD factors do not happen at the same time and rather successively.

Upf2 operates a link between Upf1 and Upf3. Upf2 binds with Upf3 through C-terminal domain (F He et al., 1997; Kadlec et al., 2004). Once Upf2 interacts with Upf1 a rise in ATPase and helicase activity is seen. This is because the interaction between these two proteins change the physical conformation of Upf1 from RNA binding to RNA unwinding form (Chakrabarti et al., 2011; Chamieh et al., 2008).

Upf3 interacts with Upf1 and increases the mRNA degradation rate due to premature stop codon on the transcript. Unlike yeast, human genome has two functional homologs, Upf3A and Upf3B (S. Lykke-Andersen et al., 2014; Mendell et al., 2004). Both proteins are associated with NMD pathway (F He et al., 1997).

\subsection{Smg proteins}

The activity of the Upf proteins are controlled by further components in the cell such as Smg proteins. Three members of this family, Smg1, Smg8, and Smg9 construct complex that has a role in Upf1 Phosphorylation. Smg1 is the only protein in the complex with a kinase activity and is regulated by Smg8 and Smg9 (Grimson et al., 2004; Kashima et al., 2006; Yamashita et al., 2009). Smg1 needs Upf2 and Upf3 and exon-junction complex (EJC) in order to 
phosphorylate Upf1 (J. Lykke-Andersen \& Bennett, 2014). Other members of this family, Smg5, Smg6, and Smg7 have an essential role in de-phosphorylation of the Upf1 protein (Page et al., 1999; Yamashita, 2013). Smg6 has an endonuclease function in the NMD pathway (S. Lykke-Andersen et al., 2014; Schmidt et al., 2014), while Smg5 and Smg7 create a heterodimer construct and recruit deadenylation complex, Ccr4-Not to enhance mRNA decay (Loh et al., 2013; Unterholzner \& Izaurralde, 2004).

\subsection{Eukaryotic release factors}

eRF1 and eRF3 are two members of this family and their role is to recruit Upf family of proteins to the mRNA (Czaplinski et al., 1995; Kashima et al., 2006; Singh et al., 2008). The interaction between Upf1, eRF1, eRF3 and Smg1 form a complex named SURF (Kashima et al., 2006). Upf1's ATPase activity lowers when it binds to any of the two release factors and hence stabilizing the mRNA-Upf1 complex (Chamieh et al., 2008; Czaplinski et al., 1995). However, binding to Upf2 and Upf3 resolves the stalled termination complex and activates Upf1 (Chamieh et al., 2008).

\subsection{Exon junction complex}

After mRNA splicing in eukaryotes, Exon junction complex (EJC) is placed close to the splice junction regions on the mRNA (le Hir et al., 2000). This complex which contains four core proteins: eIF4A3, Y14, Magoh and MLN51(Aur' et al., 2015; Kashima et al., 2006; Melero et al., 2014)and other supporting proteins has an essential part in regulating mRNAs fate in the cell (Bono \& Gehring, 2011). It has been proven that the existence of EJC close to a premature stop codon significantly increases NMD efficiency (Bühler et al., 2006; Singh 
et al., 2008). Moreover, other mRNA surveillance pathways interact with EJC. For example, Upf3 directly binds to this complex (Kim et al., 2001; J. Lykke-Andersen et al., 2000).

\subsubsection{NMD mechanism}

Extensive research on NMD mechanisms suggest three main models for NMD activation. While sharing common factors, each model fundamentally differs from the other in terms of how the NMD pathway targets its substrates.

\subsection{Exon junction complex dependant model}

Although this model has not been identified in yeast, the idea behind it originated from a study in yeast (González et al., 2000). Several factors observed in mammalian cells have developed this model. Firstly, in mammalian cells mRNAs that have gone through splicing are marked by EJCs close to the junction sites (le Hir et al., 2000). Moreover, the normal termination site being located at the last exon, means there is no EJCs after the stop codon on the spliced mRNA (Nagy \& Maquat, 1998; J. Zhang et al., 1998). Secondly, after one round of translation has been completed, EJC associated factor, Pym, removes the EJCa from the mRNA (Gehring et al., 2009). Lastly, EJC directly joins the NMD by binding to Upf3 (J. Lykke-Andersen et al., 2000). Based on several studies and the facts stated here confirm that if during the initial round of translation, the EJC is in close distance to the stop codon, the mRNA is then selected for NMD. 
The first step in this model, Upf1 binds to Smg1 and functioning similar to a clamp and at the same time binding to eRF1 and eRF3 to form the SURF complex close to the premature stop codon. Smg8 and Smg9 also bind to Smg1 to regulate its kinase activity (Chakrabarti et al., 2011; Chamieh et al., 2008; Clerici et al., 2009). Afterwards, the decay-inducing complex (DECID) is formed by the junction of the SURF complex, Upf2, Upf3 and the EJC downstream of the premature termination codon (Hug et al., 2016). DECID prompts phosphorylation of Upf1 and disassociates eRF1 and eRF3 (Fiorini et al., 2015; Franks et al., 2010). At this point due to structural configuration of Upf1, this protein acquires its helicase function (Schoenberg \& Maquat, 2012).This helicase activity will allow nucleases to access the mRNA(Eberle et al., 2009; Huntzinger et al., 2008). To further proceed to degrading the mRNA, phosphorylated Upf1 binds to Smg5, Smg6 and Smg7 (J. LykkeAndersen \& Bennett, 2014; S. Lykke-Andersen et al., 2014; Schmidt et al., 2014). Smg6 cleaves the mRNA close to the premature stop codon (Loh et al., 2013), which will then lead to mRNA degradation (Unterholzner \& Izaurralde, 2004). Subsequently, Smg5 and Smg6 bind to Upf1 and initiate deadenylation (Unterholzner \& Izaurralde, 2004) and recruit Xrn1 for decapping and degrading the mRNA 5'-3'(Unterholzner \& Izaurralde, 2004). This mechanism of NMD is illustrated in Figure 5. 


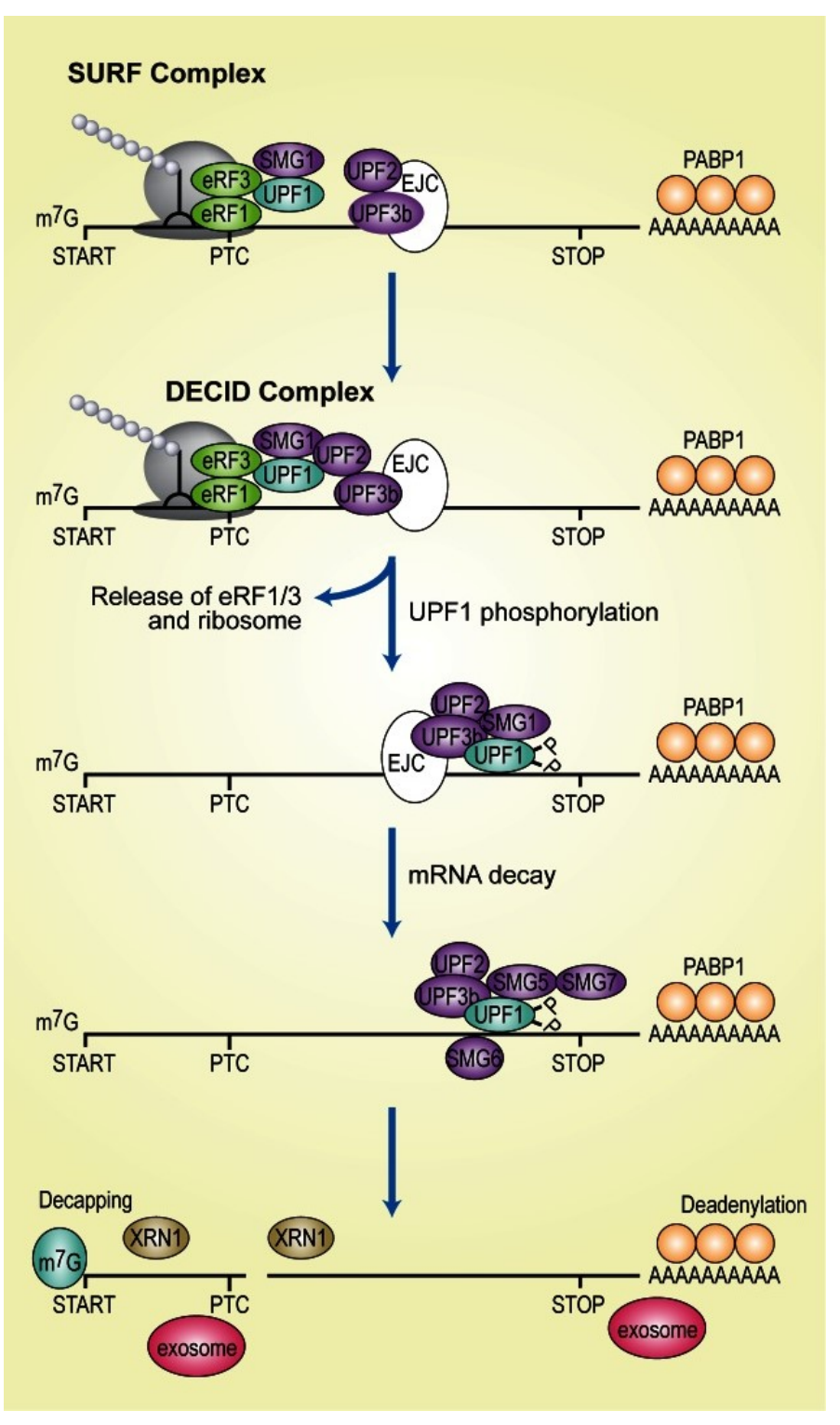

Figure 5: Exon junction model of NMD. Upf1 binds to Smg1 kinase, eRF1 and eRF3 to form the SURF complex close to the premature stop codon on the mRNA. Subsequently the DECID complex is formed by the union of the SURF complex with Upf2, Upf3 and EJC. Upf1 is the phosphorylated and eRF1 and eRF3 are released from the complex. Phosphorylated Upf1 then associates with Smg5, Smg6 and Smg7 to recruit other mRNA decay factors and degrade the target transcript. (Adapted with permission from Hug et al., 2016) 


\subsection{Exon junction complex independent model}

Even though an EJC dependant model of NMD has been confirmed, many studies have also suggested the existence of an NMD model that can trigger an NMD response in the absence of an EJC (Bühler et al., 2006). This model of NMD has been reported in organisms such as yeast, nematodes, and humans (Feng He \& Jacobson, 2015). This non-EJC dependant model has been specifically reported in mRNAs that have a long 3' UTR (Hogg \& Goff, 2010). The main factor in NMD models is the mechanism by which Upf1 binds to the mRNA containing PTC. Current research suggests that Upf1 associates with the target mRNA prior to translation and removal by the translation machinery (Gregersen et al., 2014). This subsequently leads to an increased number of Upf1 at the 3'UTR of the mRNA (Zünd et al., 2013). This might go against the previous assumption in which phosphorylated Upf1 flags mRNAs to be degraded by NMD. Additionally, previous studies have shown that NMD targets for degradation are enriched with phosphorylated Upf1, unlike in normal mRNAs which release unphosphorylated Upf1 (Kurosaki et al., 2014). Details of this mechanism and why Upf1 stays associated with the non-sense mRNA and how it subsequently gets phosphorylated are still unclear. Some studies have reported that this may be a result of Upf1 competing with PABPs for associating with eRF3 (Fatscher et al., 2015; Singh et al., 2008). 


\subsubsection{No-Go Decay (NGD)}

NGD is the most recently identified mRNA degradation pathway and was first discovered in yeast (Doma \& Parker, 2006). This mRNA surveillance pathway was first found in yeast which involves Dom34-Hbs1 (Doma \& Parker, 2006). As illustrated in Figure 6, mRNA targets of this pathway are mainly mRNAs with strong secondary structures that stall the translation machinery (Tollervey, 2006).

Targets of this pathway become prone to endonucleolytic cleavage (Doma \& Parker, 2006), but the exact endonucleases involved in the process are still unknown (Gregersen et al., 2014). In NGD the targeted mRNAs are cleaved 5' of a stalled ribosome (Chen et al., 2001), the ribosome is then removed from the mRNA by Hbs1-Dom34 pair and subsequently degraded 5'-3' and 3'-5' by Xrn1 and exosome, respectively (Figure 6) (Doma \& Parker, 2006; Pisareva et al., 2011; Shoemaker et al., 2010). Furthermore, similar to NMD this surveillance pathway also requires one round of translation hence, secondary structures at the 5'-UTR of the mRNA will not trigger NGD pathway (Doma \& Parker, 2006). 

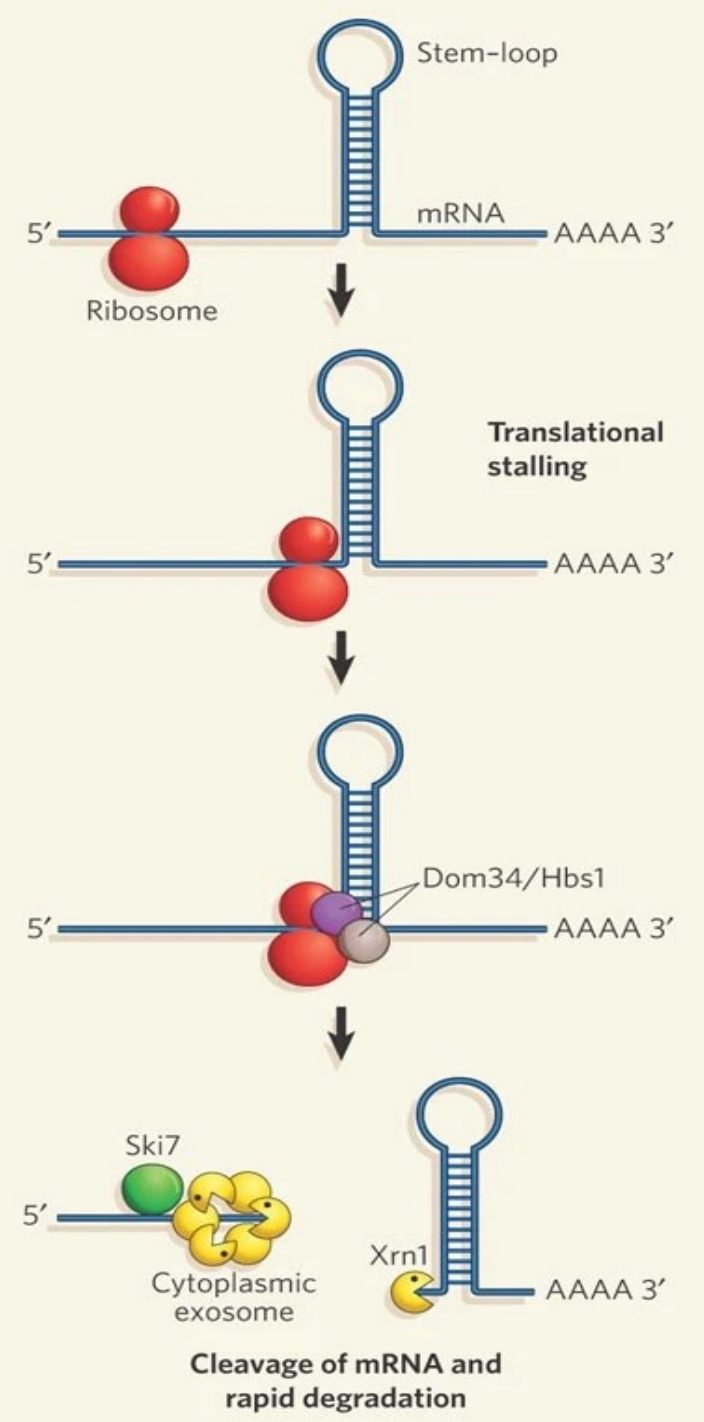

Figure 6: No-Go mRNA degradation pathway. NGD targets mRNAs with strong secondary structures which stall the ribosome during translation. NGD utilizes Dom34-Hbs1 pair to facilitate target transcripts near the stall site with an endonucleolytic activity. The mRNA fragments are then degraded 5'-3' by Xrn1 and 3'-5' by the exosome. (Adapted with permission from Tollervey., 2006) 


\subsubsection{Non-Stop Decay (NSD)}

NSD is another mRNA surveillance pathway that targets transcripts that lack an in frame stop codon. This degradation pathway was first discovered in yeast (Frischmeyer et al., 2002; van Hoof et al., 2002). Targets of NSD will elongate translation, therefore, ribosome will reach the poly A tail and as a resuly poly-lysine chain is translated. This poly-lysine polypeptide is then subjected to degradation by the proteasome in the cell (Ito-Harashima et al., 2007; Wilson et al., 2007). Also, the ribosome is eventually stalled at the end on the mRNA with an empty A site. This site is then targeted by Dom34-Hbs1 pair for degradation (Pisareva et al., 2011; Shoemaker et al., 2010).

As shown in Figure 7 NSD pathway similar to degradation of normal mRNAs requires the exosome. Additionally, NSD utilizes the SKI complex and particularly SKI7 protein (Brown et al., 2000). The Ski complex interacts with the exosome and accelerates exome-regulated degradation of the nonstop transcript in the cytoplasm (Araki et al., 2001; Meaux \& van Hoof, 2006). The specific function of each component of the Ski complex is not fully understood.

NSD differs from normal mRNA decay pathways and NMD. For example, NSD unlike normal mRNA degradation mechanisms and NMD does not require Dcp2, Xrn1, and Upf1 protein. Nonstop mRNA degradation happens without initial deadenylation of the mRNA (Frischmeyer et al., 2002). Also, NSD pathway requires Ski7 which is not essential for normal transcript decay (van Hoof et al., 2002). Lastly, nonstop mRNA decay can be effectively done by both exo- and endonuclease activity of the exosome, unlike normal transcript degradation pathways that only require exonuclease activity (Schaeffer \& van Hoof, 2011). 


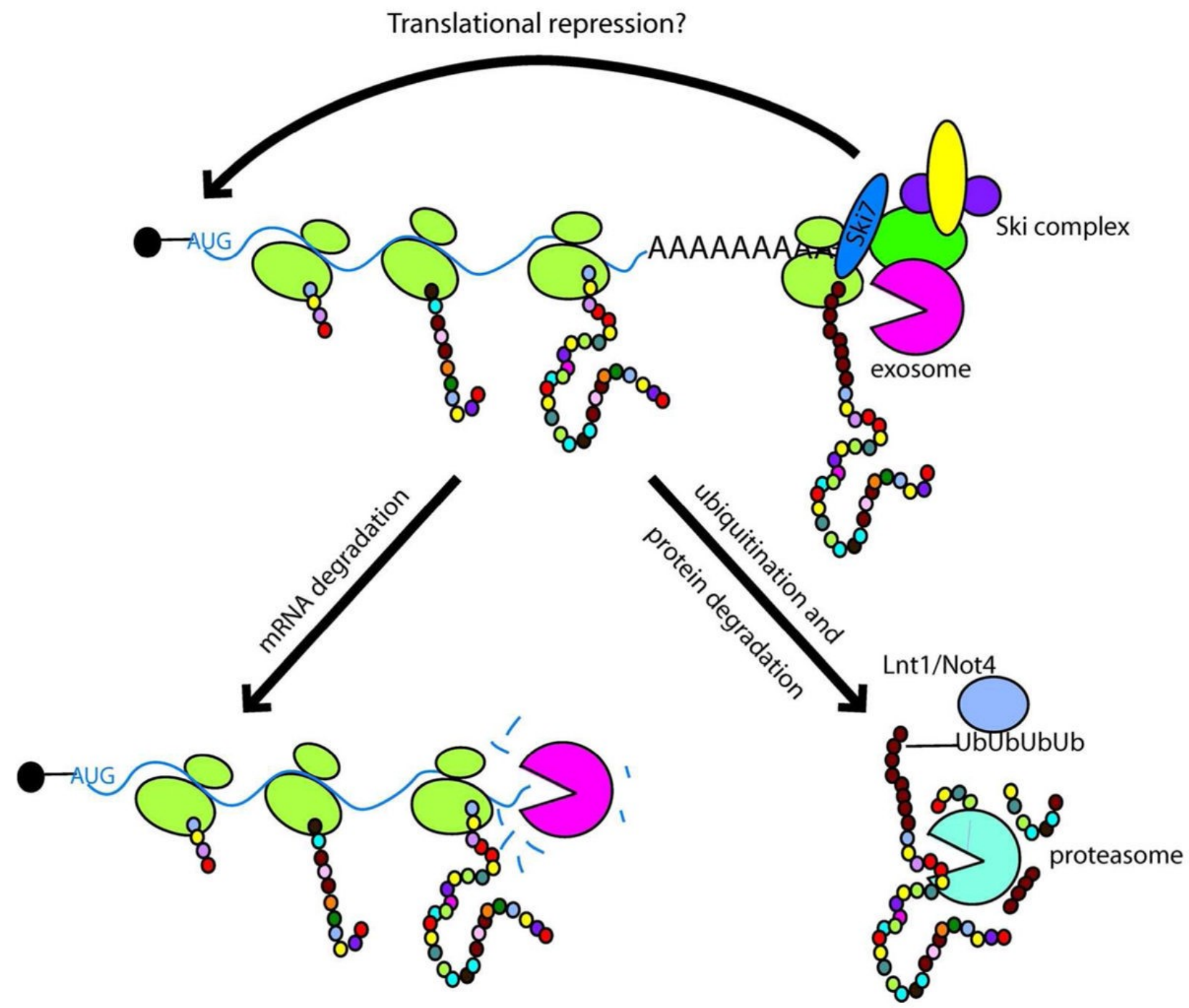

Figure 7: Mechanism of nonstop mRNA decay. Transcripts lacking an in frame stop codon are prone to rapid decay. This pathway may also prompt protein degradation and translational repression. (Adapted with permission from Klauer \& Van Hoof., 2012) 


\section{$1.4 \quad$ Focus}

Generally speaking, every RNA in the cell is subjected to degradation in order to control gene expression in the cell. Many years of research have revealed a variety of degradation mechanisms and pathways for normal mRNAs. Additionally, several mRNA surveillance pathways that specifically eliminate faulty RNAs have been identified. mRNA surveillance and degradation of normal RNAs are well researched and understood. Although, extensive studies have also been done on degradation of aberrant mRNAs like the NMD pathway, our knowledge of the complete process of NSD and specifics of various factors that are involved remain unknown. The overall goal of this study is to identify novel genes involved in the NSD process in S. cerevisiae. To do this we performed a large-scale transformation and expression screening using yeast gene knockout collection. The collection was transformed with a HIS3 mRNA expression system lacking a stop codon. Three of the genes identified in our screen belonged to the family of helicase. Deletion mutants for NAM7, ECM32 and SKI2, all showed significant growth in the absence of histidine in the media suggesting the involvement of these helicases in the NSD process. Previous studies have revealed the role of helicases in the degradation of RNAs in bacterial and eukaryotic machineries (Linder \& Jankowsky, 2011; Mohanty \& Kushner, 2016). However, the extent of RNA helicases contributions to the active RNA degradation and the NSD process is unknown. Here, we hypothesize that helicases may have a role in NSD machinery. 


\section{Chapter 2: Materials and Methods}

\subsection{Plasmid Constructs and S. cerevisiae strains, media, reagents, and drugs}

\section{Nonstop mRNA plasmid - pSA159}

To identify novel genes that are involved in the process of mRNA non-stop decay process, plasmid pSA159 was used (Zhou \& O'Shea, 2011). The obtained plasmid contains a nonstop HIS3 mutation, a GPD promoter, a Ura3 marker as well as an ampicillin resistance marker. A map of the construct is presented in Figure 8. This construct was initially produced at the Department of Molecular Biology at Nagoya University (Zhou \& O’Shea, 2011). A scheme of the marker HIS3 gene used is shown in Figure 9 (Inada \& Aiba, 2005). The translation termination is shown by bold letters and the nucleotide that was deleted to produce the nonstop codon is presented in a box. The ORF and poly A site are also indicated in the Figure 9. 


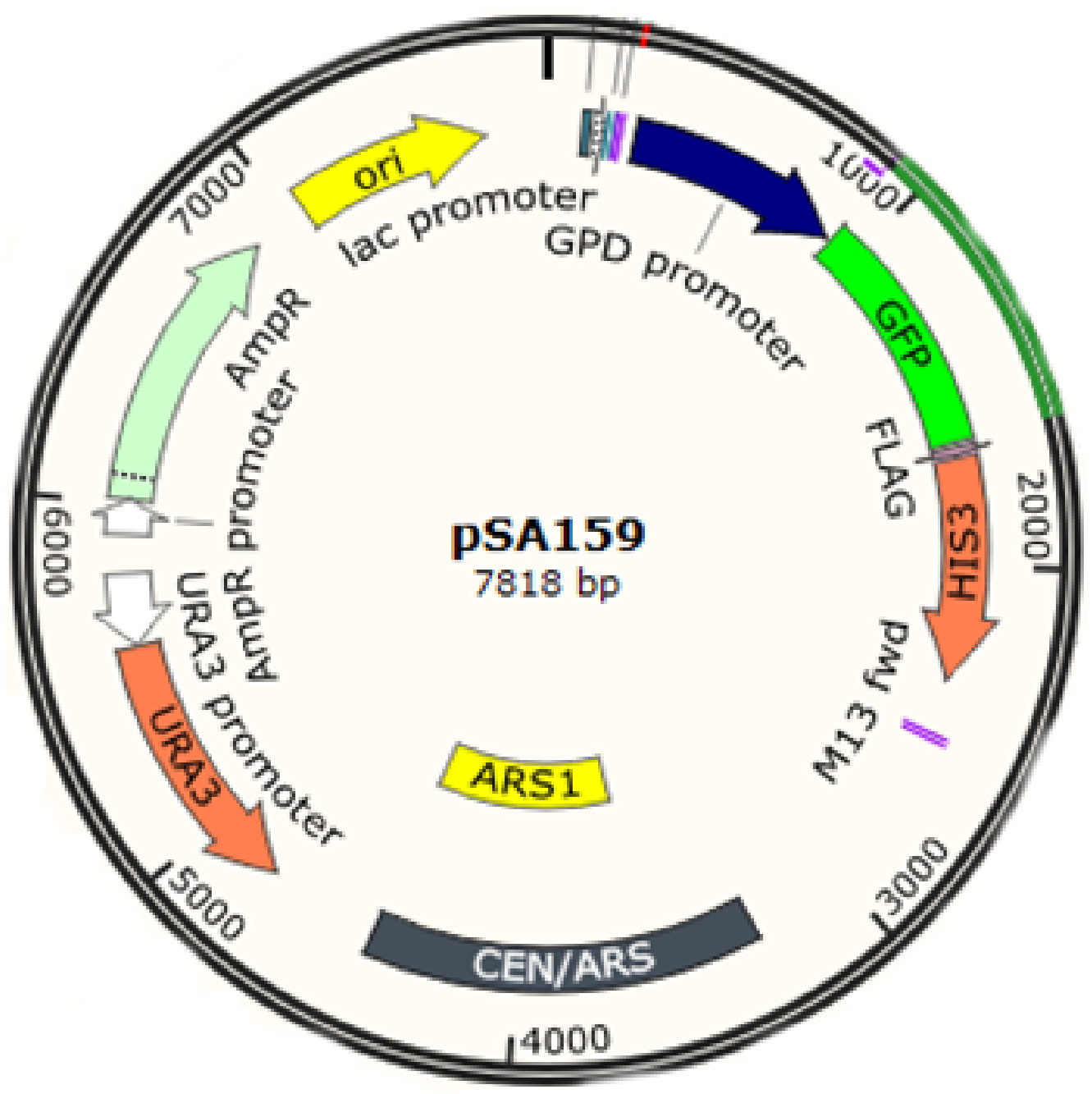

Figure 8: The pSA159 construct map. The pSA159 contains a nonstop HIS3 gene, a URA3 selectable marker and an ampicillin resistance marker. 


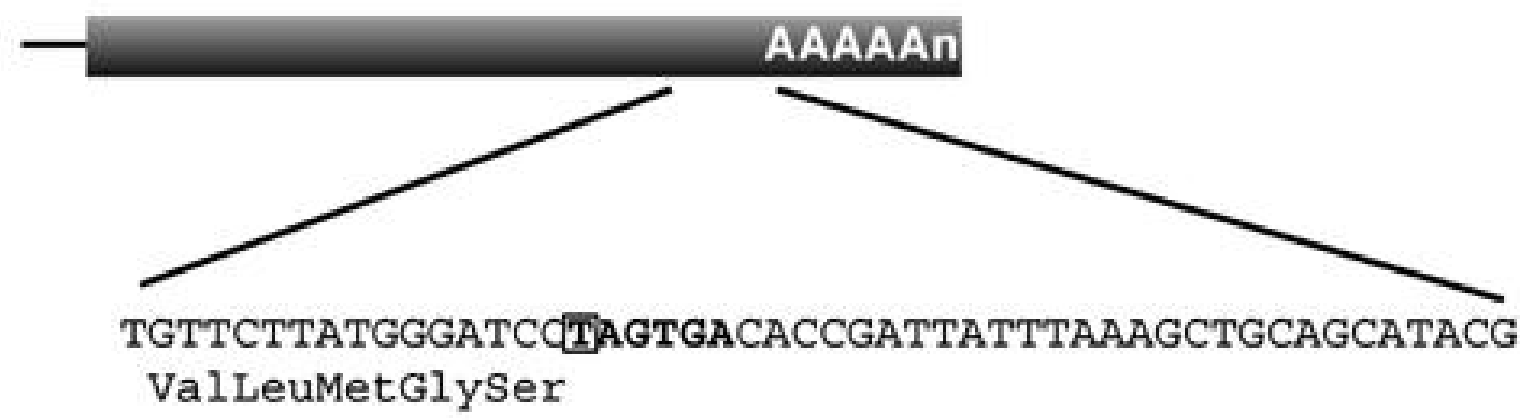

Figure 9: Nonstop HIS3 reporter gene. Shaded areas represent open reading frame of the HIS3 gene. Termination codon is bolded, and the boxed nucleotide represents the deletion to produce nonstop HIS3 construct. (Adapted with permission from Inada \& Aiba., 2005) 


\section{S. cerevisiae and Escherichia coli strains}

To perform the large-scale screening in this research we used S. cerevisiae, mating type "a" (Y4741) gene deletion set. This set contains a series of single gene deletion mutants. S. cerevisiae mating type " $\alpha$ " (Y6547) from Boone et al at the University of Toronto was used for plasmid transformation in the large-scale screening (Zhou \& O'Shea, 2011). In this a strain HIS3 gene has been deleted and, MFA1 promoter fused to $L E U 2$ has replaced $C A N 1$ gene. This strain also contained gene deletions LYPI and MET15. Competent E. coli (DH5 $\alpha)$ cells were used for plasmid replication.

\section{Media}

Yeast Peptone Dextrose (YPD) and synthetic complete (SC) media were used for yeast growth. Lysogeny broth (LB) was used for E. coli growth. -URA and -HIS dropout mix were used for selective growth media for plasmids. These dropout mixes contained the complete set of amino acids excluding amino acid Uracil and histidine, respectively. In some steps of the selection process drugs were added to the media.

\section{Drugs and antibiotics}

3-Amino-1,2,4-triazole (3-AT) is a heterocyclic organic compound that is a competitive inhibitor of the enzyme HIS3 gene product imidazoleglycerol-phosphate dehydratase (IGPD) which catalyzes the 6th step of the cellular HIS3 biosynthetic pathway (Zhou \& O'Shea, 
2011). Other drugs used and their concentrations are as follows: G418, Geneticin (200 $\mathrm{mg} / \mathrm{ml})$, ClonNat, (100mg/ml) and Ampicillin (50 mg/ml).

\subsection{NSD screening}

In order to identify novel genes involved in the mRNA nonstop decay pathway, we performed a genome wide investigation. We transformed the pSA159 construct to $S$. cerevisiae strain mating type $\alpha$ (Y4547) using standard transformation method for yeast using Lithium acetate (LiAc) (Zhou \& O'Shea, 2011).

\subsubsection{Standard transformation protocol}

Mating type " $\alpha$ " (Y6547) cells were inoculated and incubated in liquid YPD media at $30^{\circ} \mathrm{C}$, overnight. $2 \mathrm{ml}$ of the overnight culture was re-inoculated in 40ml of liquid YPD media and incubated at $30^{\circ} \mathrm{C}$ for 5 hours or until $\mathrm{OD}_{600}=1$ before being transferred to a falcon tube and centrifuged at 5000 rotations per minute (RPM) for 5 minutes. In order to collect the yeast cells the supernatant was discarded, then the pellet containing yeast cells was resuspended in $10 \mathrm{ml}$ of distilled water. After another round of centrifugation and wash the pellet was resuspended in $200 \mu \mathrm{l}$ of $0.1 \mathrm{M}$ Lithium acetate (LiAc). In the next step, $240 \mu \mathrm{L}$ of $50 \%$ Polyethylene glycol (PEG), $36 \mu \mathrm{L}$ of $1 \mathrm{M} \mathrm{LiAc}, 10 \mu \mathrm{L}$ of single stranded DNA and $5 \mu \mathrm{L}$ of the pSA159 plasmid were added to $50 \mu \mathrm{L}$ of the resuspended cell culture, respectively. The mixture was vortexed and incubated at $30^{\circ} \mathrm{C}$ for 1.5 hours, vortexing every 15 minutes. Cells were then incubated at $42^{\circ} \mathrm{C}$ for 15 minutes before moving on ice and being centrifuged at 13000 RPM for one minute. The supernatant was then discarded, and the pellet was resuspended in $100 \mu \mathrm{L}$ of milli-Q water. The cells were finally plated on -URA agar plates 
and incubated at $30^{\circ} \mathrm{C}$ for two days. This will allow to select for the yeast cells that the pSA159 plasmid had successfully been transformed to (NS $\alpha$ ).

Finally, after the incubation period the colonies that grew were re-streaked on a fresh -URA agar plate before being used in the large-scale screening.

\subsubsection{Large-scale transformation methodology}

In this step the non-stop plasmid was transferred to a deletion array set consisting of over 5000 single gene deletions using standard pinning method and series of selection.

Firstly, the NS $\alpha$ strain was pinned on top of the a-strain deletion array and incubated at $30^{\circ} \mathrm{C}$ for two days to mate and produce diploid cells. To further select for diploid cells with the non-stop construct, MATa/ $\alpha$ cells were pinned on -URA + G418 media and incubated for two days at $30^{\circ} \mathrm{C}$. These cells were then transferred to an Enriched Sporulation Media (ESM) and incubated at $22^{\circ} \mathrm{C}$ for 7 days. In this step cells will go through sporulation and produce haploid cells. In the next two rounds of selection cells were transferred to SDHis/Arg/URA+Canavanine and SD/MSG-His/Arg/URA+G418+Canavanine media, respectively and incubated for two days at $30^{\circ} \mathrm{C}$ for each step. At the end of these rounds of selection the non-stop plasmid has been transferred to 5000 MATa progeny cells in the deletion set array. Finally, the cells were pinned on -URA + G418 media and incubated for 2 days at $30^{\circ} \mathrm{C}$ and stored at $4^{\circ} \mathrm{C}$ respectively, to be then used for large-scale screening. 


\subsubsection{Selection of genes involved in NSD}

In order to identify candidate genes involved in the non-stop decay process in yeast, the deletion array set containing the non-stop his 3 construct pSA159 were transferred to -URA media lacking amino acid histidine plus $1 \mathrm{mg} / \mathrm{mL} 3-\mathrm{AT}$. The concentration of the 3-AT drug in this experiment was defined using a gradient amount of the drug and assessing the growth of the cells. After two days incubation at $30^{\circ} \mathrm{C}$ in this media cell growth and size were observed and potential genes were selected for data analysis.

\subsection{Data analysis}

Selected genes were analysed using GeneMANIA (http:// www. genemania.org/). This online database allowed to group the genes based on their molecular functions in yeast and the general processes that they are involved in (Vlasblom et al., 2015). We then looked at each group of genes and selected candidate genes to further investigate their link to the NSD process in yeast. Panther GO-slim software was also used to study and reveal the protein class of the candidate genes and to classify them based on molecular function (http://www.pantherdb.org/tools/compareToRefList.jsp). In this project we chose a family of helicases, NAM7, ECM32 and SKI2 for further investigation.

\subsection{Spot test}

To further determine the role of helicases, NAM7, ECM32 and SKI2, in the NSD pathway, a spot test was performed. Single deletion mutants of helicases with the transformed non-stop HIS3 constructs were grown overnight in -URA media to an $\mathrm{OD}_{600}$ of 1 . Cells were then 
diluted 10 -fold three times to produce 4 different concentrations. Spots of $15 \mu 1$ of each dilution were placed on solid -URA-HIS plates containing $1 \mathrm{mg} / \mathrm{ml}$ of 3 AT and -URA as a control. After 48 hours of incubation at $30^{\circ} \mathrm{C}$, cell growth on each plate were compared to the wild type based on colony sizes.

\subsection{Colony count assay}

Colony count assay was performed and evaluated based on the number of colonies formed for $N A M 7 \Delta, E C M 32 \Delta, S K I 2 \Delta$ and $W T$ strain. First, strains were grown in liquid -URA media overnight at $30^{\circ} \mathrm{C}$ before being reinoculated in liquid -URA media at the same temperature for $\sim 4$ hours to an $\mathrm{OD}_{600}=1$. Fresh cells were diluted 10-fold three times and $\mathrm{OD}_{600}$ was measured again to ensure same number of cells in all samples. Then, $20 \mu 1$ of $10^{-4}$ diluted cells were streaked on agar media lacking uracil and histidine plus $1 \mathrm{mg} / \mathrm{mL} 3-\mathrm{AT}$ and incubating at $30^{\circ} \mathrm{C}$ for two days. The number of colonies formed were counted and compared. Cells were also grown on -URA plate as a control. Each experiment was done three times and average colony counts were considered.

\section{$2.6 \quad$ qRT-PCR}

The total RNA content of the cell was extracted using RNeasy Mini Kit (QIAGEN) based on the instructions provided by the company. Then using iScript cDNA synthesis kit (Biorad), high quality RNA was converted into complementary DNA (cDNA), according to manufacturer's instructions. The cDNA was used as a template. qRT-PCR was performed 
using PowerUp SYBR Green Master Mix kit (Applied Biosystems) following manufacturer's guidelines. This experiment was performed on Bio-Rad CFX qPCR machine following this thermocycle mode: $50^{\circ} \mathrm{C}$ for $2 \mathrm{mins}, 95^{\circ} \mathrm{C}$ for 2 mins, 40 cycles of $95^{\circ} \mathrm{C}$ for $15 \mathrm{~s}-60^{\circ} \mathrm{C}$ for $1 \mathrm{~min}$ and a final $72^{\circ} \mathrm{C}$ for $10 \mathrm{mins}$. PGK-1 is used as a positive control in qRT-PCR experiments (Zhou \& O’Shea, 2011).

\subsection{Synthetic genetic array (SGA)}

In SGA, the gene of interest is deleted and replaced with nourseothricin-resistance (NAT) marker gene in mating type " $\alpha$ " and then mated with a subset of the deletion set in mating type "a". After a few rounds of selection, the progeny cells of the double mutants are obtained. The fitness of double mutant is analyzed based on growth (colony size) and compared with single deletions of original set to evaluate genetic interactions between the two genes (Memarian et al., 2007; Samanfar et al., 2013). Furthermore, Gene knockout in yeast is a two-step process where a selectable marker product is made using PCR and then is replaced with the gene of interest using homologous recombination. DNA transformation in yeast is done by the Lithium Acetate method.

In this experiment the query genes $N A M 7, E C M 32$ and $S K I 2$ were knocked out and replaced by NAT resistance gene in MAT $\alpha$ strain, Y6547. These deleted $\alpha$ strains were then matted to two different deletion mutant arrays, separately. The two mutant array libraries used in this experiment were a set of gene deletion mutants for non-stop decay pathway and translation and the other array consisted of random gene deletion mutants as a control. After 
several rounds of selection haploid progenies containing double mutations were selected and evaluated for their fitness based on their growth defects by measuring relative colony sizes. Fitness of the double mutants was evaluated using SGAtools software (http://sgatools.ccbr.utoronto.ca/). In order to enhance the coverage of negative genetic interactions, we merged our interaction results with those formerly reported (http://drygin.ccbr.utoronto.ca). Finally, gene enrichment analysis of the interactors was obtained using GeneMANIA (http:// www. genemania.org/). This experiment was repeated three times for each gene deletion and negative interaction that were observed in at least two repeats were confirmed. 


\section{Chapter 3: Results}

\subsection{NSD screen candidates}

In the first step to identify genes involved in the mRNA non-stop decay process in yeast the pSA159 plasmid that contains a non-stop HIS3 gene was transferred to the deletion array. This array consists of over 5000 nonessential gene deletions. Our understanding is that genes that are responsible or have a role in the NSD process in yeast, once deleted would allow the cell to grow under selective media lacking the amino acid histidine. Cell growth in a -HIS media is dependent on the histidine production of the non-stop his plasmid (pSA159).

From over 5000 nonessential gene deletions tested in this experiment, based on growth in the selection media, 245 genes were identified in the screen. The list of genes was then further narrowed to 68 candidate genes based on colony size, by excluding genes that showed minimal growth and small colony size. A sample plate of the screen and candidates that grew on -URA -HIS +3-AT media can be seen in Figure 10. 


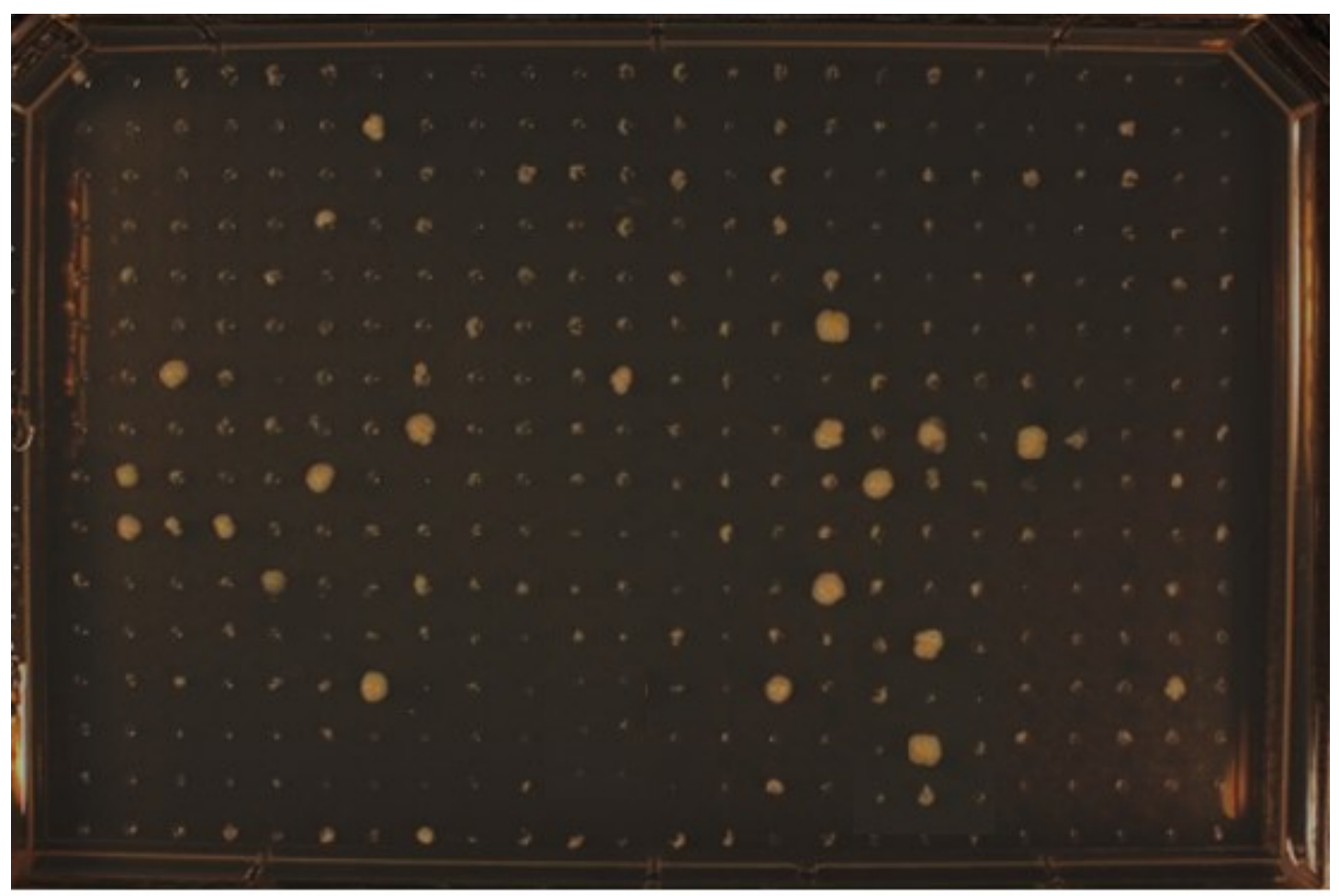

Figure 10: Sample of NSD screening plate. Candidate genes were selected from the plate based on their ability to grow on media lacking histidine plus 3-AT. 


\subsection{Gene Ontology enrichment analysis for the NSD gene candidates}

After reviewing the results from the screening, candidate genes were clustered into groups based on their function and gene family they belong to. 5 main families were identified. Details of the gene families and a description of the genes are presented in Table 1.

We then clustered the screened genes based on GO-term process to classify the genes for molecular function and their protein class using Panther software. Interestingly, $35.58 \%$ of the genes had unknown function or were not grouped. $30.89 \%$ of the screened genes had catalytic activity and $14.15 \%$ hydrolyse activity (Figure 11).

Lastly, we used Panther software to analyse the screened genes based on their protein class. Five protein classes were observed: hydrolyse proteins, member trafficking protein, ubiquitin-protein ligase, G-protein and RNA helicase (Figure 12). After reviewing the potential genes in our screening, we chose three mRNA helicases, SKI2, ECM32 and NAM7 for further investigation and their role in mRNA non-stop decay process. 
Name description

SuperKIIller

SKI7

SKI8

PHO4

PHOsphate metabolism $\mathrm{PHO5}$

PHO23

PHOSO

SPO11

SPO14

SPOrulation

SPO73

AIM18

AIM2

AIM26

REC104

RECombination

REC107

REC102

\section{Putative RNA helicase}

Component and TPR protein, mediates 3'-5' RNA degradation

GTP-binding protein

Mediates 3'-5' RNA degradation

Basic helix-loop-helix (bHLH) transcription factor, activates transcription

Repressible acid phosphatase

Component of the Rpd3L histone deacetylase complex

Cyclin; interacts with cyclin-dependent kinase Pho85p

Initiates meiotic recombination

Phospholipase D, required for meiosis and spore formation

Meiosis-specific protein required for prospore membrane morphogenesis

Unknown function

Cytoplasmic protein involved in mitochondrial function

Unknown function

Involved in early stages of meiotic recombination

Involved in early stages of meiotic recombination

Involved in early stages of meiotic recombination

Table 1: Gene clusters and description of the screened genes. 


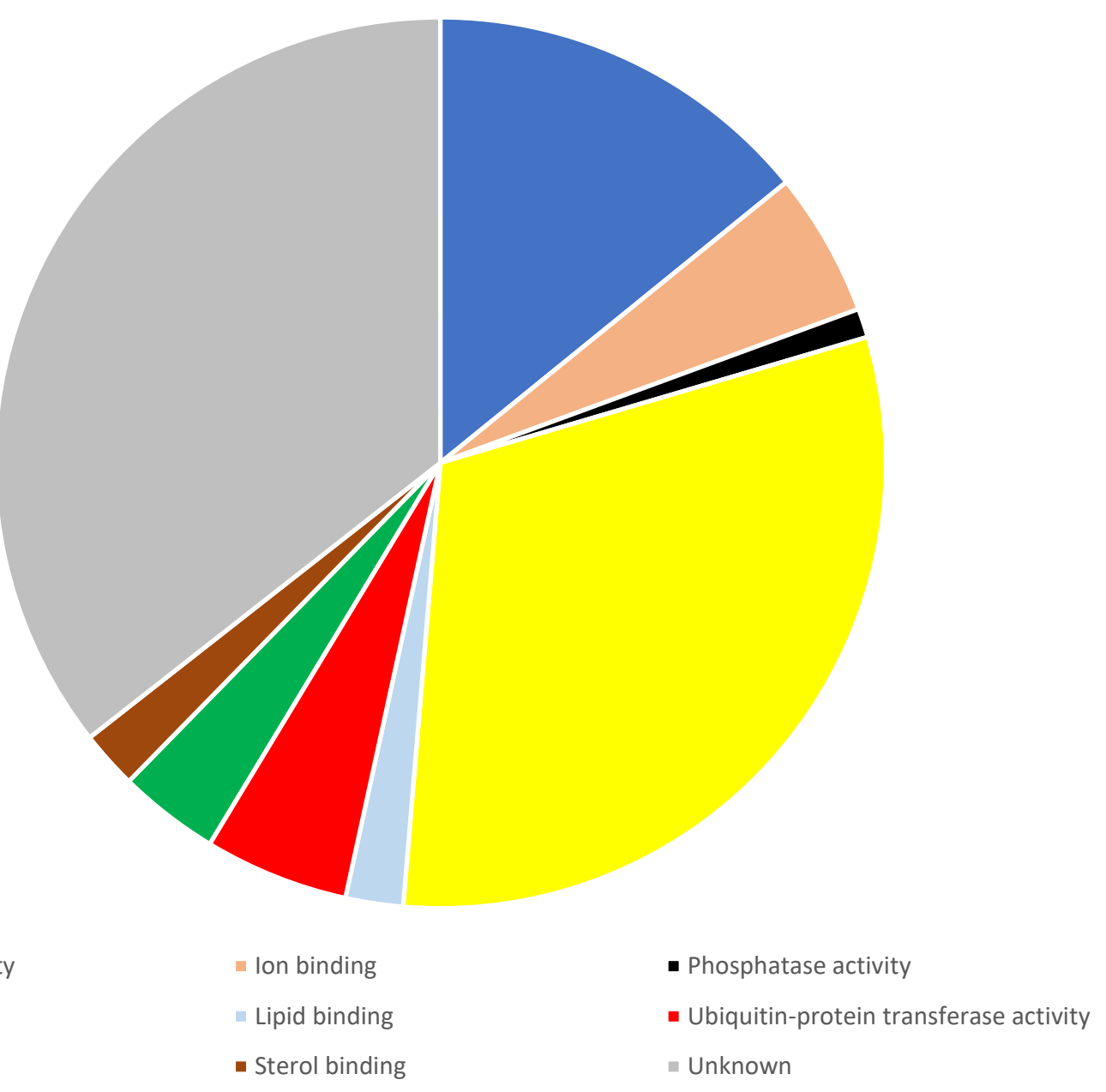

Figure 11: Gene ontology enrichment analysis for NSD screened genes. $30.89 \%$ of the enriched candidate genes have catalytic activity with p-value of 0.039 . Enriched genes with hydrolyse activity consisted of $14.15 \%$ of the total candidate genes with p-value of 0.032 . Other categories of molecular function enriched were Ion binding, Ubiquitin-protein transferase activity, ATPase activity, sterol binding, lipid binding and phosphatase activity at 5.24\% (0.039), 5.21\% (0.040), 3.66\% (0.008), $2.10 \%(0.036), 2.09 \%(0.024), 1.05 \%(0.021)$, respectively. P-values are shown in brackets. $35.58 \%$ of the screened genes had unknown functions or were not grouped. 


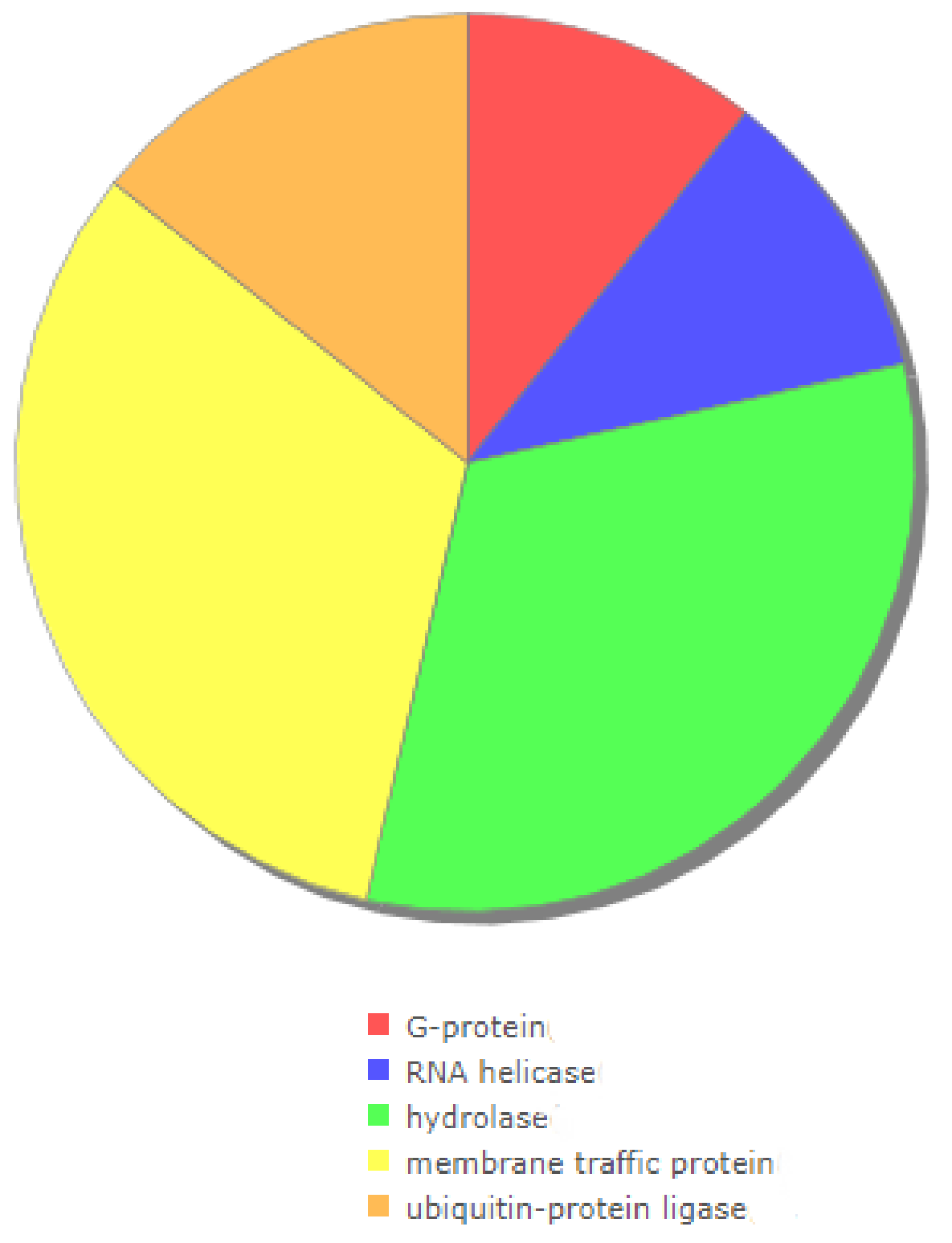

Figure 12: Candidate gene enrichment based on classified protein class. Hydrolase class and membrane traffic protein class each consist of $4.74 \%$ of proteins from our dataset with a p-value of 0.043 and 0.039, respectively. Ubiquitin-protein ligase, G-protein and RNA helicase were other enriched protein classes at $2.11 \%, 1.58 \%$, and $1.58 \%$ and p-values of $0.041,0.024,0.008$, respectively. The remaining genes were unclassified. 


\subsection{Spot test and colony counting}

In the next step non-stop HIS3 construct (pSA159) was transformed to deletion mutants for NAM7, ECM32 and SKI2. Transformed cells were plated on a selective media -URA-HIS plus $1 \mathrm{mg} / \mu \mathrm{L}$ 3-ATto evaluate their growth thus involvement of the three helicases in NSD pathway. Only cells that were able to produce the amino acid histidine from pSA159, were able to grow and form a colony. All cells were also grown on -URA solid media, under the same conditions as a control. Results from this experiment are presented in Figure 13.

All gene deletion mutants and $W T$ had similar growth on -URA control plate. This was expected, because histidine was available in the media and cells were not dependant on the production of nonstop HIS3 production of the amino acid. However, on media lacking

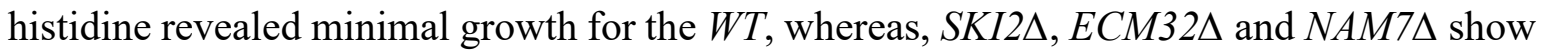

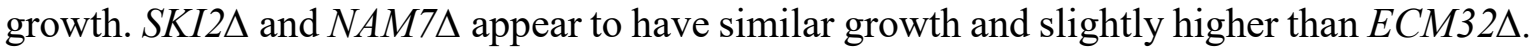
Since the $W T$ has all the genes and mRNA surveillance and degradation pathways intact, it is fair to assume that all aberrant mRNAs such as the ones lacking stop codon will be degraded in the cell and in this case resulting in lack of HIS3 gene product. Therefore, WT is unable to grow on -URA-HIS+3-AT media. These results support our initial hypothesis that the three chosen helicases might have a role in mRNA nonstop decay process.

To further quantify these results, cells were grown on -URA -HIS +3-AT media and colonies were counted. These results support the results of the spot test (Figure 14). 
A

-URA

$\begin{array}{llll}\text { WT ECM32D SKI2 } & \text { NAM7D }\end{array}$
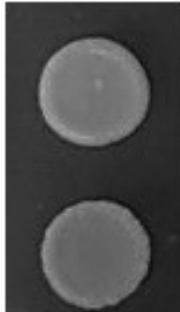

.

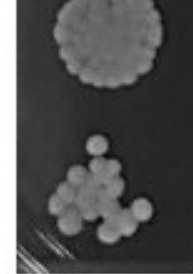

ᄂ

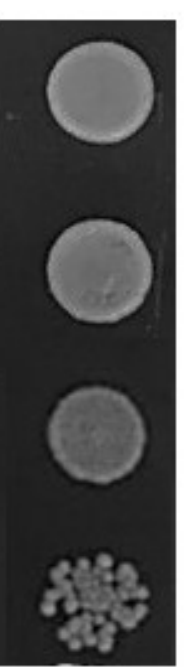

B

-URA-HIS+3-AT

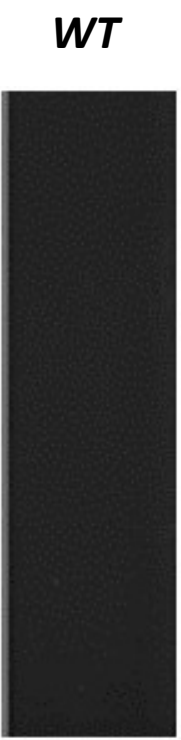

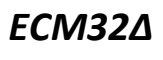

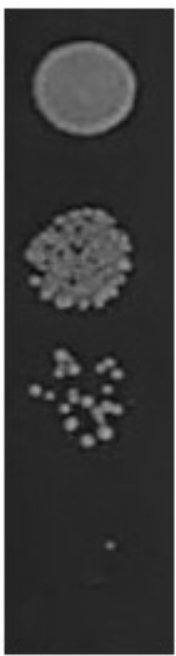

SKI2

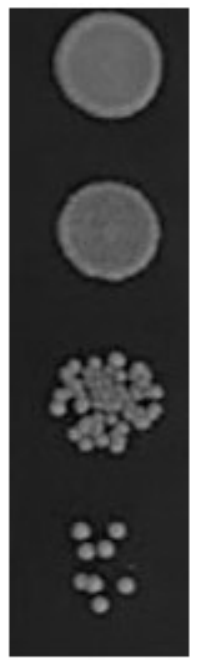

NAM7D

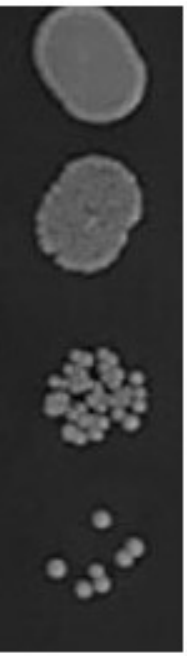

Figure 13: Growth sensitivity analysis for $W T, E C M 32 \Delta, S K I 2 \Delta$, and $N A M 7 \Delta$. Part A represents the control where all samples grew in -URA media. Second Panel B shows the wildtype and four mutants growing on media lacking Uracil and histidine, and in the presence of $1 \mathrm{mg} / \mathrm{mL} 3-\mathrm{AT}$. Each sample has been through a serial dilution, starting at $10^{-1}$ cells, and finishing at $10^{-4}$ cells. 


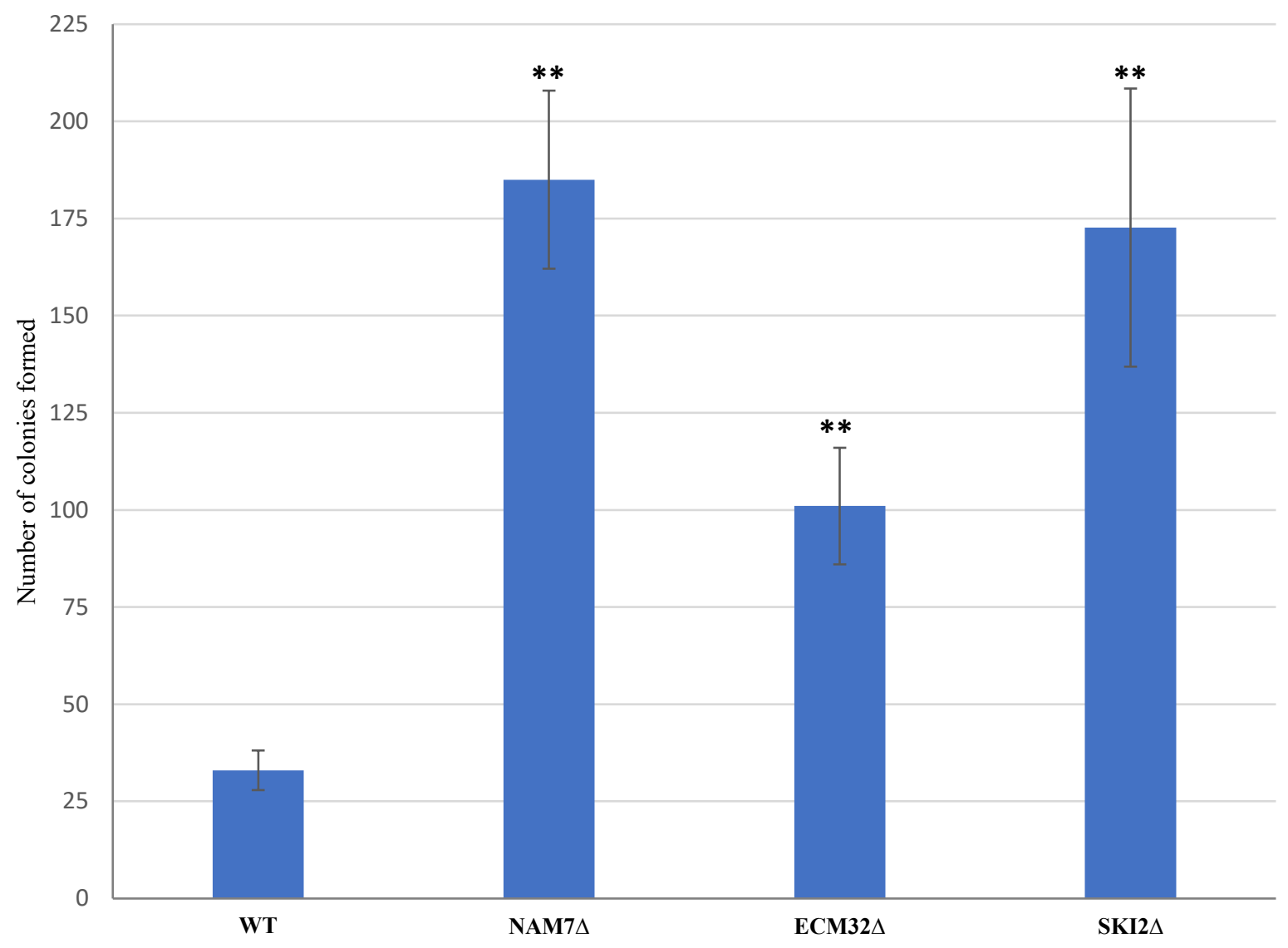

Figure 14: Colony count. Number of colonies in $W T, S K I 2 \Delta, E C M 32 \Delta$ and NAM7A with pSA159. All cells grown on media lacking histidine and $1 \mathrm{mg} / \mu \mathrm{L}$ of $3-\mathrm{AT} .{ }^{*}$ and $* *$ Indicates statistically significant differences (t-test) between $W T$ cells and mutant cells at $5 \%(\mathrm{p}<0.05)$ and $1 \%(\mathrm{p}<0.01)$, respectively. 


\subsection{Analysis of the non-stop mRNA content of mutants for HIS3 gene}

The rate at which mRNA is degraded is an important aspect of the cell. mRNA turnover has a crucial role in regulating gene expression and quality control of mRNA synthesis as well as maintaining hemostasis in the cell. Also, mRNA degradation has a significant role in the decay of aberrant mRNAs and ultimately preventing the production of defective proteins in the cell. Therefore, studying mRNA degradation pathways and mRNA quality control surveillance pathways is a hot topic of research.

Based on the results we can confirm that helicases, NAM7, ECM32 and SKI2 have a role in mRNA degradation and possibly nonstop decay pathway. In the next step we investigated the nonstop HIS3 mRNA abundance in all three candidate mutants as well as the wild type using qRT-PCR. Results from this experiment is shown in Figure 15. Based on the results all three mutants had no statistical significant difference in the amount of NS-HIS3 mRNA in comparison to the WT. PGK1 was used as a control. PGK1 mRNA remains constant and was used to normalize the results for all strains. 


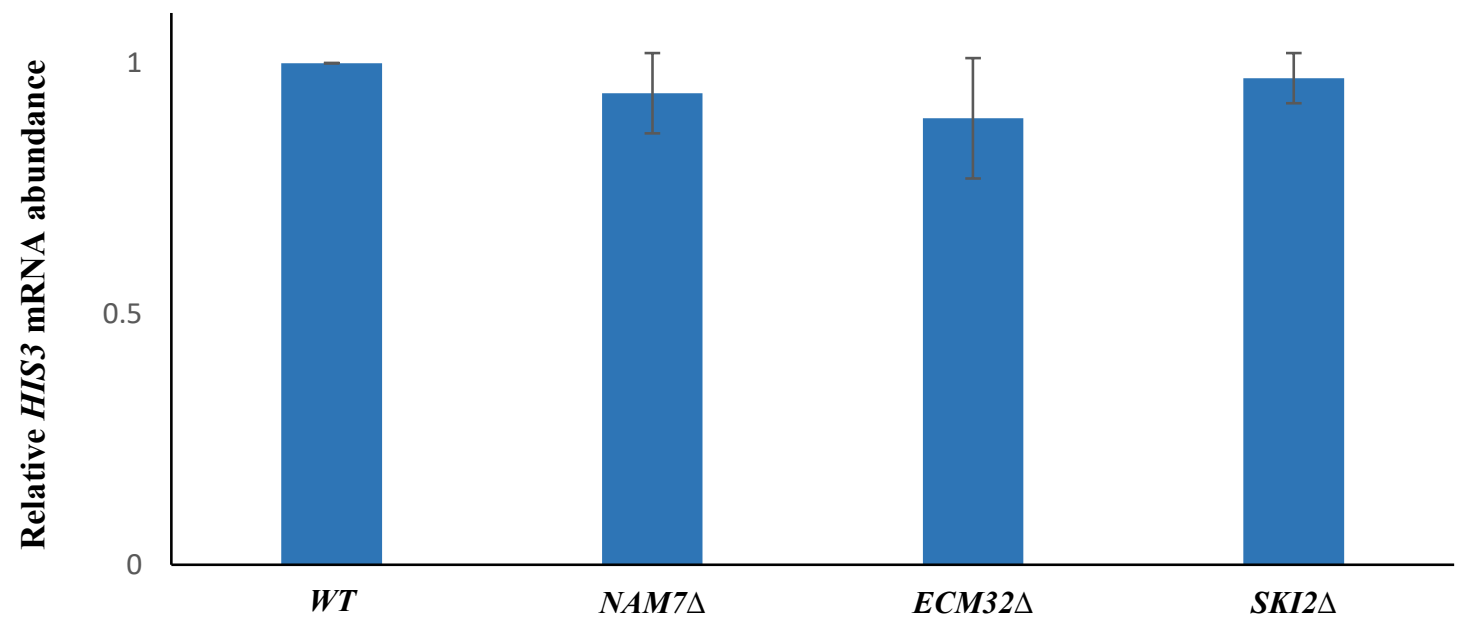

Figure 15: Relative $H I S 3$ mRNA levels for $W T, N A M 7 \Delta, E C M 32 \Delta$ and $S K I 2 \Delta$. mRNA content of PGK1 housekeeping gene was used for normalizing the samples. There is no statistical significance ( $p$-value $\leq 0.05$ ) between the mRNA content of the $W T$ and the three mutant strains. 


\subsection{Genetic interaction analysis (GI)}

Genetic interaction analysis is a common way to study the functional association between two genes in overlapping pathways (Zhou \& O'Shea, 2011). In other terms two genes have genetic interactions when the deletion of both genes results in a significantly different phenotype than each gene deletion alone. GIs can be divided into two groups positive and negative genetic interactions. In positive interactions the fitness of the double mutant is less severe than the single gene deletion and in negative interactions the double mutants show a sick or lethal phenotype (Ogawa \& Oshima, 1990). Genetic interactions are defined by comparing the phenotype (colony size) of a double gene deletion mutant to a single deletion mutant. These double mutants have a more severe phenotype than the single gene deletion mutant.

To further investigate the genes of interest in this study and unravel a more in-depth level of association between gene functions in yeast, the synthetic sick interaction of genes of interest, ECM32, NAM7 and SKI2 with a custom NSD array was studied. Firstly, in mating type " $\alpha$ " strain, genes of interest were knocked out and mated to the custom gene deletion array for NSD in "a" strain. After several rounds of pinning on selective media, double gene deletion mutants of each gene of interest and genes in the custom NSD array are produced. The double mutants are selected in mating type "a". In the end colony size were measured and compared to single gene mutants as an indicator of level of sickness of phenotypes (Alamgir et al., 2010). As a control in this experiment the target gene deletion strains were 
mated to another array consisting of random gene deletions that have no functions reported to nonstop decay process.

Synthetic genetic array analysis revealed that $E C M 32$ genetically interacts with members of genes involved in mRNA splicing, Regulation of protein modification process and TBPclass protein binding (Figure 16). As seen in Figure 18, NAM7 has shown to have interactions with genes with function in transcription and post translational regulation of gene expression. Finally based on the GIs, SKI2 genetically interacts with several genes involved in mRNA catabolic process, translation elongation and structural constituents of ribosome (Figure 17). These results support the role of these genes in translation and mRNA quality control. 


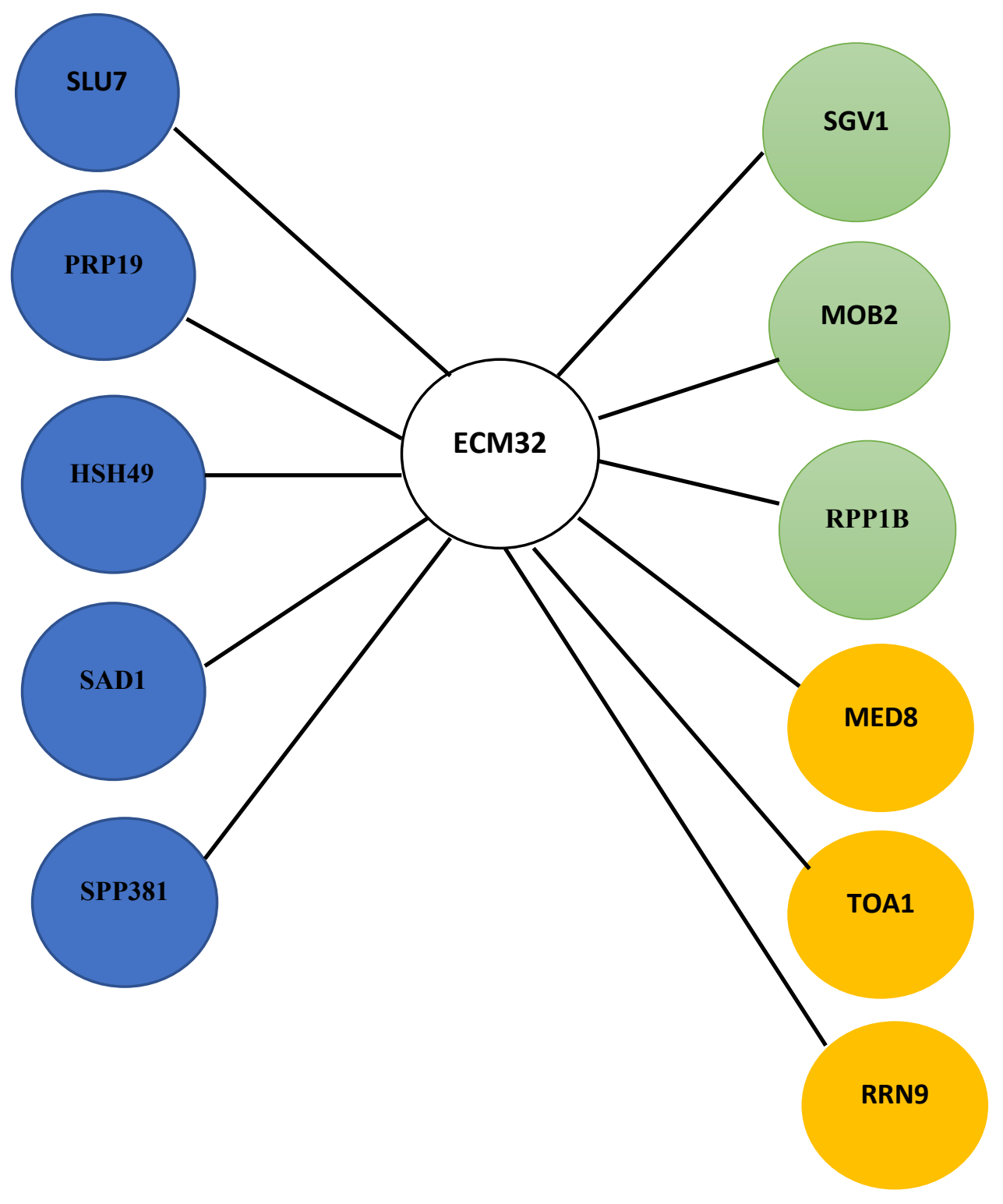

Figure 16: Negative genetic interaction of ECM32 showed several interactions with mRNA Splicing genes (blue) with P-values of 5.32 $\times 10-5$, protein modification process regulators (green) with P-values of $2.31 \times 10-5$, and TBP-class protein binding (yellow) with P-values of $4.72 \times 10-8$. 


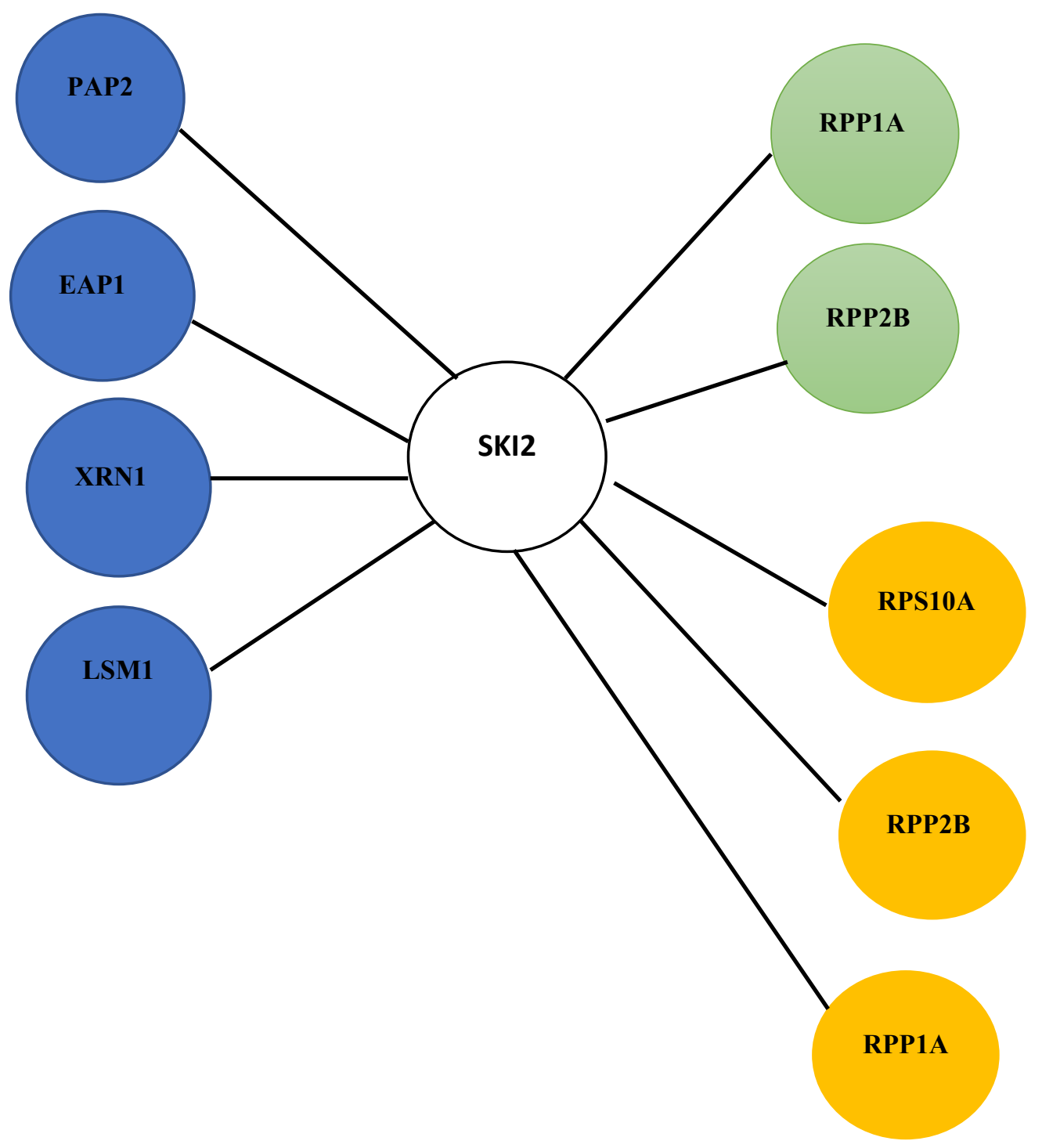

Figure 17: Negative genetic interaction of SKI2 showed several interactions with genes involved in mRNA catabolic process (blue) with P-values of $6.12 \times 10^{-4}$, Translation elongation and protein kinase activity (green) with P-values of $1.13 \times 10-3$, and Structural constituent of ribosome (yellow) with P-values of $3.65 \times 10-3$. 


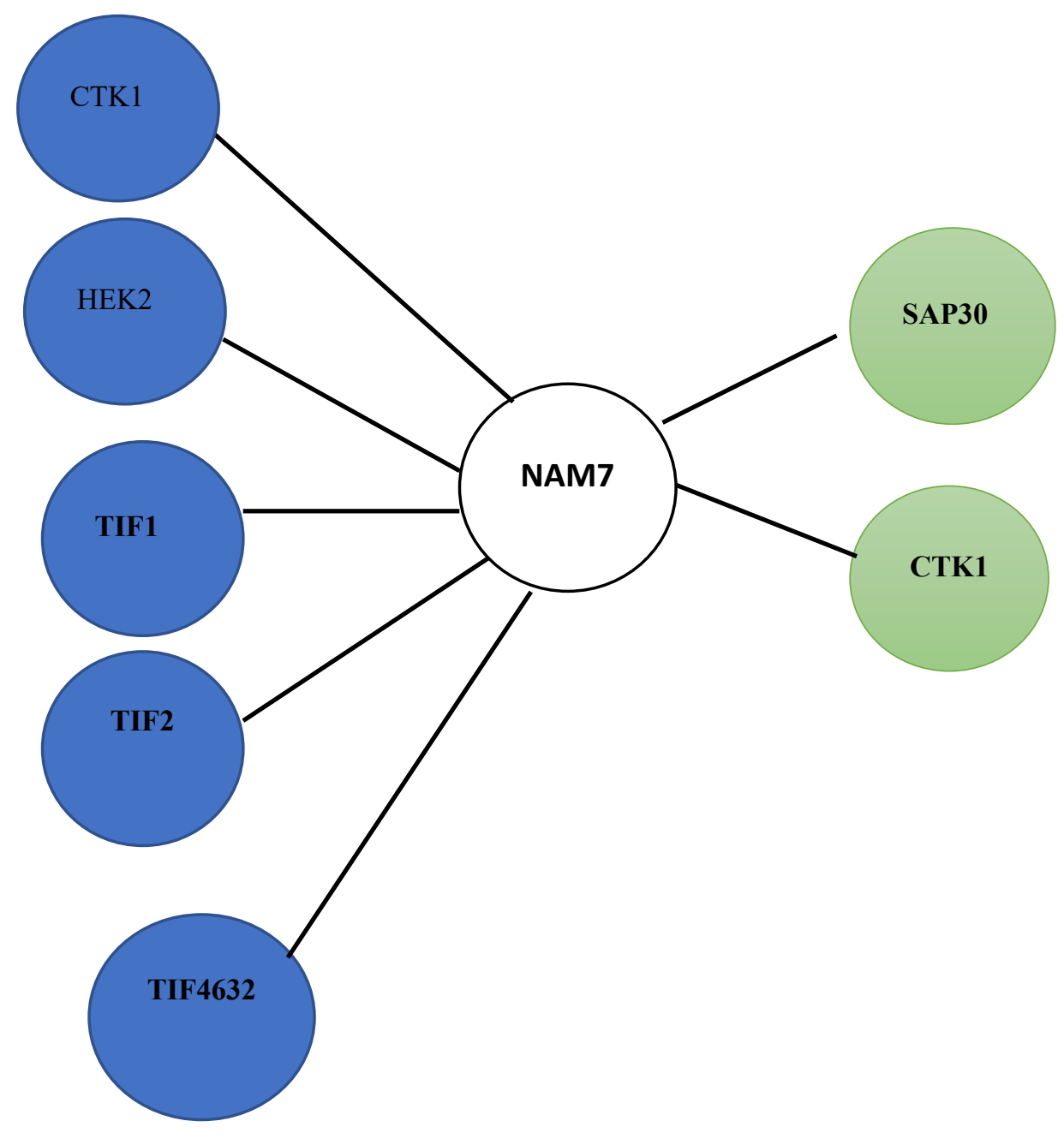

Figure 18: Negative genetic interaction of $N A M 7$ showed several interactions with Regulation of transcription from RNA polymerase I promoter genes (green) with P-values of $2.13 \times 10-3$ and genes involved in post translational regulation of gene expression (blue) with P-values of $4.51 \times 10-5$. 


\section{Chapter 4: Discussion}

\subsection{NSD screen}

The first study to recognise a degradation pathway for nonstop mRNAs was done in yeast by Herrick and Jacobson in 1989 (Herrick, 1989). They studied and compared the half life of HIS3 mRNA with a stop codon and another lacking an in frame stop codon due to 4 nucleotide deletion. They reported that the normal HIS3 mRNA was stable with a half life of 79 mins compared to 9 minutes for the nonstop HIS3 mRNA (Herrick, 1989). The NSD mRNA surveillance pathway was also introduced in another independent study on yeast PGK1 mRNA, and the mechanisms of NSD pathway was researched (Frischmeyer et al., 2002; van Hoof et al., 2002).

One of the first studies to identify genes involved in NSD pathway was done by Van Hoof in 2007 (Wilson et al., 2007). He performed a genome wide screening in yeast and introduced 16 novel gene candidates for this degradation pathway (Wilson et al., 2007). In the current study, we performed a large-scale screening analysis in yeast using the pSA159 plasmid, which contained a nonstop HIS3 gene, to identify candidate genes involved in this pathway. In this screening, we investigated a series of single gene deletions and their ability to grow on media lacking His. Since, the cell is dependant on pSA159 to produce the amino acid histidine, we hypothesized that cells that can grow in this media are incapable of executing the NSD pathway. We identified 68 gene candidates that are possibly involved in the NSD pathway. The screen was replicated three times and only those repeated at least twice were 
selected. Candidates were then grouped into their respective families. Five main families were identified. These families include Super killer (SKI), Phosphate metabolism (PHO), Sporulation (SPO), Altered Inheritance rate of Mitochondria (AIM), and Recombination (REC) genes.

\subsubsection{Phosphate metabolism genes}

The NSD screen revealed four genes from the phosphate metabolism family: $\mathrm{PHO}$, $\mathrm{PHO}$, PHO23, and PHO80. Phosphate is an important nutrient in all organisms. It is necessary for carrying out many activities in the cell such as nucleic acid synthesis, structural and metabolic functions (Auesukaree et al., 2004; Bentley-DeSousa et al., 2018; Kulaev et al., 1999; Ogawa et al., 2000; Wykoff \& O'Shea, 2001). Hence, phosphate homoeostasis is crucial for cell's existence. In yeast this pathway is controlled by phosphate metabolism gene family (PHO). In a previous NSD screen, it was also reported that the PHO family of genes are possible candidates for nonstop mRNA degradation and suggested $\mathrm{PHO} 5$ to be a novel gene candidate for NSD (Kazmirchuk, 2017).

PHO4 is a basic-helix-loop-helix (bHLH) transcriptional factor found in yeast (Ogawa \& Oshima, 1990). This gene associates with a bHLH binding site that is available in the promoter of genes (Ogawa \& Oshima, 1990). PHO4 can be found both in nuclei and cytoplasm. In phosphate rich environments, the gene is phosphorylated and moves to the cytoplasm; in conditions where phosphate is limited $\mathrm{PHO} 4$ is dephosphorylated and moves 
to the nuclei (O’Neill et al., 1996; Schneider et al., 1994). In a low Pi condition in cell, PHO4 activates genes involved in response to this limitation (Ogawa \& Oshima, 1990). It was reported that PHO4 only binds to roughly $14 \%$ of bHLH binding sites, and only one fourth of those associations results in activating gene transcription (Zhou \& O'Shea, 2011).

PHO5 is an acid phosphatase that is repressed and becomes inactive in high phosphate conditions and highly expressed when phosphate is limited (LENBURG \& OSHEA, 1996; Oshima, 1997). Activation and expression of PHO5 is regulated by phosphorylated PHO4 and PHO2 (Barbaric et al., 1996; LENBURG \& OSHEA, 1996). Also, PHO5 genetically interacts with $\mathrm{Xrnl}$ and Medl. Xrnl is a key factor in degrading mRNAs 5' $-3^{\prime}$ and Med1 is a subunit of the RNA polymerase mediator complex and has a role in regulating transcription (Balciunas et al., 1999; Kornberg, 2005). PHO23 also has a role in regulating transcription of PHO5 (Lau et al., 1998). Finally, PHO80 is from a subfamily of cyclins. Its main role is to control gene regulation and cells response to varying environmental conditions and nutrient levels (Measday et al., 1997).

A novel gene, $\mathrm{PHO} 2$ has been found to control phosphate metabolism by lowering the stability of PHO4 mRNA (Kang et al., 2014). PHO92 physically interacts with POP2 and is involved in deadenylase complex (Kang et al., 2014). POP2 is a subunit of Ccr4-Not complex and involved in 3'-5' mRNA deadenylation. Furthermore, $\mathrm{PHO} 4$ mRNA stability is controlled by the Pop2-Ccr4-Not complex through NMD and PHO95 increases PHO4 mRNA decay. 
Finally, there are evidence of the role of phosphate metabolism genes in mRNA degradation and gene expression regulation. Links between this family of gene and aberrant mRNA degradation pathways such as NMD have been suggested (Kang et al., 2014). Even though there is no clear report on the role of $\mathrm{PHO}$ genes and NSD, results from this study and previous studies done on the genes, all can strengthen the possibility of connection between PHO genes and nonstop mRNA degradation as well.

\subsubsection{Possible link between Sporulation (SPO) and Recombination (REC) genes with mRNA decay}

Another family of genes from our screen belonged to Sporulation: SPO11, SPO14, and SPO73. SPO11 is an endonuclease that is specific to meiosis in yeast and catalyzes Double stranded breaks (DSBs) formation that is needed to start meiotic recombination (Scott Keeney, 2001; Kumar et al., 2016). Even though SPO11 contains a catalytic site to create DSBs, other factors such as RAD50, Mre11 and Xrs2 are required to efficiently carry out the DSB process (S. Keeney \& Neale, 2006; Li et al., 2006; Maleki et al., 2007; Sasanuma et al., 2007). SPO11 also genetically interacts with SAE2 (Farmer et al., 2012). SAE2 is an endonuclease involved in DSB repair (Baroni et al., 2004). Interactions of SPO11 are presented in Figure 19. 


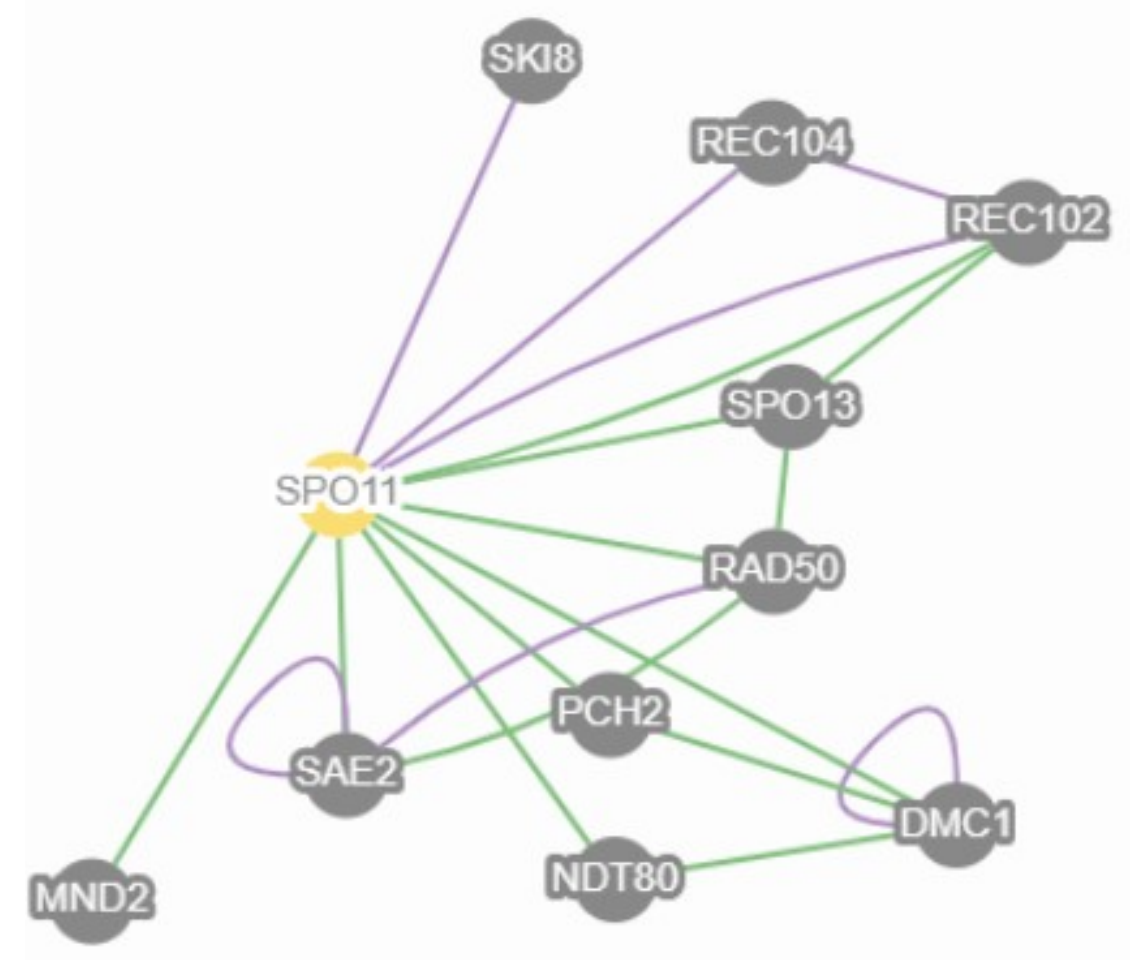

Figure 19: Interaction network of SPO11 in yeast. Physical interactions are shown in purple and genetic interactions are in green. SPO11 interaction network reveals genetic interactions with DNA damage genes such as $R A D 50, P C H 2$ and $S A E 2$. Physical interaction exists with genes Involved in early stages of meiotic recombination; REC104 and REC102 as well as a member of the super killer family involved in 3'-5' degradation, SKI8. (Adapted from https://www.yeastgenome.org) 
The role of SPO11 in DNA DSBs during meiosis is well researched. During meiosis recombination, a DNA DSBs are formed by SPO11 and subsequently repaired in the cell (Scott Keeney, 2001). SPO11 perform DSB functions with its interacting partners. In yeast this function is managed by ten proteins (Lam \& Keeney, 2015). This group of proteins are divided in three major classes; a core complex that consists of SPO11, REC102, REC104 and SKI8 (Bergerat et al., 1997; Robert et al., 2016; Vrielynck et al., 2016). Second group is the MRX complex of MRE11, RAD50 and XRS2 (Lam \& Keeney, 2015). Lastly, RMM proteins (REC114, MEI4 and MER2) (Li et al., 2006; Maleki et al., 2007; Miyoshi et al., 2012; Steiner et al., 2010).

Another member of the sporulation family that was seen in our NSD screen is SPO73. SPO73 is a protein involved in meiosis and required for the proper physical configuration of the prospore membrane (Rabitsch et al., 2001). SPO73 has been reported to have physical interaction with VTS1 protein in yeast (She et al., 2017). VTS1 gene in yeast is highly conserved in eukaryotes and is RNA and DNA binding protein that is involved in mRNA deadenylation through recruiting Ccr4-Not complex (Rendl et al., 2008). The deadenylated transcript is then further degraded 5'-3' by exonuclease Xrn1. This gene is also involved in post transcriptional regulation and a member of the Smg family (Aviv et al., 2003).

The association of sporulation and recombination genes is evident. For example, SPO11, REC102 and REC104 form a complex long with SKI8 in performing DSBs in yeast during meiosis. This may suggest a connection between mRNA degradation and DNA damage 
pathway in yeast. Moreover, the link between these group of genes and NSD is unclear. But considering that SPO and REC genes are involved in mRNA degradation through their interacting partners, it can be possible that they may be involved in NSD as well.

\subsection{Identification of candidate genes involved in mRNA NSD pathway}

To further understand the screened genes for NSD, the selected genes were enriched based on their activity and protein class. The majority of the enriched genes had a catalytic activity followed by hydrolase activity, $30.89 \%$ and $14.15 \%$, respectively. Subsequently genes were classified based on their protein class. The main protein class were hydrolase and membrane trafficking protein class. Hydrolase class are Enzymes catalyzing hydrolysis of a variety of bonds, such as esters, glycosides, or peptides. They consist of 791 subfamilies such as deacetylase, phosphatase, deaminases, galactosidase, etc. Membrane traffic proteins are located on an intracellular vesicle membrane and are responsible for the cutting or fusion of the vesicle to the cytoplasm membrane. The third class, ubiquitin-protein ligase are enzymes that binds ubiquitin to protein using a peptide bond between the C-terminal glycine of ubiquitin and an amino group of lysine residues in the protein. Fourth class of proteins identified was G-proteins which are GTP-binding proteins and consist of 115 subfamilies. Final class of proteins identified were RNA helicases. This group of proteins are associated with unwinding of the RNA in the cell. Taking into account previous studies that have shown RNA helicase protein family take part in normal RNA turnover, we decided to focus on the three helicases in our screen, NAM7, ECM32, and SKI2 and investigate whether they are potentially involved in the NSD process. 
NAM7, ECM32 and SKI2 were further tested for their involvement in mRNA NSD pathway. It is expected that deletion of these genes would affect and interrupt NSD pathway, following their identification through NSD screening and enriched network. Spot test assay confirms the role of the selected genes in this pathway. As seen in Figure 13, WT strain that all degradation pathways had remained intact, showed no growth. While, SKI2 $\triangle, E C M 32 \Delta$ and $N A M 7 \Delta$ grew on the selection media. Colony counting was performed to quantify the results. The results from this experiment was in consistence with the spot test assay (Figure 14). In conclusion deletion of the candidate genes led to a significant increase in nonstop HIS3 production and cell growth on selection media compared to the wild type.

In the next step, we further examined the role of NAM7, SKI2 and ECM32 genes in nonstop $H I S 3$ gene expression. A qRT-PCR was performed for HIS3 expression within the deletion of the chosen candidates. Based on the presented qRT-PCR analysis results in Figure 15, deletions of the selected candidates had no significant effect on HIS3 gene at the mRNA level when compared to the wild type strain. These results confirm the role of our candidate genes in the NSD process. Furthermore, it is concluded that the difference in expression of nonstop HIS3 mRNAs between wild type and gene candidate deletions is not at transcriptional level. 


\subsection{SGA reveals genetic interactions with known genes involved in translation regulation}

To better understand the role of the candidate genes in NSD we investigated the negative genetic interaction between these genes and other genes related to mRNA surveillance pathway and mRNA translation. Genetic interactions can reveal functional association between two genes. Negative genetic interactions are the most common form of studying GIs (Darvishi et al., 2013b; Jessulat et al., 2008; Samanfar et al., 2013; Tong et al., 2001).

After obtaining negative genetic interactions formed, the interacting genes were then further clustered in different functional categories based their GO terms. As illustrated in Figure 16, ECM32 showed enrichment for three clusters. Most notable cluster is mRNA splicing genes. Also, the negative genetic interaction with $M E D 8$ is notable. $M E D 8$ is subunit of the RNA polymerase II mediator complex and has an important role in regulating transcription in yeast.

SKI2 formed negative genetic interactions with several genes involved in mRNA catabolic process. Most notably XRN1, EAP1, PAP2, and LSM1. LSM1 along with other Sm like (LSM) proteins form a complex and not only have a role in regulating translation initiation but also play a role in degradation of cytoplasmic mRNAs (W. He \& Parker, 2000). This protein also has shown to have negative genetic interactions with other members of the SKI family: SKI8 and SKI3 (Collins et al., 2007; Kuzmin et al., 2018). XRN1 is an exonuclease and involved in 5'-3' mRNA decay in the cytoplasm (Larimer \& Stevens, 1990). EAPl is a 
well conserved gene, it stimulates decapping and consequently accelerating RNA degradation (Cosentino et al., 2000). Finally, last gene from the catabolic processing group enriched was $P A P 2$. This gene is a non-canonical poly A polymerase and necessary for mRNA surveillance and protection of genome integrity (Vaňáčová et al., 2005). Furthermore, SKI2 had negative genetic association with genes involved in translation elongation and protein kinase activity and Structural constituent of ribosome (Figure 17). The enriched results can validate the reliability of our assay.

Finally, NAM7 showed negative genetic interactions with two group of genes: genes involved in regulation of transcription from RNA polymerase I promoter genes and genes engaged in Post translational regulation of gene expression. These results indicate a negative genetic association between translation initiation genes and candidate genes. 


\section{Chapter 5: Conclusion and future directions}

Yeast is one of the most used model organisms in studying pathways and processes in eukaryotic cells. Whole genome of yeast has been sequenced and available online. Experimental results on function and physical/genetic interaction of budding yeast genes from peer reviewed studies are obtained and integrated in databases and available online to researchers. Also, various gene deletion arrays are available in both mating types (MATa and MAT $\alpha$ ) as well as diploid deletions. All these makes budding yeast a logical choice for functional genomic studies.

For the nonstop decay pathway screening we performed a large-scale analysis. Even though results from large-scale high-throughput genomic screens have been demonstrated to be beneficial (Darvishi et al., 2013a; Galván Márquez et al., 2018), these kind of analysis in general produce a large amount of data. Analysing such high number of results has always been a challenge for researchers. Development of proper software and tools that can put together multiple databases and integrated complicated statistical methods, has overcome this challenge, and helped researchers better interpret, visualize, and understand the data that they have produced (Jessulat et al., 2011; Schoenrock et al., 2014).

Rate of false positives and false negatives is another limiting factor while dealing with large amount of data (Pitre et al., 2012). False positives incorrectly indicate a specific hit while false negatives are hits that we fail to select in our analysis. This can limit the reliability of data produced from large-scale methods. One way to over come this issue is to run the tests 
with a smaller data set with the addition of negative and positive controls and investigating the sensitivity and effectiveness of the experiment. Also, it is recommended to perform small-scale analysis on the data gathered from large-scale analysis to further confirm the results.

To increase the reliability and accuracy of large-scale experiments, simulation studies and/or bioinformatic tools can be utilized. These predictive tools enable researchers to combine data from multiple data bases, control experimental conditions, compare different organisms, and generate large amount of data. This data needs to be validated and can be used to compare with the produced results in the lab.

In this study we used a gene deletion set array consisting of $\sim 5000$ single gene deletions in MATa haploid to investigate and identify candidate genes in the mRNA nonstop decay pathway. Gene expression and mRNA turnover is a strictly controlled pathway in all organisms. In order to regulate the level of gene expression, eukaryotes have developed two specific processes to degrade normal mRNAs in the cell. Since, mistakes are likely to happen in the cell during any stage, errors need to be identified and destroyed. While major improvements have happened in the past decade to identify the actors involved in the NMD pathway, there is still a gap of understanding the NSD mechanism and proteins associated to the process. 
In our large screen analysis several families were identified to have a potential role in the nonstop degradation pathway. Phosphorylated genes, sporulation genes and recombination genes were all clustered. SPO11 binds to SKI8 and to two other members of recombination family, REC102 and REC104 to create a complex that is involved in recombination initiation and forming DNA DSBs. SPO11 also showed genetic interactions with SAE2, RAD50 and $P C H 2$. These genes have a role in DSB repair and processing DSBs. Furthermore, RAD50 is associated with two genes: MRE11 and XRS2. MRE11 is involved in repairing DSBs in the DNA and this gene was also screened in our large-scale analysis. These results may suggest a possible connection between DNA damage genes and NSD pathway. further studies are required to unveil any connections between the two pathways. Lastly, SPO11 can also be a good candidate for NSD in future studies.

Next, negative genetic interactions of our candidates were studied using SGA analysis. Negative genetic analysis has indicated the involvement of selected candidates in mRNA splicing, mRNA catabolic process, translation elongation and post translational regulation of gene expression. This is an indication that selected genes are associated with translation related genes. In the cell translation and degradation are integrated (Roy \& Jacobson, 2013). Translation of faulty transcripts almost always leads to degradation. Nevertheless, when there is a decrease in translation initiation regularly boosts mRNA decay, but inhibiting translation elongation or termination will normally stabilize the mRNA transcript (Roy \& Jacobson, 2013). Overall, translation and mRNA degradation are closely linked and both pathways need to be well identified to have a good knowledge of gene expression in the cell (Lotan et al., 2007). 
In this study we only looked into negative genetic interactions through SGA analysis. Synthetic Dosage Lethality (SDL) and Phenotypic Suppression Analysis (PSA) (Alamgir et al., 2008)are two other large-scale analysis and revised versions of SGA. In SDL the compensating effect of over expressing one gene and the deletion of the other gene is studied. PSA follows the same rational as SDL, except the fact that it investigates the compensation of the overexpressed gene for the deleted gene in overlapping pathways when a certain stress is induced such as addition of drugs. SDL and PSA can be done as a follow up experiment to seek other genetic interactions in cell in hope of revealing compensatory effects of an overexpressed gene and overlapping pathways with NSD.

Being able to and discovering how to suppress the NSD pathway will have significant implications in the medical field and treating diseases. A widespread nonstop mutation reported in humans is the DEFB126 (Tollner et al., 2011). This gene is essential for human sperm and men who are homozygous for this gene show low fertility rates (Tollner et al., 2011). In other cases, nonstop mutation results in lower levels of mRNA in the cell and subsequently lack of protein which is the leading cause of NSD related diseases (Klauer \& van Hoof, 2012). In some cases when the nonstop mutant and C-terminally extended proteins are functional, supressing the NSD pathway and increasing the stability of theses kind of proteins can offer therapeutic advantages (Klauer \& van Hoof, 2012). In Recent Times, genetic treatments for diseases such as cystic fibrosis and Duchenne's muscular dystrophy that involve inhibiting NMD pathway are being developed and currently in clinical trial phase (Welch et al., 2007). Similarly, NSD can be targeted to inhibit mRNA or protein decay 
in the cell. More work remains to fully comprehend the NSD pathway, factors involved and how it can be controlled and/or altered. The current study highlights the necessity for further research in identifying novel factors involved in the NSD pathway. 


\section{References}

Alamgir, M., Eroukova, V., Jessulat, M., Xu, J., \& Golshani, A. (2008). Chemical-genetic profile analysis in yeast suggests that a previously uncharacterized open reading frame, YBR261C, affects protein synthesis. BMC Genomics, 9. https://doi.org/10.1186/1471-2164-9-583

Alamgir, M., Erukova, V., Jessulat, M., Azizi, A., \& Golshani, A. (2010). Chemical-genetic profile analysis of five inhibitory compounds in yeast. BMC Chemical Biology, 10. https://doi.org/10.1186/1472-6769$10-6$

Albert, T. K., Lemaire, M., van Berkum, N. L., Gentz, R., Collart, M. A., \& Th Marc Timmers, H. (2000). Isolation and characterization of human orthologs of yeast CCR4-NOT complex subunits. In Nucleic Acids Research (Vol. 28, Issue 3).

Allmang, C., Petfalski, E., Podtelejnikov, A., Mann, M., Tollervey, D., \& Mitchell, P. (1999). The yeast exosome and human PM-Scl are related complexes of 3' $\rightarrow$ 5' exonucleases. Genes and Development, 13(16), 2148-2158. https://doi.org/10.1101/gad.13.16.2148

Amrani, N., Ganesan, R., Kervestin, S., Mangus, D. A., Ghosh, S., \& Jacobson, A. (2004). A faux 3'-UTR promotes aberrant termination and triggers nonsense-mediated mRNA decay. Nature, 432(7013), 112 118. https://doi.org/10.1038/nature03060

Andersen, C. B. F., Becker, T., Blau, M., Anand, M., Halic, M., Balar, B., Mielke, T., Boesen, T., Pedersen, J. S., Spahn, C. M. T., Kinzy, T. G., Andersen, G. R., \& Beckmann, R. (2006). Structure of eEF3 and the mechanism of transfer RNA release from the E-site. Nature, 443(7112), 663-668. https://doi.org/10.1038/nature05126

Araki, Y., Takahashi, S., Kobayashi, T., Kajiho, H., Hoshino, S.-I., \& Katada, T. (2001). Ski7p G protein interacts with the exosome and the Ski complex for 3'-to-5' mRNA decay in yeast. The EMBO Journal, 20(17), 4684-4693.

Arias-Palomo, E., Yamashita, A., Fernández, I. S., Núñez-Ramírez, R., Bamba, Y., Izumi, N., Ohno, S., \& Llorca, O. (2011). The nonsense-mediated mRNA decay SMG-1 kinase is regulated by large-scale conformational changes controlled by SMG-8. Genes and Development, 25(2), 153-164. https://doi.org/10.1101/gad.606911

Auesukaree, C., Homma, T., Tochio, H., Shirakawa, M., Kaneko, Y., \& Harashima, S. (2004). Intracellular Phosphate Serves as a Signal for the Regulation of the PHO Pathway in Saccharomyces cerevisiae. Journal of Biological Chemistry, 279(17), 17289-17294. https://doi.org/10.1074/jbc.M312202200

Aur', A., Deniaud, A., Karuppasamy, M., Bock, T., Masiulis, S., Huard, K., Fréd', F., Garzoni, F., Kerschgens, K., Hentze, M. W., Kulozik, A. E., Beck, M., Neu-Yilik, G., \& Schaffitzel, C. (2015). A network of SMG-8, SMG-9 and SMG-1 C-terminal insertion domain regulates UPF1 substrate recruitment and phosphorylation. Nucleic Acids Research, 43(15), 7600-7611. https://doi.org/10.1093/nar/gkv668

Aviv, T., Lin, Z., Lau, S., Rendl, L. M., Sicheri, F., \& Smibert, C. A. (2003). The RNA-binding SAM domain of Smaug defines a new family of post-transcriptional regulators. Nature Structural Biology, 10(8), 614-621. https://doi.org/10.1038/nsb956 
Balciunas, D., Gälman, C., Ronne, H., \& Björklund, S. (1999). The Med1 subunit of the yeast mediator complex is involved in both transcriptional activation and repression. Proceedings of the National Academy of Sciences of the United States of America, 96(2), 376-381. https://doi.org/10.1073/pnas.96.2.376

Barbaric, S., Münsterkötter, M., Svaren, J., \& Hörz, W. (1996). The homeodomain protein Pho2 and the basic-helix-loop-helix protein Pho4 bind DNA cooperatively at the yeast PHO5 promoter. In Nucleic Acids Research (Vol. 24, Issue 22).

Baroni, E., Viscardi, V., Cartagena-Lirola, H., Lucchini, G., \& Longhese, M. P. (2004). The Functions of Budding Yeast Sae2 in the DNA Damage Response Require Mec1- and Tel1-Dependent Phosphorylation. Molecular and Cellular Biology, 24(10), 4151-4165. https://doi.org/10.1128/mcb.24.10.4151-4165.2004

Bentley-DeSousa, A., Holinier, C., Moteshareie, H., Tseng, Y. C., Kajjo, S., Nwosu, C., Amodeo, G. F., Bondy-Chorney, E., Sai, Y., Rudner, A., Golshani, A., Davey, N. E., \& Downey, M. (2018). A Screen for Candidate Targets of Lysine Polyphosphorylation Uncovers a Conserved Network Implicated in Ribosome Biogenesis. Cell Reports, 22(13), 3427-3439. https://doi.org/10.1016/j.celrep.2018.02.104

Bergerat, A., de Massy, B., Gadelle, D., Varoutas, P. C., Nicolas, A., \& Forterre, P. (1997). An atypical topoisomerase II from archaea with implications for meiotic recombination. Nature, 386(6623), 414 417. https://doi.org/10.1038/386414a0

Bhattacharya, A., Czaplinski, K., Trifillis, P., He, F., Jacobson, A., \& Peltz, S. W. (2000). Characterization of the biochemical properties of the human Upf1 gene product that is involved in nonsense-mediated mRNA decay. $R N A, 6(9), 1226-1235$. https://doi.org/10.1017/S1355838200000546

Boeck, R., Tarun, S., Rieger, M., Deardorff, J. A., Müller-Auer, S., \& Sachs, A. B. (1996). The yeast Pan2 protein is required for poly(A)-binding protein-stimulated poly(A)-nuclease activity. Journal of Biological Chemistry, 271(1), 432-438. https://doi.org/10.1074/jbc.271.1.432

Bono, F., \& Gehring, N. H. (2011). Assembly, disassembly and recycling. RNA Biology, 8(1), 24-29. https://doi.org/10.4161/rna.8.1.13618

Brown, C. E., Tarun, S. Z., Boeck, R., \& Sachs, A. B. (1996). PAN3 encodes a subunit of the Pab1pdependent poly(A) nuclease in Saccharomyces cerevisiae. Molecular and Cellular Biology, 16(10), 5744-5753. https://doi.org/10.1128/mcb.16.10.5744

Brown, J. T., Bai, X., \& Johnson, A. (2000). The yeast antiviral proteins Ski2p, Ski3p, and Ski8p exist as a complex in vivo. $R N A, 6(3), 449-457$. https://doi.org/10.1017/S1355838200991787

Bühler, M., Steiner, S., Mohn, F., Paillusson, A., \& Mühlemann, O. (2006). EJC-independent degradation of nonsense immunoglobulin- $\mu$ mRNA depends on 3' UTR length. Nature Structural and Molecular Biology, 13(5), 462-464. https://doi.org/10.1038/nsmb1081

Butland, G., Krogan, N. J., Xu, J., Yang, W. H., Aoki, H., Li, J. S., Krogan, N., Menendez, J., Cagney, G., Kiani, G. C., Jessulat, M. G., Datta, N., Ivanov, I., AbouHaidar, M. G., Emili, A., Greenblatt, J., Ganoza, M. C., \& Golshani, A. (2007). Investigating the in vivo activity of the DeaD protein using proteinprotein interactions and the translational activity of structured chloramphenicol acetyltransferase mRNAs. Journal of Cellular Biochemistry, 100(3), 642-652. https://doi.org/10.1002/jcb.21016 
Buttgereit, F., \& Brand, M. D. (1995). A hierarchy of ATP-consuming processes in mammalian cells. Biochemical Journal, 312(1), 163-167. https://doi.org/10.1042/bj3120163

Caponigro, G., \& Parker, R. (1995). Multiple functions for the poly(A)binding protein in mRNA decapping and deadenylation in yeast. Genes and Development, 9(19), 2421-2432. https://doi.org/10.1101/gad.9.19.2421

Celik, A., Baker, R., He, F., \& Jacobson, A. (2017). High-resolution profiling of NMD targets in yeast reveals translational fidelity as a basis for substrate selection. RNA, 23(5), 735-748. https://doi.org/10.1261/rna.060541.116

Chakrabarti, S., Jayachandran, U., Bonneau, F., Fiorini, F., Basquin, C., Domcke, S., le Hir, H., \& Conti, E. (2011). Molecular Mechanisms for the RNA-Dependent ATPase Activity of Upf1 and Its Regulation by Upf2. Molecular Cell, 41(6), 693-703. https://doi.org/10.1016/j.molcel.2011.02.010

Chamieh, H., Ballut, L., Bonneau, F., \& le Hir, H. (2008). NMD factors UPF2 and UPF3 bridge UPF1 to the exon junction complex and stimulate its RNA helicase activity. Nature Structural and Molecular Biology, 15(1), 85-93. https://doi.org/10.1038/nsmb1330

Chen, J., Rappsilber, J., Chiang, Y. C., Russell, P., Mann, M., \& Denis, C. L. (2001). Purification and characterization of the 1.0 MDa CCR4-NOT complex identifies two novel components of the complex. Journal of Molecular Biology, 314(4), 683-694. https://doi.org/10.1006/jmbi.2001.5162

Clerici, M., Mourão, A., Gutsche, I., Gehring, N. H., Hentze, M. W., Kulozik, A., Kadlec, J., Sattler, M., \& Cusack, S. (2009). Unusual bipartite mode of interaction between the nonsense-mediated decay factors, UPF1 and UPF2. EMBO Journal, 28(15), 2293-2306. https://doi.org/10.1038/emboj.2009.175

Coller, J. M., Gray, N. K., \& Wickens, M. P. (1998). mRNA stabilization by poly(A) binding protein is independent of poly(A) and requires translation. Genes and Development, 12(20), 3226-3235. https://doi.org/10.1101/gad.12.20.3226

Collins, S. R., Miller, K. M., Maas, N. L., Roguev, A., Fillingham, J., Chu, C. S., Schuldiner, M., Gebbia, M., Recht, J., Shales, M., Ding, H., Xu, H., Han, J., Ingvarsdottir, K., Cheng, B., Andrews, B., Boone, C., Berger, S. L., Hieter, P., ... Krogan, N. J. (2007). Functional dissection of protein complexes involved in yeast chromosome biology using a genetic interaction map. Nature, 446(7137), 806-810. https://doi.org/10.1038/nature05649

Cosentino, G. P., Schmelzle, T., Haghighat, A., Helliwell, S. B., Hall, M. N., \& Sonenberg, N. (2000). Eap1p, a Novel Eukaryotic Translation Initiation Factor 4E-Associated Protein in Saccharomyces cerevisiae. Molecular and Cellular Biology, 20(13), 4604-4613. https://doi.org/10.1128/mcb.20.13.46044613.2000

Czaplinski, K., Weng, Y., Hagan, K. W., \& Peltz, S. W. (1995). Purification and characterization of the Upf1 protein: A factor involved in translation and mRNA degradation. $R N A, 1(6), 610-623$.

D’Andrea, L. D., \& Regan, L. (2003). TPR proteins: The versatile helix. In Trends in Biochemical Sciences (Vol. 28, Issue 12, pp. 655-662). Elsevier Ltd. https://doi.org/10.1016/j.tibs.2003.10.007

Darvishi, E., Omidi, M., Bushehri, A. A., Golshani, A., \& Smith, M. L. (2013a). Thymol antifungal mode of action involves telomerase inhibition. Medical Mycology, 51(8), 826-834. https://doi.org/10.3109/13693786.2013.795664 
Darvishi, E., Omidi, M., Bushehri, A. A. S., Golshani, A., \& Smith, M. L. (2013b). The Antifungal Eugenol Perturbs Dual Aromatic and Branched-Chain Amino Acid Permeases in the Cytoplasmic Membrane of Yeast. PLoS ONE, 8(10). https://doi.org/10.1371/journal.pone.0076028

Dever, T. E., \& Green, R. (2012). The elongation, termination, and recycling phases of translation in eukaryotes. Cold Spring Harbor Perspectives in Biology, 4(7), 1-16. https://doi.org/10.1101/cshperspect.a013706

Dever, T. E., Kinzy, T. G., \& Pavitt, G. D. (2016). Mechanism and regulation of protein synthesis in Saccharomyces cerevisiae. In Genetics (Vol. 203, Issue 1, pp. 65-107). Genetics Society of America. https://doi.org/10.1534/genetics.115.186221

Dlaklc, M. (2000). unctionally unrelated signalling proteins contain a fold similar to Mg2+-dependent endonucleases. Trends in Biochemical Sciences, 25(6), 272-273.

Doma, M. K., \& Parker, R. (2006). Endonucleolytic cleavage of eukaryotic mRNAs with stalls in translation elongation. Nature, 440(7083), 561-564. https://doi.org/10.1038/nature04530

Dong, J., Lai, R., Nielsen, K., Fekete, C. A., Qiu, H., \& Hinnebusch, A. G. (2004). The essential ATP-binding cassette protein RLI1 functions in translation by promoting preinitiation complex assembly. Journal of Biological Chemistry, 279(40), 42157-42168. https://doi.org/10.1074/jbc.M404502200

Dziembowski, A., Lorentzen, E., Conti, E., \& Séraphin, B. (2007). A single subunit, Dis3, is essentially responsible for yeast exosome core activity. Nature Structural and Molecular Biology, 14(1), 15-22. https://doi.org/10.1038/nsmb1184

Eberle, A. B., Lykke-Andersen, S., Mühlemann, O., \& Jensen, T. H. (2009). SMG6 promotes endonucleolytic cleavage of nonsense mRNA in human cells. Nature Structural and Molecular Biology, 16(1), 49-55. https://doi.org/10.1038/nsmb.1530

Eulalio, A., Behm-Ansmant, I., \& Izaurralde, E. (2007). P bodies: At the crossroads of post-transcriptional pathways. In Nature Reviews Molecular Cell Biology (Vol. 8, Issue 1, pp. 9-22). https://doi.org/10.1038/nrm2080

Farmer, S., Hong, E. J. E., Leung, W. K., Argunhan, B., Terentyev, Y., Humphryes, N., Toyoizumi, H., \& Tsubouchi, H. (2012). Budding yeast Pch2, a widely conserved meiotic protein, is involved in the initiation of meiotic recombination. PLOS ONE, 7(6). https://doi.org/10.1371/journal.pone.0039724

Fatscher, T., Boehm, V., \& Gehring, N. H. (2015). Mechanism, factors, and physiological role of nonsensemediated mRNA decay. In Cellular and Molecular Life Sciences (Vol. 72, Issue 23, pp. 4523-4544). Birkhauser Verlag AG. https://doi.org/10.1007/s00018-015-2017-9

Ferná Ndez, I. S., Yamashita, A., Arias-Palomo, E., Bamba, Y., Bartolomé, R. A., Canales, M. A., Teixidó, J., Ohno, S., \& Llorca, O. (n.d.). Characterization of SMG-9, an essential component of the nonsensemediated mRNA decay SMG1C complex. https://doi.org/10.1093/nar/gkq749

Fiorini, F., Bagchi, D., le Hir, H., \& Croquette, V. (2015). Human Upf1 is a highly processive RNA helicase and translocase with RNP remodelling activities. Nature Communications, 6. https://doi.org/10.1038/ncomms8581 
Fiorini, F., Boudvillain, M., \& le Hir, H. (2013). Tight intramolecular regulation of the human Upf1 helicase by its N-and C-terminal domains. Nucleic Acids Research, 41(4), 2404-2415. https://doi.org/10.1093/nar/gks1320

Franks, T. M., Singh, G., \& Lykke-Andersen, J. (2010). Upf1 ATPase-dependent mRNP disassembly is required for completion of nonsense-mediated mRNA decay. Cell, 143(6), 938-950. https://doi.org/10.1016/j.cell.2010.11.043

Frischmeyer, P. A., van Hoof, A., O’Donnell, K., Guerrerio, A. L., Parker, R., \& Dietz, H. C. (2002). An mRNA surveillance mechanism that eliminates transcripts lacking termination codons. Science, 295(5563), 2258-2261. https://doi.org/10.1126/science.1067338

Gagarinova, A., Stewart, G., Samanfar, B., Phanse, S., White, C. A., Aoki, H., Deineko, V., Beloglazova, N., Yakunin, A. F., Golshani, A., Brown, E. D., Babu, M., \& Emili, A. (2016). Systematic Genetic Screens Reveal the Dynamic Global Functional Organization of the Bacterial Translation Machinery. Cell Reports, 17(3), 904-916. https://doi.org/10.1016/j.celrep.2016.09.040

Galván Márquez, I., Ghiyasvand, M., Massarsky, A., Babu, M., Samanfar, B., Omidi, K., Moon, T. W., Smith, M. L., \& Golshani, A. (2018). Zinc oxide and silver nanoparticles toxicity in the baker's yeast, Saccharomyces cerevisiae. https://doi.org/10.1371/journal.pone.0193111

Garneau, N. L., Wilusz, J., \& Wilusz, C. J. (2007). The highways and byways of mRNA decay. In Nature Reviews Molecular Cell Biology (Vol. 8, Issue 2, pp. 113-126). https://doi.org/10.1038/nrm2104

Gehring, N. H., Lamprinaki, S., Kulozik, A. E., \& Hentze, M. W. (2009). Disassembly of Exon Junction Complexes by PYM. Cell, 137(3), 536-548. https://doi.org/10.1016/j.cell.2009.02.042

González, C. I., Ruiz-Echevarría, M. J., Vasudevan, S., Henry, M. F., \& Peltz, S. W. (2000). The yeast hnRNP-like protein Hrp1/Nab4 marks a transcript for nonsense-mediated mRNA decay. Molecular Cell, 5(3), 489-499. https://doi.org/10.1016/S1097-2765(00)80443-8

Gray, N. K., Coller, J. M., Dickson, K. S., \& Wickens, M. (2000). Multiple portions of poly(A)-binding protein stimulate translation in vivo.

Gregersen, L. H., Schueler, M., Munschauer, M., Mastrobuoni, G., Chen, W., Kempa, S., Dieterich, C., \& Landthaler, M. (2014). MOV10 Is a 5' to 3' RNA Helicase Contributing to UPF1 mRNA Target Degradation by Translocation along 3' UTRs. Molecular Cell, 54(4), 573-585. https://doi.org/10.1016/j.molcel.2014.03.017

Grentzmann, G., Kelly, P. J., Laalami, S., Shuda, M., Firpo, M. A., Cenatiempo, Y., \& Kaji, A. (1998). Release factor RF-3 GTPase activity acts in disassembly of the ribosome termination complex. RNA, 4(8), 973-983. https://doi.org/10.1017/S1355838298971576

Grimson, A., O’Connor, S., Newman, C. L., \& Anderson, P. (2004). SMG-1 Is a Phosphatidylinositol KinaseRelated Protein Kinase Required for Nonsense-Mediated mRNA Decay in Caenorhabditis elegans. Molecular and Cellular Biology, 24(17), 7483-7490. https://doi.org/10.1128/mcb.24.17.74837490.2004

Harigaya, Y., \& Parker, R. (2010). No-go decay: A quality control mechanism for RNA in translation. In Wiley Interdisciplinary Reviews: RNA (Vol. 1, Issue 1, pp. 132-141). https://doi.org/10.1002/wrna.17 
He, F, Brown, A. H., \& Jacobson, A. (1997). Upf1p, Nmd2p, and Upf3p are interacting components of the yeast nonsense-mediated mRNA decay pathway. Molecular and Cellular Biology, 17(3), 1580-1594. https://doi.org/10.1128/mcb.17.3.1580

He, Feng, \& Jacobson, A. (1995). Identification of a novel component of the nonsense-mediated mRNA decay pathway by use of an interacting protein screen. Genes and Development, 9(4), 437-454. https://doi.org/10.1101/gad.9.4.437

He, Feng, \& Jacobson, A. (2001). Upflp, Nmd2p, and Upf3p Regulate the Decapping and Exonucleolytic Degradation of both Nonsense-Containing mRNAs and Wild-Type mRNAs. Molecular and Cellular Biology, 21(5), 1515-1530. https://doi.org/10.1128/mcb.21.5.1515-1530.2001

He, Feng, \& Jacobson, A. (2015). Nonsense-Mediated mRNA Decay: Degradation of Defective Transcripts Is Only Part of the Story. Annual Review of Genetics, 49(1), 339-366. https://doi.org/10.1146/annurevgenet-112414-054639

He, Feng, Li, X., Spatrick, P., Casillo, R., Dong, S., \& Jacobson, A. (2003). Genome-Wide Analysis of mRNAs Regulated by the Nonsense-Mediated and 5' to 3' mRNA Decay Pathways in Yeast. Molecular Cell, 12(6), 1439-1452. https://doi.org/10.1016/S1097-2765(03)00446-5

He, W., \& Parker, R. (2000). Functions of Lsm proteins in mRNA degradation and splicing. In Current Opinion in Cell Biology (Vol. 12, Issue 3, pp. 346-350). Current Biology Ltd. https://doi.org/10.1016/S0955-0674(00)00098-3

Herrick, D. (1989). Structural Determinants of mRNA Turnover in Yeast: a Thesis Structural Determinants of mRNA Turnover in Yeast: a Thesis. https://doi.org/10.13028/eqvd-rx27

Herrick, D., Parker, R., \& Jacobson, A. (1990). Identification and Comparison of Stable and Unstable mRNAs in Saccharomyces cerevisiae. In MOLECULAR AND CELLULAR BIOLOGY (Vol. 10, Issue 5).

Hogg, J. R., \& Goff, S. P. (2010). Upf1 senses 3'UTR length to potentiate mRNA decay. Cell, 143(3), 379389. https://doi.org/10.1016/j.cell.2010.10.005

Hu, G., McQuiston, T., Bernard, A., Park, Y. D., Qiu, J., Vural, A., Zhang, N., Waterman, S. R., Blewett, N. H., Myers, T. G., Maraia, R. J., Kehrl, J. H., Uzel, G., Klionsky, D. J., \& Williamson, P. R. (2015). A conserved mechanism of TOR-dependent RCK-mediated mRNA degradation regulates autophagy. Nature Cell Biology, 17(7), 930-942. https://doi.org/10.1038/ncb3189

Hug, N., Longman, D., \& C, J. F. (2016). SURVEY AND SUMMARY Mechanism and regulation of the nonsense-mediated decay pathway. Nucleic Acids Research, 44(4), 1483-1495. https://doi.org/10.1093/nar/gkw010

Huntzinger, E., Kashima, I., Fauser, M., Saulière, J., \& Izaurralde, E. (2008). SMG6 is the catalytic endonuclease that cleaves mRNAs containing nonsense codons in metazoan. $R N A, 14(12), 2609-2617$. https://doi.org/10.1261/rna.1386208

Inada, T., \& Aiba, H. (2005). Translation of aberrant mRNAs lacking a termination codon or with a shortened 3'-UTR is repressed after initiation in yeast. EMBO Journal, 24(8), 1584-1595. https://doi.org/10.1038/sj.emboj.7600636 
Isken, O., \& Maquat, L. E. (2007). Quality control of eukaryotic mRNA: Safeguarding cells from abnormal mRNA function. In Genes and Development (Vol. 21, Issue 15, pp. 1833-1856). https://doi.org/10.1101/gad.1566807

Ito-Harashima, S., Kuroha, K., Tatematsu, T., \& Inada, T. (2007). Translation of the poly(A) tail plays crucial roles in nonstop mRNA surveillance via translation repression and protein destabilization by proteasome in yeast. Genes and Development, 21(5), 519-524. https://doi.org/10.1101/gad.1490207

Jackson, R. J., Hellen, C. U. T., \& Pestova, T. v. (2010). The mechanism of eukaryotic translation initiation and principles of its regulation. In Nature Reviews Molecular Cell Biology (Vol. 11, Issue 2, pp. 113127). https://doi.org/10.1038/nrm2838

Jessulat, M., Alamgir, M., Salsali, H., Greenblatt, J., Xu, J., \& Golshani, A. (2008). Interacting proteins Rtt109 and Vps75 affect the efficiency of non-homologous end-joining in Saccharomyces cerevisiae. Archives of Biochemistry and Biophysics, 469(2), 157-164. https://doi.org/10.1016/j.abb.2007.11.001

Jessulat, M., Pitre, S., Gui, Y., Hooshyar, M., Omidi, K., Samanfar, B., Tan, L. H., Alamgir, M., Green, J., Dehne, F., \& Golshani, A. (2011). Recent advances in proteinprotein interaction prediction: Experimental and computational methods. In Expert Opinion on Drug Discovery (Vol. 6, Issue 9, pp. 921-935). Taylor \& Francis. https://doi.org/10.1517/17460441.2011.603722

Jinek, M., Coyle, S. M., \& Doudna, J. A. (2011). Coupled 5' Nucleotide Recognition and Processivity in Xrn1-Mediated mRNA Decay. Molecular Cell, 41(5), 600-608. https://doi.org/10.1016/j.molcel.2011.02.004

Jonas, S., Christie, M., Peter, D., Bhandari, D., Loh, B., Huntzinger, E., Weichenrieder, O., \& Izaurralde, E. (2014). An asymmetric PAN3 dimer recruits a single PAN2 exonuclease to mediate mRNA deadenylation and decay. Nature Structural and Molecular Biology, 21(7), 599-608. https://doi.org/10.1038/nsmb.2837

Kadaba, S., Krueger, A., Trice, T., Krecic, A. M., Hinnebusch, A. G., \& Anderson, J. (2004). Nuclear surveillance and degradation of hypomodified initiator tRNA Met in S. cerevisiae. Genes and Development, 18(11), 1227-1240. https://doi.org/10.1101/gad.1183804

Kadlec, J., Izaurralde, E., \& Cusack, S. (2004). The structural basis for the interaction between nonsensemediated mRNA decay factors UPF2 and UPF3. Nature Structural and Molecular Biology, 11(4), 330337. https://doi.org/10.1038/nsmb741

Kang, H. J., Jeong, S. J., Kim, K. N., Baek, I. J., Chang, M., Kang, C. M., Park, Y. S., \& Yun, C. W. (2014). A novel protein, Pho92, has a conserved YTH domain and regulates phosphate metabolism by decreasing the mRNA stability of PHO4 in Saccharomyces cerevisiae. Biochemical Journal, 457(3), 391-400. https://doi.org/10.1042/BJ20130862

Kapp, L. D., \& Lorsch, J. R. (2004). The Molecular Mechanics of Eukaryotic Translation. Annual Review of Biochemistry, 73(1), 657-704. https://doi.org/10.1146/annurev.biochem.73.030403.080419

Kashima, I., Yamashita, A., Izumi, N., Kataoka, N., Morishita, R., Hoshino, S., Ohno, M., Dreyfuss, G., \& Ohno, S. (2006). Binding of a novel SMG-1-Upf1-eRF1-eRF3 complex (SURF) to the exon junction complex triggers Upf1 phosphorylation and nonsense-mediated mRNA decay. Genes and Development, 20(3), 355-367. https://doi.org/10.1101/gad.1389006 
Keeney, S., \& Neale, M. J. (2006). Initiation of meiotic recombination by formation of DNA double-strand breaks: Mechanism and regulation. In Biochemical Society Transactions (Vol. 34, Issue 4, pp. 523525). Biochem Soc Trans. https://doi.org/10.1042/BST0340523

Keeney, Scott. (2001). Mechanism and control of meiotic recombination initiation. In Current Topics in Developmental Biology (Vol. 52, pp. 1-53). Curr Top Dev Biol. https://doi.org/10.1016/s00702153(01)52008-6

Kim, V. N., Kataoka, N., \& Dreyfuss, G. (2001). Role of the nonsense-mediated decay factor hUpf3 in the splicing-dependent exon-exon junction complex. Science, 293(5536), 1832-1836. https://doi.org/10.1126/science.1062829

Klauer, A. A., \& van Hoof, A. (2012). Degradation of mRNAs that lack a stop codon: A decade of nonstop progress. In Wiley Interdisciplinary Reviews: RNA (Vol. 3, Issue 5, pp. 649-660). Wiley Interdiscip Rev RNA. https://doi.org/10.1002/wrna.1124

Kornberg, R. D. (2005). Mediator and the mechanism of transcriptional activation. In Trends in Biochemical Sciences (Vol. 30, Issue 5, pp. 235-239). Trends Biochem Sci. https://doi.org/10.1016/j.tibs.2005.03.011

Kulaev, I., Vagabov, V., \& Kulakovskaya, T. (1999). New aspects of inorganic polyphosphate metabolism and function. In Journal of Bioscience and Bioengineering (Vol. 88, Issue 2, pp. 111-129). Society of Fermentation and Bioengineering. https://doi.org/10.1016/S1389-1723(99)80189-3

Kumar, A., Beloglazova, N., Bundalovic-Torma, C., Phanse, S., Deineko, V., Gagarinova, A., Musso, G., Vlasblom, J., Lemak, S., Hooshyar, M., Minic, Z., Wagih, O., Mosca, R., Aloy, P., Golshani, A., Parkinson, J., Emili, A., Yakunin, A. F., \& Babu, M. (2016). Conditional Epistatic Interaction Maps Reveal Global Functional Rewiring of Genome Integrity Pathways in Escherichia coli. Cell Reports, 14(3), 648-661. https://doi.org/10.1016/j.celrep.2015.12.060

Kurosaki, T., Li, W., Hoque, M., Popp, M. W. L., Ermolenko, D. N., Tian, B., \& Maquat, L. E. (2014). A Post-Translational regulatory switch on UPF1 controls targeted mRNA degradation. Genes and Development, 28(17), 1900-1916. https://doi.org/10.1101/gad.245506.114

Kuzmin, E., VanderSluis, B., Wang, W., Tan, G., Deshpande, R., Chen, Y., Usaj, M., Balint, A., Usaj, M. M., van Leeuwen, J., Koch, E. N., Pons, C., Dagilis, A. J., Pryszlak, M., Wang, J. Z. Y., Hanchard, J., Riggi, M., Xu, K., Heydari, H., ... Myers, C. L. (2018). Supplementary Materials for Systematic Systematic analysis of complex genetic interactions. Science, 360(6386), 1729. https://doi.org/10.1126/science.aao1729

LaCava, J., Houseley, J., Saveanu, C., Petfalski, E., Thompson, E., Jacquier, A., \& Tollervey, D. (2005). RNA degradation by the exosome is promoted by a nuclear polyadenylation complex. Cell, 121(5), 713-724. https://doi.org/10.1016/j.cell.2005.04.029

Lam, I., \& Keeney, S. (2015). Mechanism and regulation of meiotic recombination initiation. Cold Spring Harbor Perspectives in Biology, 7(1). https://doi.org/10.1101/cshperspect.a016634

Larimer, F. W., \& Stevens, A. (1990). Disruption of the gene XRN1, coding for a 5 ' $\rightarrow 3^{\prime}$ exoribonuclease, restricts yeast cell growth. Gene, 95(1), 85-90. https://doi.org/10.1016/0378-1119(90)90417-P

Lau, W. W., Schneider, K. R., \& O’Shea, E. K. (1998). A genetic study of signaling processes for repression of PHO5 transcription in Saccharomyces cerevisiae. Genetics, 150(4), 1349. 
le Hir, H. Â., Izaurralde, E., Maquat, L. E., \& Moore, M. J. (2000). The spliceosome deposits multiple proteins 20-24 nucleotides upstream of mRNA exon-exon junctions. The EMBO Journal, 19(24), 6860-6869.

Lebreton, A., Tomecki, R., Dziembowski, A., \& Séraphin, B. (2008). Endonucleolytic RNA cleavage by a eukaryotic exosome. Nature, 456(7224), 993-996. https://doi.org/10.1038/nature07480

Leeds, P., Peltz, S. W., Jacobson, A., \& Culbertson, M. R. (1991). The product of the yeast UPF1 gene is required for rapid turnover of mRNAs containing a premature translational termination codon. Genes and Development, 5(12 A), 2303-2314. https://doi.org/10.1101/gad.5.12a.2303

LENBURG, M., \& OSHEA, E. (1996). Signaling phosphate starvation. Trends in Biochemical Sciences, 21(10), 383-387. https://doi.org/10.1016/s0968-0004(96)10048-7

Li, J., Hooker, G. W., \& Roeder, G. S. (2006). Saccharomyces cerevisiae Mer2, Mei4 and Rec114 form a complex required for meiotic double-strand break formation. Genetics, 173(4), 1969-1981. https://doi.org/10.1534/genetics.106.058768

Linder, P., \& Jankowsky, E. (2011). From unwinding to clamping $\mathrm{g} €$ " the DEAD box RNA helicase family. In Nature Reviews Molecular Cell Biology (Vol. 12, Issue 8, pp. 505-516). Nat Rev Mol Cell Biol. https://doi.org/10.1038/nrm3154

Liu, H., Luo, M., \& Wen, J. K. (2014). mRNA stability in the nucleus. In Journal of Zhejiang University: Science $B \quad$ (Vol. 15, Issue 5, pp. 444-454). Zhejiang University Press. https://doi.org/10.1631/jzus.B1400088

Loh, B., Jonas, S., \& Izaurralde, E. (2013). The SMG5-SMG7 heterodimer directly recruits the CCR4-NOT deadenylase complex to mRNAs containing nonsense codons via interaction with POP2. Genes and Development, 27(19), 2125-2138. https://doi.org/10.1101/gad.226951.113

Long, R. M., \& McNally, M. T. (2003). mRNA decay: X (Xrn1) marks the spot. In Molecular Cell (Vol. 11, Issue 5, pp. 1126-1128). Cell Press. https://doi.org/10.1016/S1097-2765(03)00198-9

Lotan, R., Goler-Baron, V., Duek, L., Haimovich, G., \& Choder, M. (2007). The Rpb7p subunit of yeast RNA polymerase II plays roles in the two major cytoplasmic mRNA decay mechanisms. Journal of Cell Biology, 178(7), 1133-1143. https://doi.org/10.1083/jcb.200701165

Lowell, J. E., Rudner, D. Z., \& Sachs, A. B. (1992). 3'-UTR-dependent deadenylation by the yeast poly(A) nuclease. Genes and Development, 6(11), 2088-2099. https://doi.org/10.1101/gad.6.11.2088

Lykke-Andersen, J., \& Bennett, E. J. (2014). Protecting the proteome: Eukaryotic cotranslational quality control pathways. In Journal of Cell Biology (Vol. 204, Issue 4, pp. 467-476). https://doi.org/10.1083/jcb.201311103

Lykke-Andersen, J., Shu, M. di, \& Steitz, J. A. (2000). Human Upf proteins target an mRNA for nonsensemediated decay when downstream of a termination codon. Cell, 103(7), 1121-1131. https://doi.org/10.1016/S0092-8674(00)00214-2

Lykke-Andersen, S., Chen, Y., Ardal, B. R., Lilje, B., Waage, J., Sandelin, A., \& Jensen, T. H. (2014). Human nonsense-mediated RNA decay initiates widely by endonucleolysis and targets snoRNA host genes. Genes and Development, 28(22), 2498-2517. https://doi.org/10.1101/gad.246538.114 
Maleki, S., Neale, M. J., Arora, C., Henderson, K. A., \& Keeney, S. (2007). Interactions between Mei4, Rec114, and other proteins required for meiotic DNA double-strand break formation in Saccharomyces cerevisiae. Chromosoma, 116(5), 471-486. https://doi.org/10.1007/s00412-007-0111-y

Measday, V., Moore, L., Retnakaran, R., Lee, J., Donoviel, M., Neiman, A. M., \& Andrews, B. (1997). A family of cyclin-like proteins that interact with the Pho85 cyclin-dependent kinase. Molecular and Cellular Biology, 17(3), 1212-1223. https://doi.org/10.1128/mcb.17.3.1212

Meaux, S., \& van Hoof, A. (2006). Yeast transcripts cleaved by an internal ribozyme provide new insight into the role of the cap and poly(A) tail in translation and mRNA decay. $R N A, 12(7), 1323-1337$. https://doi.org/10.1261/rna.46306

Melero, R., Uchiyama, A., Castaño, R., Kataoka, N., Kurosawa, H., Ohno, S., Yamashita, A., \& Llorca, O. (2014). Structures of SMG1-UPFs complexes: SMG1 contributes to regulate UPF2-dependent activation of UPF1 in NMD. Structure, 22(8), 1105-1119. https://doi.org/10.1016/j.str.2014.05.015

Memarian, N., Jessulat, M., Alirezaie, J., Mir-Rashed, N., Xu, J., Zareie, M., Smith, M., \& Golshani, A. (2007). Colony size measurement of the yeast gene deletion strains for functional genomics. BMC Bioinformatics, 8, 117. https://doi.org/10.1186/1471-2105-8-117

Mendell, J. T., Sharifi, N. A., Meyers, J. L., Martinez-Murillo, F., \& Dietz, H. C. (2004). Nonsense surveillance regulates expression of diverse classes of mammalian transcripts and mutes genomic noise. Nature Genetics, 36(10), 1073-1078. https://doi.org/10.1038/ng1429

Min, E. E., Roy, B., Amrani, N., He, F., \& Jacobson, A. (2013). Yeast Upf1 CH domain interacts with Rps26 of the 40S ribosomal subunit. $R N A, 19(8), 1105-1115$. https://doi.org/10.1261/rna.039396.113

Mitchell, P., Petfalski, E., Houalla, R., Podtelejnikov, A., Mann, M., \& Tollervey, D. (2003). Rrp47p Is an Exosome-Associated Protein Required for the 3' Processing of Stable RNAs. Molecular and Cellular Biology, 23(19), 6982-6992. https://doi.org/10.1128/mcb.23.19.6982-6992.2003

Mitchell, P., Petfalski, E., Shevchenko, A., Mann, M., \& Tollervey, D. (1997). The exosome: A conserved eukaryotic RNA processing complex containing multiple 3' $\rightarrow$ 5' exoribonucleases. Cell, 91(4), 457466. https://doi.org/10.1016/S0092-8674(00)80432-8

Miyoshi, T., Ito, M., Kugou, K., Yamada, S., Furuichi, M., Oda, A., Yamada, T., Hirota, K., Masai, H., \& Ohta, K. (2012). A Central Coupler for Recombination Initiation Linking Chromosome Architecture to S Phase Checkpoint. Molecular Cell, 47(5), 722-733. https://doi.org/10.1016/j.molcel.2012.06.023

Mohanty, B. K., \& Kushner, S. R. (2016). Regulation of mRNA Decay in Bacteria. Annual Review of Microbiology, 70(1), 25-44. https://doi.org/10.1146/annurev-micro-091014-104515

Nagy, E., \& Maquat, L. E. (1998). A rule for termination-codon position within intron-containing genes: When nonsense affects RNA abundance. Trends in Biochemical Sciences, 23(6), 198-199. https://doi.org/10.1016/S0968-0004(98)01208-0

Nicholson, P., \& Mühlemann, O. (2010). Cutting the nonsense: The degradation of PTC-containing mRNAs. Biochemical Society Transactions, 38(6), 1615-1620. https://doi.org/10.1042/BST0381615

Nicholson, P., Yepiskoposyan, H., Metze, S., Orozco, R. Z., Kleinschmidt, N., Mühlemann, O., Zamudio Orozco, R., Kleinschmidt, N., \& Mühlemann, O. (2010). Nonsense-mediated mRNA decay in human cells: Mechanistic insights, functions beyond quality control and the double-life of NMD factors. In 
Cellular and Molecular Life Sciences (Vol. 67, Issue 5, pp. 677-700). Cell Mol Life Sci. https://doi.org/10.1007/s00018-009-0177-1

Ogawa, N., DeRisi, J., \& Brown, P. O. (2000). New components of a system for phosphate accumulation and polyphosphate metabolism in Saccharomyces cerevisiae revealed by genomic expression analysis. Molecular Biology of the Cell, 11(12), 4309-4321. https://doi.org/10.1091/mbc.11.12.4309

Ogawa, N., \& Oshima, Y. (1990). Functional domains of a positive regulatory protein, PHO4, for transcriptional control of the phosphatase regulon in Saccharomyces cerevisiae. Molecular and Cellular Biology, 10(5), 2224-2236. https://doi.org/10.1128/mcb.10.5.2224

Omidi, K. (2017). Identification and characterization of novel genes involved in DNA double strand break repair process in the yeast Saccharomyces cerevisiae.

O’Neill, E. M., Kaffman, A., Jolly, E. R., \& O’Shea, E. K. (1996). Regulation of PHO4 nuclear localization by the PHO80-PH085 cyclin-CDK complex. Science, 271(5246), 209-212. https://doi.org/10.1126/science.271.5246.209

Oshima, Y. (1997). The phosphatase system in Saccharomyces cerevisiae. In Genes and Genetic Systems (Vol. 72, Issue 6, pp. 323-334). Genes Genet Syst. https://doi.org/10.1266/ggs.72.323

Page, M. F., Carr, B., Anders, K. R., Grimson, A., \& Anderson, P. (1999). SMG-2 Is a Phosphorylated Protein Required for mRNA Surveillance in Caenorhabditis elegans and Related to Upf1p of Yeast. Molecular and Cellular Biology, 19(9), 5943-5951. https://doi.org/10.1128/mcb.19.9.5943

Parker, R. (2012). RNA degradation in Saccharomyces cerevisae. Genetics, 191(3), 671-702. https://doi.org/10.1534/genetics.111.137265

Parker, R., \& Sheth, U. (2007). P Bodies and the Control of mRNA Translation and Degradation. In Molecular Cell (Vol. 25, Issue 5, pp. 635-646). https://doi.org/10.1016/j.molcel.2007.02.011

Peltz, S. W., Brown, A. H., \& Jacobson, A. (1993). mRNA destabilization triggered by premature translational termination depends on at least three cis-acting sequence elements and one trans-acting factor. Genes and Development, 7(9), 1737-1754. https://doi.org/10.1101/gad.7.9.1737

Perlick, H. A., Medghalchi, S. M., Spencer, F. A., Kendzior, R. J., \& Dietz, H. C. (1996). Mammalian orthologues of a yeast regulator of nonsense transcript stability. Proceedings of the National Academy of Sciences of the United States of America, 93(20), 10928-10932. https://doi.org/10.1073/pnas.93.20.10928

Petit, A.-P., Wohlbold, L., Bawankar, P., Huntzinger, E., Schmidt, S., Izaurralde, E., \& Weichenrieder, O. (2012). The structural basis for the interaction between the CAF1 nuclease and the NOT1 scaffold of the human CCR4-NOT deadenylase complex. https://doi.org/10.1093/nar/gks883

Pisareva, V. P., Skabkin, M. A., Hellen, C. U. T., Pestova, T. v., \& Pisarev, A. v. (2011). Dissociation by Pelota, Hbs1 and ABCE1 of mammalian vacant $80 \mathrm{~S}$ ribosomes and stalled elongation complexes. EMBO Journal, 30(9), 1804-1817. https://doi.org/10.1038/emboj.2011.93

Pitre, S., Hooshyar, M., Schoenrock, A., Samanfar, B., Jessulat, M., Green, J. R., Dehne, F., \& Golshani, A. (2012). Short co-occurring polypeptide regions can predict global protein interaction maps. Scientific Reports, 2(1), 1-10. https://doi.org/10.1038/srep00239 
Pontes, M. H., Sevostyanova, A., \& Groisman, E. A. (2015). When Too Much ATP Is Bad for Protein Synthesis. In Journal of Molecular Biology (Vol. 427, Issue 16, pp. 2586-2594). Academic Press. https://doi.org/10.1016/j.jmb.2015.06.021

Presnyak, V., Alhusaini, N., Chen, Y. H., Martin, S., Morris, N., Kline, N., Olson, S., Weinberg, D., Baker, K. E., Graveley, B. R., \& Coller, J. (2015). Codon optimality is a major determinant of mRNA stability. Cell, 160(6), 1111-1124. https://doi.org/10.1016/j.cell.2015.02.029

Pulak, R., \& Anderson, P. (1993). mRNA Surveillance by the Caenorhabditis elegans smg genes. Genes and Development, 7(10), 1885-1897. https://doi.org/10.1101/gad.7.10.1885

Rabitsch, K. P., Tóth, A., Gálová, M., Schleiffer, A., Schaffner, G., Aigner, E., Rupp, C., Penkner, A. M., Moreno-Borchart, A. C., Primig, M., Esposito, R. E., Klein, F., Knop, M., \& Nasmyth, K. (2001). A screen for genes required for meiosis and spore formation based on whole-genome expression. Current Biology, 11(13), 1001-1009. https://doi.org/10.1016/S0960-9822(01)00274-3

Rendl, L. M., Bieman, M. A., \& Smibert, C. A. (2008). S. cerevisiae Vts1p induces deadenylation-dependent transcript degradation and interacts with the Ccr4p-Pop2p-Not deadenylase complex. $R N A, 14(7)$, 1328-1336. https://doi.org/10.1261/rna.955508

Robert, T., Nore, A., Brun, C., Maffre, C., Crimi, B., Bourbon, H. M., \& de Massy, B. (2016). The Topo VIB-Like protein family is required for meiotic DNA double-strand break formation. Science, 351(6276), 943-949. https://doi.org/10.1126/science.aad5309

Roy, B., \& Jacobson, A. (2013). The intimate relationships of mRNA decay and translation. In Trends in Genetics (Vol. 29, Issue 12, pp. 691-699). NIH Public Access. https://doi.org/10.1016/j.tig.2013.09.002

Russell, J. B., \& Cook, G. M. (1995). Energetics of bacterial growth: Balance of anabolic and catabolic reactions. In Microbiological Reviews (Vol. 59, Issue 1, pp. 48-62). American Society for Microbiology (ASM). https://doi.org/10.1128/mmbr.59.1.48-62.1995

Sachs, A. B., \& Davis, R. W. (1989). The poly(A) binding protein is required for poly(A) shortening and 60S ribosomal subunit-dependent translation initiation. Cell, 58(5), 857-867. https://doi.org/10.1016/00928674(89)90938-0

Sachs, A. B., \& Deardorff, J. A. (1992). Translation initiation requires the PAB-dependent poly(A) ribonuclease in yeast. Cell, 70(6), 961-973. https://doi.org/10.1016/0092-8674(92)90246-9

Salas-Marco, J., \& Bedwell, D. M. (2004). GTP Hydrolysis by eRF3 Facilitates Stop Codon Decoding during Eukaryotic Translation Termination. Molecular and Cellular Biology, 24(17), 7769-7778. https://doi.org/10.1128/mcb.24.17.7769-7778.2004

Samanfar, B., Omidi, K., Hooshyar, M., Laliberte, B., Alamgir, M., Seal, A. J., Ahmed-Muhsin, E., Viteri, D. F., Said, K., Chalabian, F., Wainer, G., Burnside, D., Shostak, K., Bugno, M., Willmore, W. G., Smith, M. L., Golshani, A., \& Golshani, A. (2013). Large-scale investigation of oxygen response mutants in Saccharomyces cerevisiae. Molecular BioSystems, 9(6), 1351-1359. https://doi.org/10.1039/c3mb25516f

Samanfar, B., Tan, L. H., Shostak, K., Chalabian, F., Wu, Z., Alamgir, M., Sunba, N., Burnside, D., Omidi, K., Hooshyar, M., Galván Márquez, I., Jessulat, M., Smith, M. L., Babu, M., Azizi, A., \& Golshani, A. (2014). A global investigation of gene deletion strains that affect premature stop codon bypass in yeast, 
Saccharomyces cerevisiae. Molecular BioSystems, $\quad$ 10(4), 916-924. https://doi.org/10.1039/c3mb70501c

Sandbake\&, M. G., Lupisellaj, J. A., Didomeniao\$, B., \& Chakraburtty, K. (1990). Protein Synthesis in Yeast STRUCTURAL AND FUNCTIONAL ANALYSIS OF THE GENE ENCODING ELONGATION FACTOR 3*(Vol. 265, Issue 26). http://www.jbc.org/

Sasanuma, H., Murakami, H., Fukuda, T., Shibata, T., Nicolas, A., \& Ohta, K. (2007). Meiotic association between Spo11 regulated by Rec102, Rec104 and Rec114. Nucleic Acids Research, 35(4), 1119-1133. https://doi.org/10.1093/nar/gk11162

Schaeffer, D., \& van Hoof, A. (2011). Different nuclease requirements for exosome-mediated degradation of normal and nonstop mRNAs. Proceedings of the National Academy of Sciences of the United States of America, 108(6), 2366-2371. https://doi.org/10.1073/pnas.1013180108

Schäfer, I. B., Rode, M., Bonneau, F., Schüssler, S., \& Conti, E. (2014). The structure of the Pan2-Pan3 core complex reveals cross-talk between deadenylase and pseudokinase. Nature Structural and Molecular Biology, 21(7), 591-598. https://doi.org/10.1038/nsmb.2834

Schäfer, I. B., Yamashita, M., Schuller, J. M., Schüssler, S., Reichelt, P., Strauss, M., \& Conti, E. (2019). Molecular Basis for poly(A) RNP Architecture and Recognition by the Pan2-Pan3 Deadenylase. Cell, 177(6), 1619-1631.e21. https://doi.org/10.1016/j.cell.2019.04.013

Schmidt, S. A., Foley, P. L., Jeong, D.-H., Rymarquis, L. A., Doyle, F., Tenenbaum, S. A., Belasco, J. G., \& Green, P. J. (2014). Identification of SMG6 cleavage sites and a preferred RNA cleavage motif by global analysis of endogenous NMD targets in human cells. Nucleic Acids Research, 43(1), 309-323. https://doi.org/10.1093/nar/gku1258

Schmitt, M. E., Brown, T. A., \& Trumpower, B. L. (1990). A rapid and simple method for preparation of RNA from Saccharomyces cerevisiae. Nucleic Acids Research, 18(10), 3091-3092. https://doi.org/10.1093/nar/18.10.3091

Schneider, K. R., Smith, R. L., \& O’Shea, E. K. (1994). Phosphate-regulated inactivation of the kinase? PHO80-PHO85 by the CDK inhibitor PHO81. Science, 266(5182), 122-126. https://doi.org/10.1126/science.7939631

Schoenberg, D. R., \& Maquat, L. E. (2012). Regulation of cytoplasmic mRNA decay. In Nature Reviews Genetics (Vol. 13, Issue 4, pp. 246-259). Nat Rev Genet. https://doi.org/10.1038/nrg3160

Schoenrock, A., Samanfar, B., Pitre, S., Hooshyar, M., Jin, K., Phillips, C. A., Wang, H., Phanse, S., Omidi, K., Gui, Y., Alamgir, M., Wong, A., Barrenäs, F., Babu, M., Benson, M., Langston, M. A., Green, J. R., Dehne, F., \& Golshani, A. (2014). Efficient prediction of human protein-protein interactions at a global scale. BMC Bioinformatics, 15(1). https://doi.org/10.1186/s12859-014-0383-1

Schweingruber, C., Rufener, S. C., Zünd, D., Yamashita, A., \& Mühlemann, O. (2013). Nonsense-mediated mRNA decay - Mechanisms of substrate mRNA recognition and degradation in mammalian cells. In Biochimica et Biophysica Acta - Gene Regulatory Mechanisms (Vol. 1829, Issues 6-7, pp. 612-623). https://doi.org/10.1016/j.bbagrm.2013.02.005

Serin, G., Gersappe, A., Black, J. D., Aronoff, R., \& Maquat, L. E. (2001). Identification and Characterization of Human Orthologues to Saccharomyces cerevisiae Upf2 Protein and Upf3 Protein (Caenorhabditis 
elegans SMG-4). Molecular and Cellular Biology, 21(1), 209-223. https://doi.org/10.1128/mcb.21.1.209-223.2001

She, R., Chakravarty, A. K., Layton, C. J., Chircus, L. M., Andreasson, J. O. L., Damaraju, N., McMahon, P. L., Buenrostro, J. D., Jarosz, D. F., \& Greenleaf, W. J. (2017). Comprehensive and quantitative mapping of RNA-protein interactions across a transcribed eukaryotic genome. Proceedings of the National Academy of Sciences of the United States of America, 114(14), 3619-3624. https://doi.org/10.1073/pnas.1618370114

Shoemaker, C. J., Eyler, D. E., \& Green, R. (2010). Dom34:Hbs1 promotes subunit dissociation and peptidyltRNA drop-off to initiate no-go decay. Science, 330(6002), 369-372. https://doi.org/10.1126/science. 1192430

Shoemaker, C. J., \& Green, R. (2011). Kinetic analysis reveals the ordered coupling of translation termination and ribosome recycling in yeast. Proceedings of the National Academy of Sciences of the United States of America, 108(51). https://doi.org/10.1073/pnas.1113956108

Shoemaker, C. J., \& Green, R. (2012). Translation drives mRNA quality control. In Nature Structural and Molecular Biology (Vol. 19, Issue 6, pp. 594-601). https://doi.org/10.1038/nsmb.2301

Singh, G., Rebbapragada, I., \& Lykke-Andersen, J. (2008). A Competition between Stimulators and Antagonists of Upf Complex Recruitment Governs Human Nonsense-Mediated mRNA Decay. PLoS Biology, 6(4), e111. https://doi.org/10.1371/journal.pbio.0060111

SJacobs Anderson, J., \& Parker, R. (1998). The 3 to 5 degradation of yeast mRNAs is a general mechanism for mRNA turnover that requires the SKI2 DEVH box protein and 3 to 5 exonucleases of the exosome complex. In The EMBO Journal (Vol. 17, Issue 5).

Song, M.-G., Bail, S., \& Kiledjian, M. (2013). Multiple Nudix family proteins possess mRNA decapping activity. https://doi.org/10.1261/rna.037309.112

Steiger, M., Carr-Schmid, A., Schwartz, D. C., Kiledjian, M., \& Parker, R. (2003). Analysis of recombinant yeast decapping enzyme. $R N A, 9(2), 231-238$. https://doi.org/10.1261/rna.2151403

Steiner, S., Kohli, J., \& Ludin, K. (2010). Functional interactions among members of the meiotic initiation complex in fission yeast. Current Genetics, 56(3), 237-249. https://doi.org/10.1007/s00294-010-02960

Stirnimann, C. U., Petsalaki, E., Russell, R. B., \& Müller, C. W. (2010). WD40 proteins propel cellular networks: Trends in Biochemical Sciences. Trends in Biochemical Sciences, 35(10), 565-574. https://www.cell.com/trends/biochemical-sciences/fulltext/S0968-0004(10)00072-

1?_returnURL=https\%3A\%2F\%2Flinkinghub.elsevier.com\%2Fretrieve $\% 2 F p i i \% 2 F S 0968000410000$

$721 \% 3$ Fshowall $\% 3$ Dtrue

Sun, L., Wu, J., Du, F., Chen, X., \& Chen, Z. J. (2013). Cyclic GMP-AMP synthase is a cytosolic DNA sensor that activates the type I interferon pathway. Science, 339(6121), 786-791. https://doi.org/10.1126/science.1232458

Synowsky, S. A., \& Heck, A. J. R. (2007). The yeast Ski complex is a hetero-tetramer. Protein Science, 17(1), 119-125. https://doi.org/10.1110/ps.073155908 
Synowsky, Silvia A., van Wijk, M., Raijmakers, R., \& Heck, A. J. R. (2009). Comparative Multiplexed Mass Spectrometric Analyses of Endogenously Expressed Yeast Nuclear and Cytoplasmic Exosomes. Journal of Molecular Biology, 385(4), 1300-1313. https://doi.org/10.1016/j.jmb.2008.11.011

Takahashi, S., Araki, Y., Sakuno, T., \& Katada, T. (2003). Interaction between Ski7p and Upflp is required for nonsense-mediated 3'-to-5' mRNA decay in yeast | The EMBO Journal. The EMBO Journal, 22(15), 3951-3959. https://www.embopress.org/doi/10.1093/emboj/cdg374

Temme, C., Zaessinger, S., Meyer, S., Simonelig, M., \& Wahle, E. (2004). A complex containing the CCR4 and CAF1 proteins is involved in mRNA deadenylation in Drosophila. EMBO Journal, 23(14), 28622871. https://doi.org/10.1038/sj.emboj.7600273

Tollervey, D. (2006). Molecular biology: RNA lost in translation. In Nature (Vol. 440, Issue 7083, pp. 425426). Nature Publishing Group. https://doi.org/10.1038/440425a

Tong, A. H. Y., Evangelista, M., Parsons, A. B., Xu, H., Bader, G. D., Pagé, N., Robinson, M., Raghibizadeh, S., Hogue, C. W. V., Bussey, H., Andrews, B., Tyers, M., \& Boone, C. (2001). Systematic genetic analysis with ordered arrays of yeast deletion mutants. Science, 294(5550), 2364-2368. https://doi.org/10.1126/science.1065810

Tucker, M., Staples, R. R., Valencia-Sanchez, M. A., Muhlrad, D., \& Parke, R. (2001). Ccr4p is the catalytic subunit of a Ccr4p/Pop2p/Notp mRNA deadenylase complex in Saccharomyces cerevisiae. https://www.embopress.org/doi/epdf/10.1093/emboj/21.6.1427

Uchida, N., Hoshino, S. I., \& Katada, T. (2004). Identification of a Human Cytoplasmic Poly(A) Nuclease Complex Stimulated by Poly(A)-binding Protein. Journal of Biological Chemistry, 279(2), 1383-1391. https://doi.org/10.1074/jbc.M309125200

Unbehaun, A., Borukhov, S. I., Hellen, C. U. T., \& Pestova, T. v. (2004). Release of initiation factors from $48 \mathrm{~S}$ complexes during ribosomal subunit joining and the link between establishment of codon-anticodon base-pairing and hydrolysis of eIF2-bound GTP. Genes and Development, 18(24), 3078-3093. https://doi.org/10.1101/gad.1255704

Unterholzner, L., \& Izaurralde, E. (2004). SMG7 acts as a molecular link between mRNA surveillance and mRNA decay. Molecular Cell, 16(4), 587-596. https://doi.org/10.1016/j.molcel.2004.10.013

Valencia-Sanchez, M. A., Liu, J., Hannon, G. J., \& Parker, R. (2006). Control of translation and mRNA degradation by miRNAs and siRNAs. In Genes and Development (Vol. 20, Issue 5, pp. 515-524). https://doi.org/10.1101/gad.1399806

van Dijk, E., Cougot, N., Meyer, S., Babajko, S., Wahle, E., \& Séraphin, B. (2002). Human Dcp2: A catalytically active mRNA decapping enzyme located in specific cytoplasmic structures. EMBO Journal, 21(24), 6915-6924. https://doi.org/10.1093/emboj/cdf678

van Hoof, A., Frischmeyer, P. A., Dietz, H. C., \& Parker, R. (2002). Exosome-mediated recognition and degradation of mRNAs lacking a termination codon. Science, 295(5563), 2262-2264. https://doi.org/10.1126/science.1067272

van Hoof, A., Staples, R. R., Baker, R. E., \& Parker, R. (2000). Function of the Ski4p (Cs14p) and Ski7p Proteins in 3'-to-5' Degradation of mRNA. Molecular and Cellular Biology, 20(21), 8230-8243. https://doi.org/10.1128/mcb.20.21.8230-8243.2000 
van Hoof, A., \& Wagner, E. J. (2011). A brief survey of mRNA surveillance. In Trends in Biochemical Sciences (Vol. 36, Issue 11, pp. 585-592). https://doi.org/10.1016/j.tibs.2011.07.005

Vaňáčová, Š., Wolf, J., Martin, G., Blank, D., Dettwiler, S., Friedlein, A., Langen, H., Keith, G., \& Keller, W. (2005). A New Yeast Poly(A) Polymerase Complex Involved in RNA Quality Control. PLoS Biology, 3(6), e189. https://doi.org/10.1371/journal.pbio.0030189

Vlasblom, J., Zuberi, K., Rodriguez, H., Arnold, R., Gagarinova, A., Deineko, V., Kumar, A., Leung, E., Rizzolo, K., Samanfar, B., Chang, L., Phanse, S., Golshani, A., Greenblatt, J. F., Houry, W. A., Emili, A., Morris, Q., Bader, G., \& Babu, M. (2015). Systems biology Novel function discovery with GeneMANIA: a new integrated resource for gene function prediction in Escherichia coli. BIOINFORMATICS DISCOVERY NOTE, 306-310. https://doi.org/10.1093/bioinformatics/btu671

von der Haar, T. (2008). A quantitative estimation of the global translational activity in logarithmically growing yeast cells. BMC Systems Biology, 2, 87. https://doi.org/10.1186/1752-0509-2-87

Vrielynck, N., Chambon, A., Vezon, D., Pereira, L., Chelysheva, L., de Muyt, A., Mézard, C., Mayer, C., \& Grelon, M. (2016). A DNA topoisomerase VI-like complex initiates meiotic recombination. Science, 351(6276), 939-943. https://doi.org/10.1126/science.aad5196

Wahle, E., \& Winkler, G. S. (2013a). RNA decay machines: Deadenylation by the Ccr4-Not and Pan2-Pan3 complexes. In Biochimica et Biophysica Acta - Gene Regulatory Mechanisms (Vol. 1829, Issues 6-7, pp. 561-570). https://doi.org/10.1016/j.bbagrm.2013.01.003

Wahle, E., \& Winkler, G. S. (2013b). RNA decay machines: Deadenylation by the Ccr4-Not and Pan2-Pan3 complexes. In Biochimica et Biophysica Acta - Gene Regulatory Mechanisms (Vol. 1829, Issues 6-7, pp. 561-570). https://doi.org/10.1016/j.bbagrm.2013.01.003

Wang, L., Lewis, M. S., \& Johnson, A. W. (2005). Domain interactions within the Ski2/3/8 complex and between the Ski complex and Ski7p. $R N A, 11(8), 1291-1302$. https://doi.org/10.1261/rna.2060405

Wasmuth, E. v., \& Lima, C. D. (2012). Exo- and Endoribonucleolytic Activities of Yeast Cytoplasmic and Nuclear RNA Exosomes Are Dependent on the Noncatalytic Core and Central Channel. Molecular Cell, 48(1), 133-144. https://doi.org/10.1016/j.molcel.2012.07.012

Welch, E. M., Barton, E. R., Zhuo, J., Tomizawa, Y., Friesen, W. J., Trifillis, P., Paushkin, S., Patel, M., Trotta, C. R., Hwang, S., Wilde, R. G., Karp, G., Takasugi, J., Chen, G., Jones, S., Ren, H., Moon, Y. C., Corson, D., Turpoff, A. A., ... Sweeney, H. L. (2007). PTC124 targets genetic disorders caused by nonsense mutations. Nature, 447(7140), 87-91. https://doi.org/10.1038/nature05756

Wilson, M. A., Meaux, S., \& van Hoof, A. (2007). A genomic screen in yeast reveals novel aspects of nonstop mRNA metabolism. Genetics, 177(2), 773-784. https://doi.org/10.1534/genetics.107.073205

Winkler, G. S., Mulder, K. W., Bardwell, V. J., Kalkhoven, E., \& Timmers, H. T. M. (2006). Human Ccr4Not complex is a ligand-dependent repressor of nuclear receptor-mediated transcription. EMBO Journal, 25(13), 3089-3099. https://doi.org/10.1038/sj.emboj.7601194

Wolf, J., Valkov, E., Allen, M. D., Meineke, B., Gordiyenko, Y., McLaughlin, S. H., Olsen, T. M., Robinson, C. v, Bycroft, M., Stewart, M., \& Passmore, L. A. (2014). Structural basis for P an3 binding to P an2 and its function in mRNA recruitment and deadenylation. The EMBO Journal, 33(14), 1514-1526. https://doi.org/10.15252/embj.201488373 
Wyers, F., Rougemaille, M., Badis, G., Rousselle, J. C., Dufour, M. E., Boulay, J., Régnault, B., Devaux, F., Namane, A., Séraphin, B., Libri, D., \& Jacquier, A. (2005). Cryptic Pol II transcripts are degraded by a nuclear quality control pathway involving a new poly(A) polymerase. Cell, 121(5), 725-737. https://doi.org/10.1016/j.cell.2005.04.030

Wykoff, D. D., \& O'Shea, E. K. (2001). Phosphate transport and sensing in Saccharomyces cerevisiae. Genetics, 159(4), 1491-1499.

Yamashita, A. (2013). Role of SMG-1-mediated Upf1 phosphorylation in mammalian nonsense-mediated mRNA decay. In Genes to Cells (Vol. 18, Issue 3, pp. 161-175). Genes Cells. https://doi.org/10.1111/gtc.12033

Yamashita, A., Chang, T. C., Yamashita, Y., Zhu, W., Zhong, Z., Chen, C. Y. A., \& Shyu, A. bin. (2005). Concerted action of poly(A) nucleases and decapping enzyme in mammalian mRNA turnover. Nature Structural and Molecular Biology, 12(12), 1054-1063. https://doi.org/10.1038/nsmb1016

Yamashita, A., Izumi, N., Kashima, I., Ohnishi, T., Saari, B., Katsuhata, Y., Muramatsu, R., Morita, T., Iwamatsu, A., Hachiya, T., Kurata, R., Hirano, H., Anderson, P., \& Ohno, S. (2009). SMG-8 and SMG9, two novel subunits of the SMG-1 complex, regulate remodeling of the mRNA surveillance complex during nonsense-mediated mRNA decay. Genes and Development, 23(9), 1091-1105. https://doi.org/10.1101/gad.1767209

Yi, H., Park, J., Ha, M., Lim, J., Chang, H., \& Kim, V. N. (2018). PABP Cooperates with the CCR4-NOT Complex to Promote mRNA Deadenylation and Block Precocious Decay. Molecular Cell, 70(6), 10811088.e5. https://doi.org/10.1016/j.molcel.2018.05.009

Zenklusen, D., Larson, D. R., \& Singer, R. H. (2008). Single-RNA counting reveals alternative modes of gene expression in yeast. Nature Structural and Molecular Biology, 15(12), 1263-1271. https://doi.org/10.1038/nsmb.1514

Zhang, J., Sun, X., Qian, Y., \& Maquat, L. E. (1998). Intron function in the nonsense-mediated decay of $\beta$ globin mRNA: Indications that pre-mRNA splicing in the nucleus can influence mRNA translation in the cytoplasm. $R N A, 4(7), 801-815$. https://doi.org/10.1017/S1355838298971849

Zhang, L., Liu, N., Ma, X., \& Jiang, L. (2013). The transcriptional control machinery as well as the cell wall integrity and its regulation are involved in the detoxification of the organic solvent dimethyl sulfoxide in Saccharomyces cerevisiae. FEMS Yeast Research, 13(2), 200-218. https://doi.org/10.1111/15671364.12022

Zhou, X., \& O'Shea, E. K. (2011). Integrated Approaches Reveal Determinants of Genome-wide Binding and Function of the Transcription Factor Pho4. Molecular Cell, 42(6), 826-836. https://doi.org/10.1016/j.molcel.2011.05.025

Zünd, D., Gruber, A. R., Zavolan, M., \& Mühlemann, O. (2013). Translation-dependent displacement of UPF1 from coding sequences causes its enrichment in 3' UTRs. Nature Structural and Molecular Biology, 20(8), 936-943. https://doi.org/10.1038/nsmb.2635 